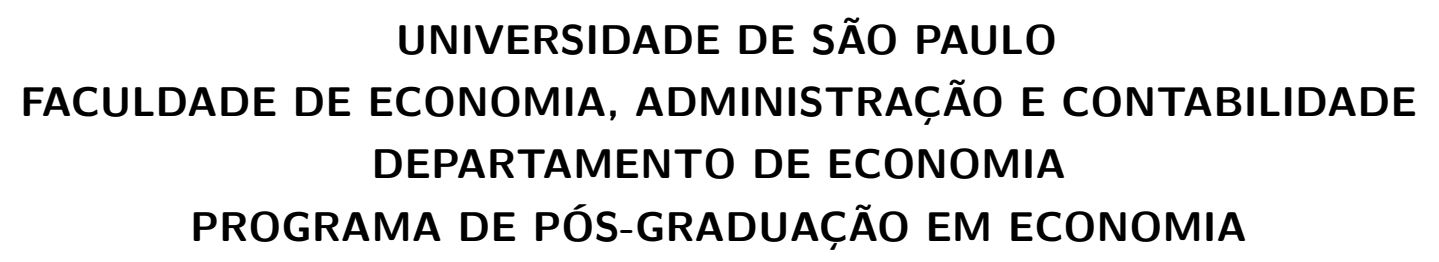

Política habitacional e a oferta de trabalho: Evidências de sorteios do Minha Casa Minha Vida

Guilherme Malvezzi Rocha

Orientador: Prof. Dr. André Luis Squarize Chagas

Brasil

2018 
Prof. Dr. Vahan Agopyan

Reitor da Universidade de São Paulo

Prof. Dr. Adalberto Américo Fischmann

Diretor da Faculdade de Economia, Administração e Contabilidade

Prof. Dr. Eduardo Amaral Haddad

Chefe do Departamento de Economia

Prof. Dr. Ariaster Baumgratz Chimeli

Coordenador do Programa de Pós-Graduação em Economia 


\title{
Política habitacional e a oferta de trabalho: Evidências de sorteios do Minha Casa Minha Vida
}

\author{
Dissertação apresentada ao Departamento \\ de Economia da Faculdade de Economia, \\ Administração e Contabilidade da Univer- \\ sidade de São Paulo como requisito parcial \\ para a obtenção do título de Mestre em \\ Ciências
}

Orientador: Prof. Dr. André Luis Squarize Chagas

Versão Original

Brasil

2018 
FICHA CATALOGRÁFICA

Elaborada por Rafael Mielli Rodrigues - CRB-8/7286

Seção de Processamento Técnico do SBD/FEA/USP

Rocha, Guilherme Malvezzi

Política habitacional e a oferta de trabalho: evidências de sorteios do minha casa minha vida / Guilherme Malvezzi Rocha. - São Paulo, 2018. $88 \mathrm{p}$.

Dissertação (Mestrado) - Universidade de São Paulo, 2018.

Orientador: André Luis Squarize Chagas.

1. Políticas públicas 2. Política habitacional 3. Mercado de trabalho I. Universidade de São Paulo. Faculdade de Economia, Administração e Contabilidade. II. Título.

$\mathrm{CDD}-320.6$ 


\section{Agradecimentos}

Agradeço ao meu orientador, André Chagas, por toda a atenção e por todas as sugestões que deu ao longo de toda essa jornada. Agradeço também a todos os professores da FEA-USP que ajudaram em minha formação, principalmente, aos professores Paula Pereda e Danilo Igliori pelas sugestões e correções feitas durante a elaboração desse trabalho.

Agradeço aos grandes amigos que fiz durante o mestrado, que me ajudaram tanto no curso quanto na vida. Bruno, Bruna, Carol, Cristiano, Gabriel, Ieda, Michael e muitos outros que contribuíram enormemente para a realização desse trabalho.

Agradeço aos meus pais e à minha irmã por todo o apoio que me deram desde que eu saí de casa para morar em São Paulo. Agradeço também à minha namorada, Débora, por ter estado ao meu lado durante todo esse percurso. Sem vocês esse trabalho não teria acontecido.

Por fim, agradeço à FIPE-USP e ao CNPQ pelo apoio financeiro durante o mestrado. 



\section{Resumo}

Políticas habitacionais para melhorar a qualidade de vida dos mais pobres têm sido empregadas há muito tempo. Em países em desenvolvimento, como o Brasil, a urbanização aumentou o número de favelas, incentivando a criação de programas habitacionais. Esse é o caso do Minha Casa Minha Vida (MCMV), lançado em 2009 no Brasil. Por mais que a provisão de moradias de qualidade tenda a aumentar o bem-estar das famílias beneficiadas, estudos têm criticado a má localização dos empreendimentos do programa, gerando dúvidas sobre o impacto da política. A seleção dos beneficiários do Minha Casa Minha Vida enquadrados na Faixa I, destinada aos mais pobres, é feita por sorteio. Isso permitiu dividir os indivíduos em grupos de tratamento e controle para os municípios do Rio de Janeiro e de São José do Rio Preto, no interior de São Paulo. Ao combinar bases de dados que contêm os indivíduos sorteados e não sorteados para o programa com o Relatório Anual de Informações Sociais (RAIS) e o Cadastro Único, estimou-se o efeito do MCMV sobre a participação no mercado de trabalho formal para os dois grupos. Além disso, também verifica-se o impacto sobre a participação no Bolsa Família, principal programa social do país. Os resultados indicam que o programa afetou negativamente a oferta de trabalho, reduzindo a probabilidade de o beneficiário estar empregado formalmente. Além disso, também aumentou a proporção dos beneficiários que recebem o Bolsa Família. Esse é um dos primeiros artigos a analisar micro-dados do Minha Casa Minha Vida, fornecendo uma importante medida de impacto do programa.

Palavras-chaves: políticas públicas, política habitacional, mercado de trabalho. 



\section{Abstract}

Housing policies to improve the quality of life of the poorest have been employed for a long time. In developing countries, such as Brazil, urbanization has increased the number of slums, encouraging the creation of housing programs. This is the case of the Minha Casa Minha Vida program, launched in 2009 in Brazil. Although the provision of quality housing tends to increase the welfare of the beneficiary families, studies have criticized the poor location of the program's houses, generating doubts about the impact of the policy. Since the demand for housing is much larger than the supply, the poorest families in Minha Casa Minha Vida are randomly selected. This allowed us to divide individuals into treatment and control groups for the municipalities of Rio de Janeiro and São José do Rio Preto, in the state of São Paulo. By combining databases containing the individuals that were randomly selected and those who were not with administrative data from the Relatório Anual de Informações Sociais (RAIS) and the Cadastro Único we were able to measure the changes in the formal labor market for both groups. In addition, we also check the impact on participation in Bolsa Família, the country's main social program. The results indicate that the program has negatively affected the labor supply, reducing the likelihood that the recipient will be formally employed. In addition, the program increased the proportion of families receiving the Bolsa Família program. This is one of the first articles to analyze microdata from Minha Casa Minha Vida, providing an important measure of the program's impact.

Key-words: public policies, housing policy, labor market. 



\section{Lista de ilustrações}

Figura 1 - Unidades habitacionais contratadas no MCMV . . . . . . . . . . . 25

Figura 2 - Empreendimentos do MCMV no Rio de Janeiro - Faixa I . . . . . . . . 32

Figura 3 - Rendimento mensal médio por setor censitário no Rio de Janeiro . . . . 32

Figura 4 - Distribuição dos postos de emprego formais no Rio de Janeiro por setor censitário . . . . . . . . . . . . . . . . . . 33

Figura 5 - Localização dos beneficiários antes e depois . . . . . . . . . . . 40

Figura 6 - Endereço dos beneficiários em São José do Rio Preto . . . . . . . . . . 41

Figura 7 - Distribuição dos postos de emprego formais em São José do Rio Preto . 42

Figura 8 - Efeito do programa sobre a probabilidade de emprego ao longo do tempo para cada sorteio. . . . . . . . . . . . . . . . 5 55

Figura 9 - Efeito do programa sobre a probabilidade de emprego e participação no Bolsa Família ao longo do tempo. . . . . . . . . . . . . . . . . . 65 



\section{Lista de tabelas}

Tabela 1 - Sorteios do MCMV no Rio de Janeiro . . . . . . . . . . . . . . . 30

Tabela 2 - Balanceamento - Sorteio 003 . . . . . . . . . . . 35

Tabela 3 - Balanceamento - Sorteio $006 \ldots \ldots$. . . . . . . . . 36

Tabela 4 - Balanceamento - Sorteio $009 \ldots \ldots$. . . . . . . . . 37

Tabela 5 - Características do domicílio dos beneficiários . . . . . . . . . 39

Tabela 6 - Características dos indivíduos dos grupos de tratamento e controle . . 44

Tabela 7 - Características dos domicílios dos grupos de tratamento e controle . . 45

Tabela 8 - Efeitos do sorteio e de outras características sobre a participação no

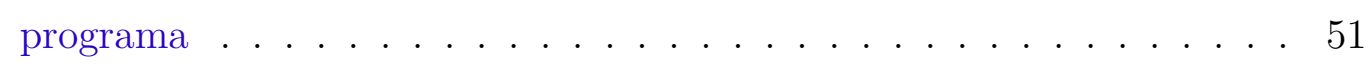

Tabela 9 - Impactos do programa - Rio de Janeiro . . . . . . . . . . . . . . 54

Tabela 10 - Impactos do programa por subgrupo - Rio de Janeiro . . . . . . . . . . 58

Tabela 11 - Efeitos do sorteio e de outras características do indivíduo sobre a participação no programa - Rio Preto . . . . . . . . . . . . . . . 60

Tabela 12 - Impactos do programa sobre os indivíduos - Rio Preto . . . . . . . . . 63

Tabela 13 - Impactos do programa por subgrupo - Rio Preto . . . . . . . . . . . . 64

Tabela 14 - Balanceamento com variáveis RAIS - São José do Rio Preto . . . . . . 67

Tabela 15 - Impactos do programa sobre a probabilidade de emprego formal Amostra RAIS . . . . . . . . . . . . . . . . . . . 68

Tabela 16 - Empreendimentos por sorteio - Rio de Janeiro . . . . . . . . . . . . . . 79

Tabela 17 - Balanceamento - Sorteio $003 \ldots \ldots$. . . . . . . . . 80

Tabela 18 - Balanceamento - Sorteio $006 \ldots$. . . . . . . . . . . . . 81

Tabela 19 - Balanceamento - Sorteio 009 . . . . . . . . . . . . . . . 82

Tabela 20 - Impactos do programa no Rio de Janeiro - Excluindo outros sorteados 83

Tabela 21 - Balanceamento - Sorteio $003 \ldots \ldots$. . . . . . . . . . . . 84

Tabela 22 - Balanceamento - Sorteio $006 \ldots \ldots$. . . . . . . . . . 85

Tabela 23 - Balanceamento - Sorteio $009 \ldots \ldots$. . . . . . . . . . 86

Tabela 24 - Impactos do programa sobre a probabilidade de emprego formal - RAIS 2006 a $2010 \ldots \ldots$. . . . . . . . . . . . . . . . . . . . 87

Tabela 25 - Impactos do programa (Probit) - Rio de Janeiro . . . . . . . . . . . . 88 



\section{Sumário}

Introdução $\ldots \ldots \ldots \ldots \ldots \ldots \ldots \ldots$

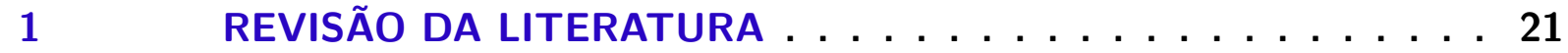

1.1 Evidências empíricas de programas habitacionais . . . . . . . 21

1.2 Minha Casa Minha Vida e a questão habitacional no Brasil . . . . . 23

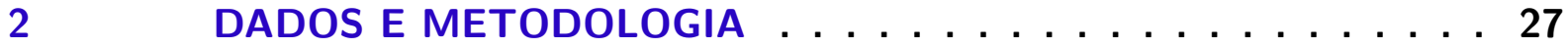

$2.1 \quad$ Bases de dados utilizadas . . . . . . . . . . . . . . 27

$2.2 \quad$ O Minha Casa Minha Vida no Rio de Janeiro . . . . . . . . . . . 29

2.2.1 Características dos grupos de tratamento e controle . . . . . . . . . . . . 31

2.2.2 Características do domicílio dos beneficiários . . . . . . . . . . . . . 38

$2.3 \quad$ O Minha Casa Minha Vida em São José do Rio Preto . . . . . . . 40

2.3.1 Características dos grupos de tratamento e controle . . . . . . . . . . 41

$2.4 \quad$ Metodologia . . . . . . . . . . . . . . . . . . 46

$3 \quad$ RESULTADOS . . . . . . . . . . . . . 49

$3.1 \quad$ Resultados para o Rio de Janeiro . . . . . . . . . . . . . 49

3.1.1 Efeito do sorteio sobre a participação no Minha Casa Minha Vida . . . . . 49

3.1.2 Impactos do programa sobre os indivíduos . . . . . . . . . . . . 50

3.2 Resultados para São José do Rio Preto . . . . . . . . . . . . . 59

3.2.1 Efeito do sorteio sobre a participação no Minha Casa Minha Vida . . . . . 59

3.2.2 Impactos do programa sobre os indivíduos . . . . . . . . . 60

3.2.3 Resultados com variáveis da RAIS . . . . . . . . . . . . . 65

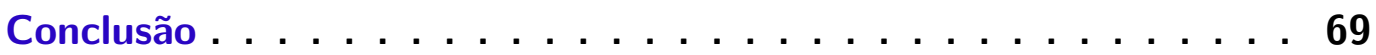

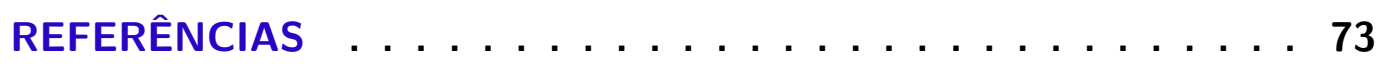

$\begin{array}{ll}\text { APÊNDICES } & 77\end{array}$

APÊNDICE A-TABELAS . . . . . . . . . . 79 



\section{Introdução}

O acesso a moradias de qualidade é questão prioritária em grande parte dos países do mundo. Ao longo do tempo, programas habitacionais têm sido empregados para melhorar o acesso a moradias de qualidade sob diferentes justificativas e de diferentes formas. No Brasil e em outros países em desenvolvimento, a questão habitacional é ainda mais séria. Atualmente, estima-se que um terço da população urbana dos países em desenvolvimento mora em favelas (ONU-HABITAT, 2016). Apesar da importância do problema, as evidências empíricas, sobretudo em países em desenvolvimento, ainda são escassas.

O programa Minha Casa Minha Vida, lançado em 2009, se tornou o principal programa habitacional no país, chegando a um custo anual de mais de $\mathrm{R} \$ 14$ bilhões e tendo contratado quase 5 milhões de unidades habitacionais até o momento.

Contudo, existem poucos trabalhos que analisam o impacto sobre os beneficiários do programa. Este trabalho pretende preencher essa lacuna ao analisar o desempenho dos indivíduos beneficiados e não beneficiados pelo Minha Casa Minha Vida (MCMV) nas cidades do Rio de Janeiro e de São José do Rio Preto no mercado de trabalho.

A seleção dos beneficiários do programa na Faixa I, destinada às famílias mais pobres, é normalmente feita através de sorteio. A aleatorização dos participantes do Minha Casa Minha Vida fornece uma rara fonte de exogeneidade e que ainda não foi explorada pela literatura econômica. Nos capítulos seguintes, mostra-se que, em ambas as cidades analisadas, essa seleção foi, de fato, aleatória e influenciou a participação no Minha Casa Minha Vida.

A teoria econômica que trata de programas habitacionais é ambígua quanto aos potenciais efeitos de um benefício habitacional sobre a oferta de trabalho e sobre outros indicadores econômicos, como participação em programas sociais (JACOB; LUDWIG, 2012; SHRODER, 2002). Contudo, estudos mais recentes, que conseguem superar problemas de endogeneidade, apontam que a assistência habitacional pode reduzir a oferta de trabalho para os indivíduos beneficiados (JACOB; LUDWIG, 2012; WOOD; TURNHAM; MILLS, 2008).

Além da teoria econômica, o programa Minha Casa Minha Vida foi alvo de várias críticas nos últimos anos por construir casas em regiões periféricas, longe de oportunidades de emprego e dos centros urbanos (MARQUES; RODRIGUES, 2013; ROLNIK et al., 2015; PEQUENO; RENATO, 2013).

A má localização pode gerar transtornos para os indivíduos beneficiados pelo pro- 
grama. Isso pode gerar não só um aumento no custo de transporte ${ }^{1}$, mas prejudicar essas pessoas no mercado de trabalho, como é previsto pela hipótese de spatial mismatch (descasamento espacial)(KAIN, 1968).

A principal contribuição do presente trabalho é fornecer uma estimativa do efeito do programa Minha Casa Minha Vida, o principal programa habitacional do país, sobre a oferta de trabalho e a participação em programas sociais das pessoas beneficiadas. Além disso, esse é um dos primeiros trabalhos a explorar os sorteios ocorridos no Rio de Janeiro e em São José do Rio Preto para a seleção dos beneficiários do programa.

O Rio de Janeiro é a cidade com mais unidades habitacionais do programa. Atualmente, são beneficiadas 27843 famílias no município. O trabalho analisa a seleção de 3934 beneficiários para o programa, ocorrida em 2011. Dentre 361805 participantes, a prefeitura sorteou, através da Loteria Federal, 23472 pessoas para participarem do programa em 12 conjuntos residenciais diferentes.

A prefeitura da cidade teve grande dificuldade em preencher as vagas para o programa. Essa dificuldade está bastante relacionada à localização dos empreendimentos, concentrados na Zona Oeste do Rio de Janeiro, onde a distância ao centro da cidade, que concentra os empregos e a população de alta renda, é de mais de $30 \mathrm{~km} .^{2}$

Adicionalmente, estima-se o impacto do programa na cidade de São José do Rio Preto, no interior de São Paulo, onde a prefeitura selecionou aleatoriamente 1665 beneficiários para o programa em 2013. De forma similar ao Rio de Janeiro, os empreendimentos estavam localizados na periferia da cidade. A análise é feita de forma separada, pois a qualidade dos dados, em São José do Rio Preto, é melhor. Contudo, mostra-se que, com dados semelhantes ao Rio de Janeiro, os resultados apresentados são mantidos.

As estimativas mostram que os indivíduos sorteados no MCMV que se mudaram para os empreendimentos do programa foram prejudicados no mercado de trabalho formal. A mudança para os empreendimentos do Minha Casa Minha Vida diminuiu a probabilidade de estar empregado (formalmente) tanto no Rio de Janeiro, quanto em São José do Rio Preto. As estimativas apontam um efeito negativo do programa de 3,3\% em São José do Rio Preto e de até 4,9\% no Rio de Janeiro sobre a taxa de emprego formal.

Contudo, a renda dos indivíduos não parece ter sido afetada. Além disso, o programa tem um impacto positivo sobre a participação no Bolsa Família, o principal programa social do país. As estimativas apontam um efeito positivo de $4 \%$ em São José do

1 Esse aumento foi relatado pelos beneficiários em pesquisa oficial, encomendada pelo Min. Desenvolvimento em 2014 (BRASIL, 2014). A má-localização dos empreendimentos foi o principal problema apontado pelos beneficiários na pesquisa.

2 A localização dos empreendimentos, sobretudo na linha destinada a população de até 3 Salários Mínimos (que concentra $70 \%$ do déficit habitacional do país), tem sido o grande problema do programa, conforme apontado por Marques e Rodrigues (2013), Rolnik et al. (2015), Pequeno e Renato (2013), Cardoso e Lago (2015). 
Rio Preto e de até 7\% no Rio de Janeiro sobre a participação no programa Bolsa Família. O trabalho é dividido em três capítulos, além dessa introdução e da conclusão. O primeiro capítulo faz uma revisão da literatura sobre programas habitacionais e sobre o Minha Casa Minha Vida. O segundo capítulo introduz as bases de dados que foram utilizadas, apresenta o programa MCMV nas duas cidades analisadas e indica a estratégia empírica para identificar o efeito do programa. O terceiro capítulo apresenta os resultados do impacto do programa. Mostra-se que, nas duas cidades, os grupos de tratamento e controle são comparáveis e que o programa Minha Casa Minha Vida impacta negativamente a taxa de emprego formal e positivamente a participação no Bolsa Família. 



\section{Revisão da literatura}

\subsection{Evidências empíricas de programas habitacionais}

A análise de beneficiários de programas habitacionais é de interesse dos economistas no mundo todo. Diversos estudos procuram analisar o que acontece com indivíduos que recebem assistência habitacional, tanto na forma de vouchers ${ }^{1}$, predominante nos Estados Unidos, quanto na provisão direta de moradias, que tem dominado a política habitacional em países em desenvolvimento (BUCKLEY; KALLERGIS; WAINER, 2016).

Apesar da existência de uma literatura consolidada sobre programas habitacionais, são poucos os estudos que conseguem isolar relações causais dos programas. A grande maioria sofre com problemas de endogeneidade, que se originam no fato de o beneficiário escolher participar do programa (COLLINSON; ELLEN; LUDWIG, 2015). Esses trabalhos estão interessados no impacto dos programas sobre a qualidade habitacional e acessibilidade às moradias, mas também no impacto sobre a oferta de trabalho, a saúde e sobre as crianças dos indivíduos beneficiados.

Os artigos que conseguem superar os problemas de endogeneidade mostram que a assistência habitacional normalmente melhora a qualidade habitacional, tanto para o caso de vouchers (JACOB; LUDWIG, 2012) (WOOD; TURNHAM; MILLS, 2008), quanto para o caso de habitação pública (CURRIE; YELOWITZ, 2000). Além disso, também mostram que a parcela da renda gasta com o aluguel diminui substantivamente (JACOB; LUDWIG, 2012). ${ }^{2}$

Tão importantes quanto os efeitos dos programas habitacionais sobre a qualidade da moradia e acessibilidade são os efeitos indiretos que esse tipo de assistência pode gerar. Isto pois, a ideia de que a assistência habitacional gera externalidades positivas é uma das principais razões para a existência desse tipo de benefício. Se a assistência habitacional não trouxer outros ganhos além da redução no aluguel e na qualidade da moradia, é possível que uma transferência em espécie fosse mais eficiente. ${ }^{3}$

Na literatura econômica sobre programas habitacionais, existem muitas evidências empíricas dos Estados Unidos. O país tem uma longa história com programas habitacionais que vem desde o início do século XX. No início, a assistência habitacional se dava principalmente através de unidades construídas e administradas pelo governo, os projects,

1 Nesse caso, o indivíduo aluga a moradia no mercado privado e o governo subsidia parte do aluguel.

2 Jacob e Ludwig (2012) utiliza o fato de que a seleção para os beneficiários do programa na cidade de Chicago foi feita por sorteio. Currie e Yelowitz (2000) utiliza uma variável instrumental baseada no gênero das crianças das famílias que participaram do programa de habitação pública.

3 Para uma discussão sobre transferências in-kind e em espécie, ver Currie e Gahvari (2008). 
que eram alugadas às famílias que precisassem.

Esse tipo de assistência foi bastante criticado no país por duas razões principais. Primeiro, esses conjuntos residenciais eram construídos em áreas que já eram ocupadas pelos mais pobres, o que poderia levar a uma concentração maior da pobreza e intensificar a segregação racial nas cidades. Além disso, com o passar do tempo, esses conjuntos ficaram associados a lugares de alta criminalidade e pobreza (CURRIE; YELOWITZ, 2000). ${ }^{4}$

Uma das principais externalidades que os economistas e governantes esperam é um efeito sobre a participação do indivíduo no mercado de trabalho. Foi com esse intuito, e após décadas de críticas sobre a localização das habitações públicas, que o governo dos Estados Unidos criou o programa Moving to Opportunity. Desenhado como um experimento, o programa selecionou famílias por sorteio e concedeu um subsídio para que elas se mudassem para áreas de baixa pobreza. Um dos principais efeitos aguardados pelos formuladores do programa era o impacto sobre a taxa de emprego.

Recentemente, Chetty, Hendren e Katz (2016), Jacob e Ludwig (2012), Ludwig et al. (2013), Susin (2005) e Wood, Turnham e Mills (2008) mostraram que programas habitacionais afetam a oferta de trabalho e a saúde física e mental dos indivíduos beneficiados. Contudo, as avaliações do efeito do $M T O$ sobre a taxa de emprego dos adultos beneficiados não encontraram impactos significantes (KLING; LIEBMAN; KATZ, 2007; CHETTY; HENDREN; KATZ, 2016).

Particularmente importantes são os trabalhos de Jacob e Ludwig (2012) e Chetty, Hendren e Katz (2016). O primeiro trabalho mostrou que o benefício habitacional em forma de voucher do programa Section 8 reduziu a probabilidade de estar empregado em $4 \%$ e a renda em $\$ 329$ dólares. A identificação das estimações é garantida pois a seleção dos beneficiários na cidade de Chicago foi feita por um sorteio. Os resultados desse trabalho mostram que o efeito sobre a taxa de emprego é de longo prazo, se mantendo negativo até oito anos depois da concessão do benefício. Além disso, o benefício habitacional também aumenta de maneira significativa a proporção de pessoas que recebem outras assistências governamentais, como a Temporary Assistance for Needy Families (TANF). ${ }^{5}$

O segundo analisou as crianças das famílias beneficiadas pelo programa Moving to Opportunity (MTO $)^{6}$ para mostrar que as crianças que cresceram em bairros de famílias menos pobres, beneficiadas pelo programa, ganham 30\% a mais do que aquelas do grupo

4 Essas críticas levaram os Estados Unidos a priorizar os programas habitacionais baseados em vouchers, desestimulando o modelo de habitação pública.

5 A TANF é um benefício para famílias de baixa renda nos Estados Unidos. Esse programa ajuda financeiramente famílias de baixa renda e que possuem crianças menores de idade.

6 O MTO selecionou os candidatos por sorteio e exigiu que os beneficiários se mudassem para áreas de baixa pobreza, fornecendo uma fonte de exogeneidade bastante única na literatura que analisa o efeito dos bairros. 
de controle, que cresceram em bairros pobres. Além disso, essas crianças tiveram uma probabilidade maior de fazer faculdade do que as crianças no grupo de controle.

Programas habitacionais têm se tornado cada vez mais importantes em países em desenvolvimento. Buckley, Kallergis e Wainer (2016) identificam 16 países em desenvolvimento que lançaram programas habitacionais multibilionários nos últimos anos. ${ }^{7}$ No entanto, existem pouquíssimas evidências empíricas desses países na literatura econômica.

A única evidência experimental até o momento é Barnhardt, Field e Pande (2017). Nesse trabalho, o autor estuda um programa habitacional na Índia que, como o Brasil, tem aumentado os gastos com programas habitacionais nos últimos anos. O programa ofereceu moradias em condições melhores na periferia da cidade a um custo mensal bem abaixo do mercado a moradores de favelas no centro de Ahmedabad, selecionando os beneficiários através de sorteio. Em função da distância dessas moradias, um terço dos ganhadores preferiu não se mudar. Além disso, $32 \%$ dos ganhadores se mudaram e voltaram às favelas em um período de 10 anos. As principais razões apontadas para desistir do benefício estavam ligadas ao isolamento das moradias.

Após 14 anos, os ganhadores não apresentavam melhoras em termos de renda ou capital humano, além disso os vínculos sociais dos ganhadores foram bastante prejudicados, sugerindo que o programa não gerou benefícios econômicos de longo prazo.

\subsection{Minha Casa Minha Vida e a questão habitacional no Brasil}

O Brasil sofreu um intenso processo de urbanização a partir da segunda metade do século XX. Em 60 anos, a população urbana cresceu de $36 \%$ para $84 \%$ da população total no país. ${ }^{8}$ São várias as consequências desse processo, sobretudo nas grandes cidades brasileiras.

A aglomeração de pessoas em favelas, regiões com alta pobreza e ausência de infraestrutura adequada, é um dos principais problemas do país. Atualmente, cerca de $6 \%$ da população brasileira mora em favelas. Nas grandes cidades o problema é ainda maior: no Rio de Janeiro, $22 \%$ da população mora em favelas; em Belém, esse número chega a $54 \%$ da população (CENSO, 2010).

A falta de moradias adequadas é outro problema associado a intensa urbanização que ocorreu no país. Calcula-se que, em 2010, o déficit habitacional no Brasil era de 6,9

7 Dentre eles: Brasil, Índia, África Do Sul, Colômbia.

8 Ver (CENSO, 2010). A população urbana no país era de 36\% em 1950 e de 84\% em 2010. 
milhões de casas (PINHEIRO, 2016). ${ }^{9}$ Além disso, $63 \%$ do déficit habitacional urbano ${ }^{10}$ está concentrado em domicílios com renda de até 3 salários mínimos.

Para enfrentar a crise habitacional, alguns programas foram criados no Brasil ao longo das últimas décadas. O mais importante foi o Banco Nacional de Habitação (BNH), criado em 1964, que garantia subsídios para que famílias das classes baixa e média conseguissem financiar a casa própria. Esse programa financiou a construção de 4,3 milhões de novas unidades habitacionais, sendo 2,4 milhões para as famílias mais pobres (BONDUKI, 2008).

O BNH foi a principal política habitacional do país até a sua extinção em 1987. Após o fim do programa, o país ficou décadas sem uma estratégia nacional de combate ao problema habitacional.

O Programa Minha Casa Minha Vida foi lançado em 2009 com o objetivo de reduzir o déficit habitacional do país. O programa é voltado para famílias com rendimento entre 0 e 10 Salários Mínimos. Desde 2009, o programa acumulou 4,9 milhões de Unidades Habitacionais contratadas. Desse total, 3,5 milhões de UH já foram entregues.

O programa é dividido em três frentes principais, de acordo com a renda das famílias beneficiadas. A Faixa I é destinada à famílias com renda de até $\mathrm{R} \$ 1600,00$ (3 salários mínimos). As Faixas II e III atendem famílias de 3 a 6 salários mínimos e de 6 a 10 salários mínimos, respectivamente ${ }^{11}$. Apesar de a maior parte do déficit habitacional estar concentrado em famílias com até 3 salários mínimos, apenas um terço das unidades entregues foi direcionada a essa faixa de renda. A evolução das unidades habitacionais contratadas por faixa de renda ao longo do tempo pode ser visualizada na Figura 1.

Além do critério de renda familiar, as três modalidades do programa diferem quanto ao modo de seleção dos beneficiários. O subsídio para as famílias na Faixa I é muito elevado, o que não ocorre nas Faixas II e III que têm pouco ou nenhum subsídio. Por isso, para a Faixa I, a seleção dos beneficiários do programa é feita pelas prefeituras nas quais serão construídos os empreendimentos. Como a demanda por habitação normalmente supera a oferta, as regras do programa determinam que as famílias elegíveis ao programa sejam cadastradas e sorteadas pelas prefeituras para a obtenção da moradia. Para as duas outras faixas, as próprias famílias procuram empreendimentos do programa e verificam o seu enquadramento nos critérios de seleção (MARQUES; RODRIGUES, 2013).

9 São consideradas parte do déficit habitacional as casas que estão em condições precárias e que precisam ser repostas e também as casas em que: a) vivem duas ou mais famílias ou b) a renda familiar é de até 3 salários mínimos e o gasto com o aluguel excede $30 \%$ dela. Para mais detalhes, ver: (PINHEIRO, 2016).

10 O déficit habitacional urbano é cerca de $84 \%$ do déficit habitacional total.

11 Esses valores foram reajustados recentemente. A renda máxima para a Faixa I foi para $\mathrm{R} \$ 1800,00$. Até 2011, o valor era de $\mathrm{R} \$ 1395,00$. 


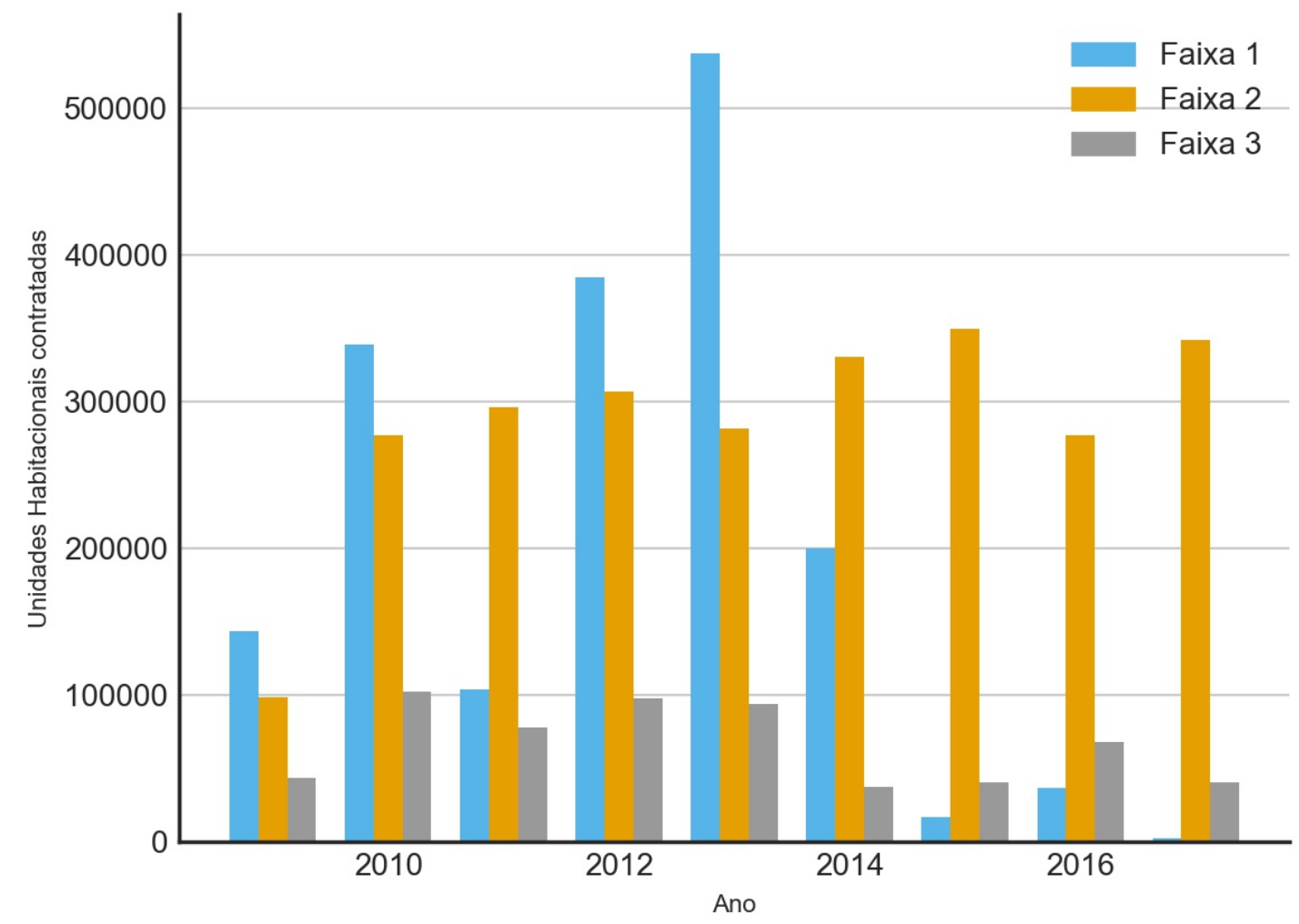

Figura 1 - Unidades habitacionais contratadas no MCMV

Dados do Ministério das Cidades. Elaboração própria.

Atualmente, existem 11375 empreendimentos para a Faixa I em todo o Brasil, totalizando cerca de 1,76 milhão de unidades habitacionais. Algumas cidades como São Paulo e Rio de Janeiro possuem dezenas de empreendimentos. São Paulo havia contratado 40 empreendimentos até essa data e o Rio de Janeiro 100 empreendimentos.

Os empreendimentos construídos na Faixa I são o principal instrumento de construção de moradias populares do país. Nessa categoria, o projeto e a execução do empreendimento ficam a cargo da iniciativa privada. As prefeituras de cada município selecionam os beneficiários do programa e, por fim, a Caixa Econômica Federal financia essas unidades para os indivíduos selecionados, subsidiando a maior parte do valor do imóvel.

Para essa faixa de renda os subsídios podem chegar a 90\% do valor do imóvel e as prestações se estendem por até 120 meses (MARQUES; RODRIGUES, 2013).

Uma das grandes críticas ao programa é a localização dos empreendimentos construídos, sobretudo na Faixa I. Diversos estudos apontam que os empreendimentos são construídos em bairros periféricos, afastados de oportunidades de emprego, comércio, transporte público, unidades de saúde e escolas (MARQUES; RODRIGUES, 2013; ROLNIK et al., 2015; PEQUENO; RENATO, 2013). De fato, este problema também foi apontado 
pelos próprios beneficiários do programa em pesquisa oficial do Ministério do Desenvolvimento, realizada em 2013 (BRASIL, 2014).

O problema da localização repete a experiência do BNH, que também priorizou a construção de grandes conjuntos habitacionais na periferia das cidades em lugares pouco urbanizados (BONDUKI, 2008). ${ }^{12}$

Dada a má localização dos empreendimentos, outra literatura é relevante para analisar o efeito sobre a oferta de trabalho. É a literatura que trata da hipótese de spatial mismatch (descasamento espacial).

Formulada por Kain (1968), ela discute os efeitos adversos da segregação espacial na oferta de trabalho dos indivíduos. A hipótese introduzida por esse autor é a de que populações urbanas que moram em áreas distantes de (e mal conectadas a) centros de emprego têm grandes dificuldades em encontrar e manter bons empregos, o que prejudica o seu desempenho no mercado de trabalho.

Os piores resultados no mercado de trabalho podem ser causados por uma série de mecanismos: (i) Os trabalhadores podem rejeitar empregos que envolvam um longo tempo de commuting; (ii) A eficiência da busca por emprego pode diminuir, dada a grande distância de empregos; (iii) Os trabalhadores que moram longe demais de empregos podem diminuir seus esforços de busca; (iv) Os custos de procurar por um emprego podem ser muito elevados, levando os trabalhadores a restringir a busca em vizinhanças mais próximas de onde moram; (v) Empregadores podem não contratar ou demitir empregados que moram longe demais devido ao longo tempo de commuting, que pode afetar sua produtividade; (vi) Esses indivíduos podem custar mais caro para as firmas, que devem compensá-lo pelo custo de transporte, dentre outros. Os efeitos sobre essa população podem incluir: tempo de commuting maior, salários menores e maior desemprego (GOBILLON; SELOD; ZENOU, 2007).

12 Para uma comparação das habitações produzidas no âmbito dos programas BNH e MCMV ver Marques e Rodrigues (2013), Silva e Tourinho (2015). 


\section{Dados e metodologia}

\subsection{Bases de dados utilizadas}

Esta seção descreve brevemente as bases de dados utilizadas e o procedimento para construção das amostras nas duas cidades analisadas por este trabalho.

A análise se baseia em cinco fontes de dados principais. Em primeiro lugar, a lista de beneficiários do programa Minha Casa Minha Vida foi obtida junto a Caixa Econômica Federal (CEF). Essa lista contém o nome, o Cadastro de Pessoa Física (CPF), a data de assinatura do financiamento e dados do empreendimento de todos os beneficiários do Minha Casa Minha Vida - Faixa I.

As informações sobre a seleção dos beneficiários no Rio de Janeiro foram obtidas no site da Prefeitura do Rio de Janeiro. ${ }^{1}$ Essas informações relatam todos os inscritos e sorteados, identificados por nome e CPF, para os sorteios realizados em 2011. Para montar a base de dados inicial, cruzou-se as informações dessas duas bases de dados a partir do CPF dos indivíduos. ${ }^{2}$

As informações sobre a seleção dos beneficiários em São José Rio Preto também estão disponíveis na internet, no site da Prefeitura de São José do Rio Preto ${ }^{3}$. Da mesma forma, as informações relatam todos os inscritos e sorteados, identificados por nome e CPF. Nesse caso, os sorteios foram realizados em 2013.

Essas bases de dados não contêm nenhuma variável socioeconômica dos indivíduos, apenas os nomes e CPFs.

A partir dessas bases iniciais, buscou-se obter características dos indivíduos, bem como informações sobre a participação no mercado de trabalho formal e programas sociais. Para isso, foram utilizadas duas bases sigilosas e identificadas por CPF: a base de microdados do Relatório Anual de Informações Sociais (RAIS) e a base do Cadastro Único. O cruzamento com essas bases foi feito a partir do CPF dos indivíduos.

A RAIS é um relatório de informações socioeconômicas exigido pelo Ministério do Trabalho de todas as empresas formais no Brasil. Os empregadores devem preencher anualmente informações sobre suas empresas e sobre seus empregados. Essas informações são condensadas em uma base de micro-dados em painel que contém informações sobre

1 Ver: < http://www.rio.rj.gov.br/web/smhc/minhacasaminhavida-2011>.

2 A taxa de beneficiários do programa nos empreendimentos analisados no Rio de Janeiro e que foram sorteados foi de cerca de 95\%. Os indivíduos beneficiários do programa nos empreendimentos analisados que não constavam na lista de sorteados foram excluídos da análise.

3 Ver < http://www.riopreto.sp.gov.br/PortalGOV/do/subportais_Show?c=116062>. 
todos os trabalhadores formais do país e que podem ser identificados através do CPF.

As informações contidas na RAIS apontam quais indivíduos estavam trabalhando no mercado formal em um dado ano. A base também mostra informações sobre o emprego do indivíduo, como salário, setor de atuação, data em que começou no emprego e data em que foi desligado. Por isso, construiu-se a variável de emprego formal a partir das informações da RAIS. Ela é uma dummy igual a 1 se o indivíduo aparece na RAIS em um dado ano e 0 caso contrário.

Além disso, a RAIS apresenta características dos indivíduos. Ela indica informações como gênero, idade, escolaridade e cor da pele.

Trabalhar com essa base restringe a análise aos trabalhadores formais do país. Apesar de a informalidade ainda ser relevante no país, a taxa de emprego formal para a população analisada varia de $50 \%$ a $58 \%$ no período analisado. Além disso, entre 2006 e 2014, 75\% dos indivíduos analisados apareceram na RAIS pelo menos uma vez. Isto é, apenas um quarto não passou pelo mercado formal.

A outra base utilizada é a base identificada do Cadastro Único, que foi fornecida pelo Ministério do Desenvolvimento. Ela contém informações sobre as famílias brasileiras em situação de pobreza ou extrema pobreza e que são beneficiárias de programas sociais do Estado. As informações contidas nessa base são muito mais completas do que as informações na RAIS, pois incluem não só características dos indivíduos, mas também de toda a sua família. Além disso, ela também conta com os indivíduos que trabalham no mercado informal.

Além de fornecer informações sobre os indivíduos e suas famílias, a base do Cadastro Único também indica os participantes do programa Bolsa Família, o principal programa social do país. Por isso, constrói-se uma variável de participação no Bolsa Família a partir desses dados.

Todos os beneficiários do Minha Casa Minha Vida devem estar inscritos no Cadastro Único. Por isso, essa base contém informações completas sobre os indivíduos e as famílias dos indivíduos beneficiados pelo programa.

A opção por fazer duas análises separadas para o Rio de Janeiro e São José do Rio Preto se deu por conta das diferenças nas bases de dados disponíveis em cada um dos casos. No caso de São José do Rio Preto, a prefeitura inseriu no Cadastro Único quase todos os indivíduos (99\%) que participaram do sorteio realizado em 2013. No caso do Rio de Janeiro, apenas os beneficiários foram cadastrados no Cadastro Único e apenas 25\% do total da amostra estava na base no ano de 2012.

Por isso, no caso de São José do Rio Preto, constrói-se as variáveis de controle a partir de informações do Cadastro Único. Para o caso do Rio de Janeiro, as variáveis de 
controle são construídas a partir de informações da RAIS. ${ }^{4}$

Para o caso do Rio de Janeiro, são reunidas todas as características socioeconômicas dos indivíduos que são encontrados na RAIS entre os anos de 2006 a 2014. Com isso, consegue-se informações de gênero, cor da pele, escolaridade, idade e informações do mercado de trabalho formal de cerca de $75 \%$ da amostra. ${ }^{5}$

Para o caso de São José do Rio Preto, as características socioeconômicas dos indivíduos são do Cadastro Único. Com essa base, consegue-se informações de $99 \%$ da amostra.

\subsection{O Minha Casa Minha Vida no Rio de Janeiro}

A cidade do Rio de Janeiro é a cidade com mais beneficiários do programa MCMV na Faixa I. Atualmente, 27843 famílias são beneficiadas na cidade. Entre 2009 e 2012 foram inaugurados 48 empreendimentos, sendo que 36 desses empreendimentos foram utilizados para reassentamento de famílias que habitavam em áreas de risco e em áreas que seriam reformadas pela prefeitura. ${ }^{6}$ Os 12 empreendimentos restantes foram destinados a famílias que estavam inscritas no cadastro habitacional da prefeitura, composto por famílias que careciam de moradia (CARDOSO; LAGO, 2015).

Para esse segundo grupo de empreendimentos a seleção dos 3934 beneficiários foi feita pela prefeitura através de sorteio, com base em extração da Loteria Federal. Cada participante recebeu um número e aguardou o resultado da loteria federal da Caixa Econômica. Se os dois últimos dígitos do número de inscrição do participante fossem os mesmos dos dois últimos dígitos da extração da loteria federal, então os agentes da prefeitura do Rio de Janeiro entrariam em contato com aquele participante. ${ }^{7}$

Restringe-se a análise a esses empreendimentos que tiveram a seleção feita de forma aleatória. No total, foram realizados 9 sorteios para a seleção dos beneficiários em 2011. No entanto, analisa-se apenas os três em que os inscritos eram provenientes do Cadastro de Demanda Geral da Secretária Municipal de Habitação do Rio de Janeiro (Sorteios 003,

4 Na seção 3.2.3 constrói-se uma amostra para São José do Rio Preto da mesma forma que para o Rio de Janeiro, isto é, com as variáveis da RAIS. Mostra-se nessa seção que os resultados são bastante similares.

5 No caso do Rio de Janeiro, incorporar as informações do Cadastro Único enviesaria a amostra. Isto pois, dado que o compliance é imperfeito, os indivíduos que se tornaram beneficiários do programa são diferentes dos indivíduos não sorteados. Como os beneficiários foram inseridos no Cadastro Único, introduzir as informações completas do Cadastro Único tornaria os grupos de tratamento e controle desbalanceados.

6 O Rio de Janeiro sediou a Copa do Mundo de 2014 e as Olimpíadas de 2016. Foram feitas diversas intervenções na cidade que causaram o reassentamento de milhares de famílias. O Minha Casa Minha Vida foi utilizado para reassentar a maior parte dessa população deslocada. Para mais informações, ver Cardoso e Lago (2015).

7 Para mais detalhes, ver os editais dos sorteios, presentes na página da prefeitura do Rio de Janeiro: <http://www.rio.rj.gov.br/web/smhc/minhacasaminhavida-2011> 
006 e 009). Isto é, exclui-se aqueles que foram exclusivos para pessoas com deficiência e idosos. $^{8}$

Na Tabela 1 observa-se o número de inscritos, sorteados e compliance dos três sorteios do cadastro geral, realizados em 2011.

Tabela 1 - Sorteios do MCMV no Rio de Janeiro

\begin{tabular}{lccccc}
\hline \hline & Data do sorteio & Inscritos & Sorteados & Beneficiários & Compliance \\
\hline Edital 003/2011 & $11 / 06 / 2011$ & 297867 & 2983 & 912 & $30,6 \%$ \\
Edital 006/2011 & $13 / 08 / 2011$ & 325080 & 6505 & 1352 & 20,8\% \\
Edital 009/2011 & $02 / 11 / 2011$ & 351094 & 14056 & 1695 & 12,1\% \\
\hline Total & & 361805 & 23472 & 3934 & $16,8 \%$ \\
\hline \hline
\end{tabular}

Notas: Dados da Prefeitura do Rio de Janeiro. Cada um dos editais corresponde a um sorteio diferente.

Ao longo do ano de 2011, em três sorteios separados, foram sorteados 23472 indivíduos para o preenchimento das vagas no programa. Esses indivíduos foram contatados por telefone ou carta por agentes da prefeitura do Rio de Janeiro e foram oferecidas as vagas no programa.

É importante ressaltar que, apesar de cada sorteio possuir mais inscritos do que o anterior, nem todos os inscritos do sorteio anterior estão no sorteio posterior. Isto é, há, por exemplo, 25316 pessoas que participaram do Sorteio 003 e que não participaram do Sorteio 006. Desse total, 24321 estavam no Sorteio 009. Os editais de cada sorteio não deixam claro o por quê de isso ter acontecido. Ao invés disso, declaram que todos os participantes do sorteio provém do "Banco de Cadastro de Demandas"da Secretária Municipal de Habitação.

Cerca de 16,8\% de todos os indivíduos sorteados efetivamente se tornaram beneficiários pelo programa. Contudo, a taxa de compliance variou bastante por sorteio. Uma das explicações possíveis para essa variação é a localização dos empreendimentos oferecidos em cada sorteio. ${ }^{9}$ O primeiro sorteio, que teve o maior compliance, ofereceu mais vagas em empreendimentos próximos ao transporte público e em bairros mais consolidados do que o segundo sorteio (empreendimentos Destri e Residencial Rio Bonito). Por fim, grande parte das unidades do último sorteio eram de vagas remanescentes dos dois últimos sorteios. A divisão dos beneficiários de cada empreendimento por sorteio está na Tabela 16 do apêndice. Além disso, pode-se observar a localização dos empreendimentos de cada sorteio na Figura 2.

8 Os 6 sorteios restantes foram especiais para idosos e pessoas com deficiência. Além do número de sorteados ser pequeno (417), para fins de análise do mercado de trabalho, prefere-se a análise apenas dos indivíduos nos sorteios gerais.

9 Também podem haver outros fatores que explicam o baixo compliance, como o não enquadramento no critério de renda do programa. 
Em virtude da grande diferença entre as taxas de compliance e da diferente composição da lista de inscritos em cada sorteio, a análise do presente trabalho será feita separadamente para cada sorteio. Isto é, na amostra de cada sorteio constará apenas os indivíduos que estavam inscritos naquele sorteio e serão considerados como sorteados apenas os indivíduos sorteados naquele sorteio. ${ }^{10}$

Ao aceitar a unidade habitacional, a família passa por uma verificação de renda e de adequação aos critérios do programa, feita pela Caixa Econômica Federal. Após a aprovação, a família passa a aguardar a entrega do empreendimento.

Os critérios para enquadramento no programa incluem: a) Possuir renda familiar de até 3 salários mínimos, b) Não ser proprietário de algum imóvel financiado pela Caixa e c) Não possuir nenhum financiamento ativo no âmbito do Sistema Financeiro de Habitação.

Os 12 empreendimentos foram entregues ao longo do ano de 2012 em diferentes endereços na Zona Oeste do Rio de Janeiro (Figura 2). A distância desses empreendimentos ao centro da cidade, que concentra os empregos no município, varia entre $20 \mathrm{~km}$ e $30 \mathrm{~km}$ em linha reta, tornando os deslocamentos para essa região bastante onerosos (CARDOSO; LAGO, 2015).

Além disso, as áreas escolhidas apresentam menor quantidade de empregos e concentram a população de baixa renda da cidade (Figuras 3 e 4). Diversos estudos criticam a localização desses conjuntos residenciais, destacando a concentração de famílias de baixa renda em áreas com pouca infraestrutura e serviços urbanos (CARDOSO; LAGO, 2015).

\subsubsection{Características dos grupos de tratamento e controle}

Nessa seção, mostra-se que os grupos de tratamento e controle nos três sorteios são balanceados. Além disso, descreve-se o processo de construção da amostra para o caso do Rio de Janeiro.

Os dados da prefeitura do Rio de Janeiro contêm apenas o nome, o CPF, os inscritos e sorteados de cada um dos sorteios. Esses dados não contém qualquer informação socioeconômica ou de mercado de trabalho dos indivíduos participantes dos sorteios. Por isso, o grande desafio do presente trabalho foi construir uma amostra com informações econômicas desse grupo de pessoas para comprovar a validade dos sorteios e, com isso, estimar o impacto do Minha Casa Minha Vida.

As características dos indivíduos são obtidas a partir do cruzamento do CPF, fornecido pela prefeitura do Rio de Janeiro, com as bases de dados sigilosas e identificadas da RAIS, fornecidas pelo Ministério do Trabalho. Foram utilizadas as bases da RAIS entre

\footnotetext{
10 Nos resultados apresentados na parte principal, os indivíduos sorteados nos outros dois sorteios são mantidos na amostra (por exemplo, na amostra do sorteio 003 são mantidos os indivíduos sorteados nos sorteios 006 e 009). No apêndice, mostra-se que a exclusão desses indivíduos não altera os resultados principais.
} 


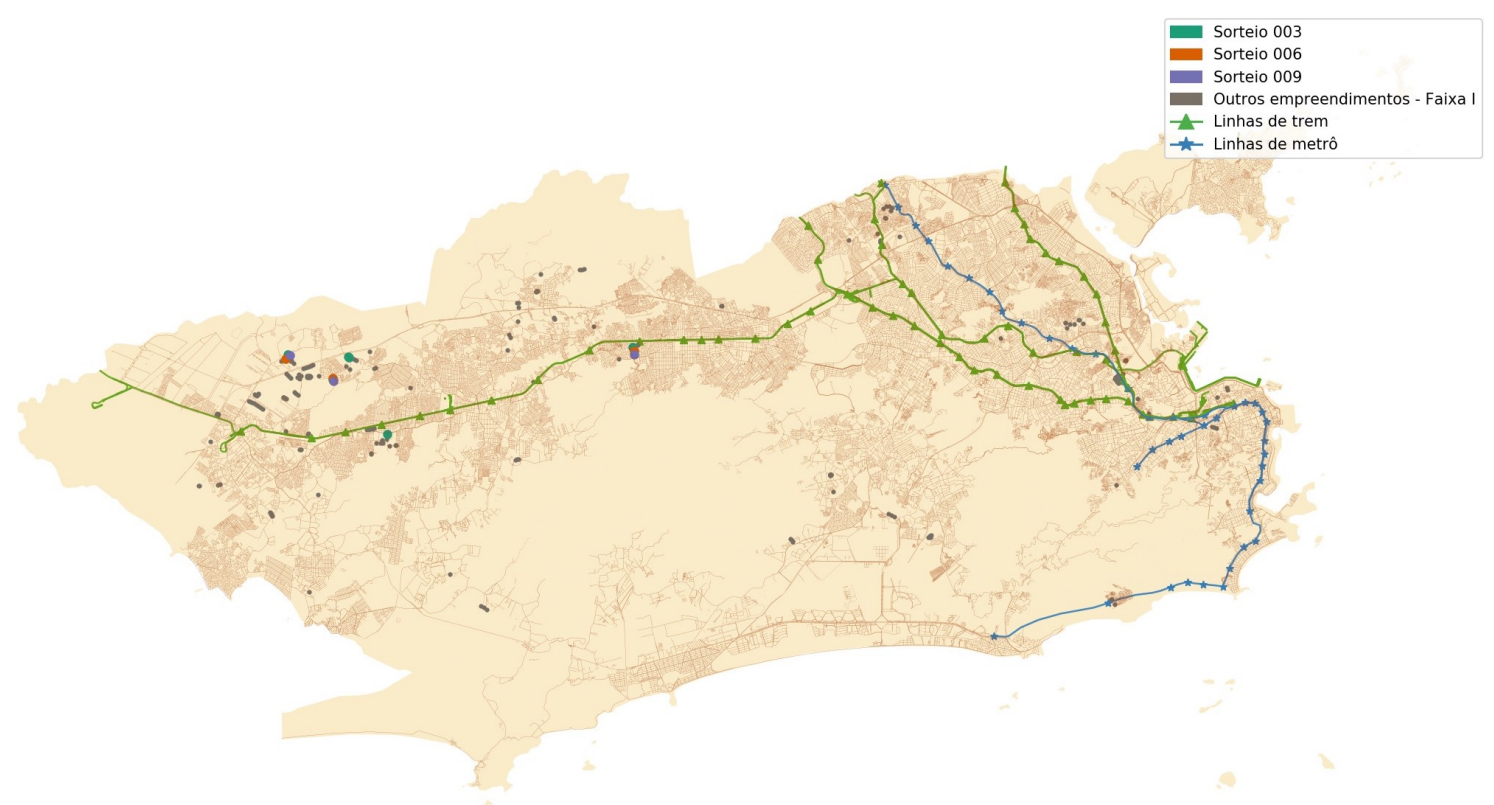

Figura 2 - Empreendimentos do MCMV no Rio de Janeiro - Faixa I Dados da Prefeitura do Rio de Janeiro. Elaboração própria.

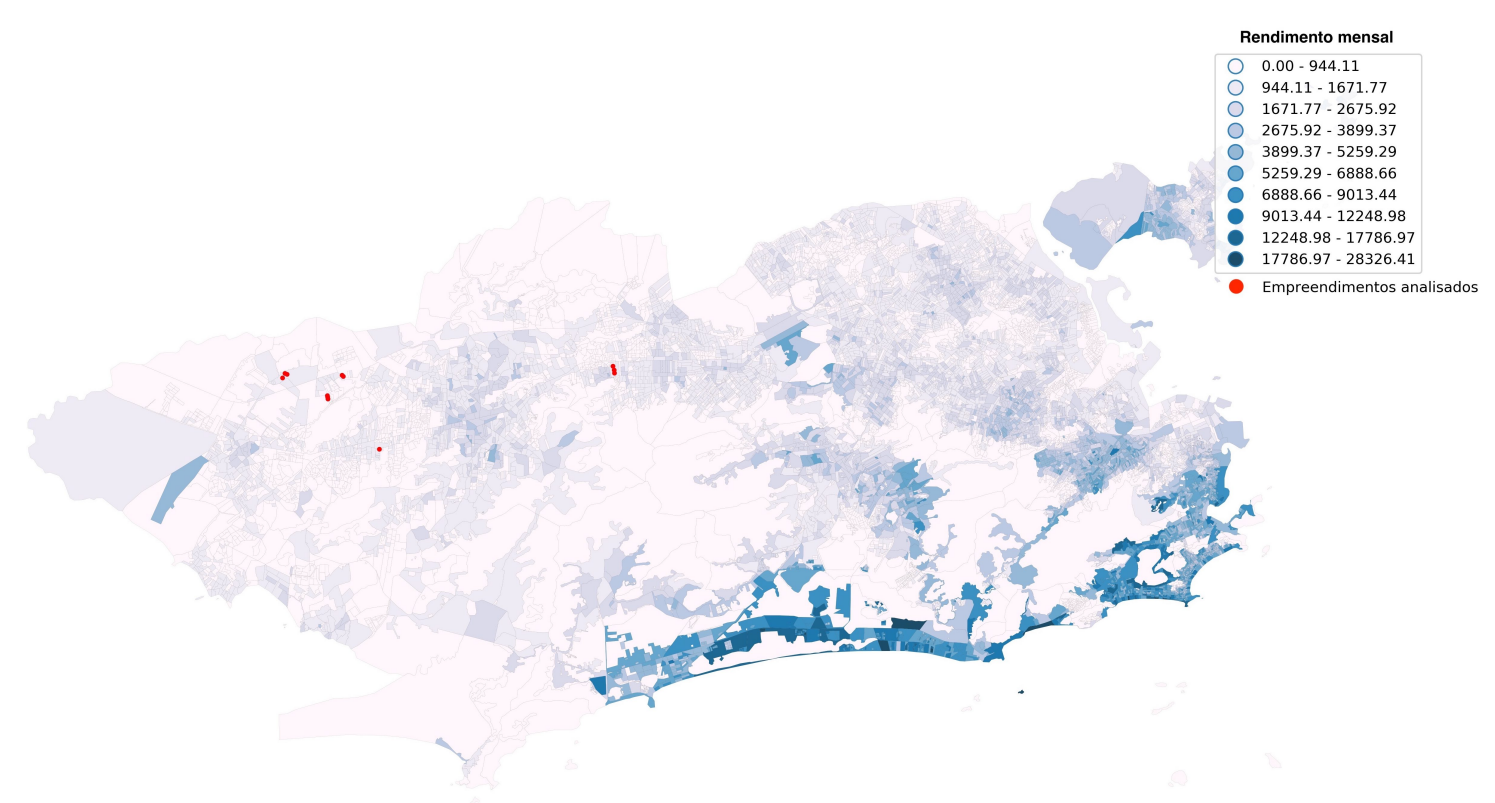

Figura 3 - Rendimento mensal médio por setor censitário no Rio de Janeiro Dados do Censo 2010. Elaboração própria. 


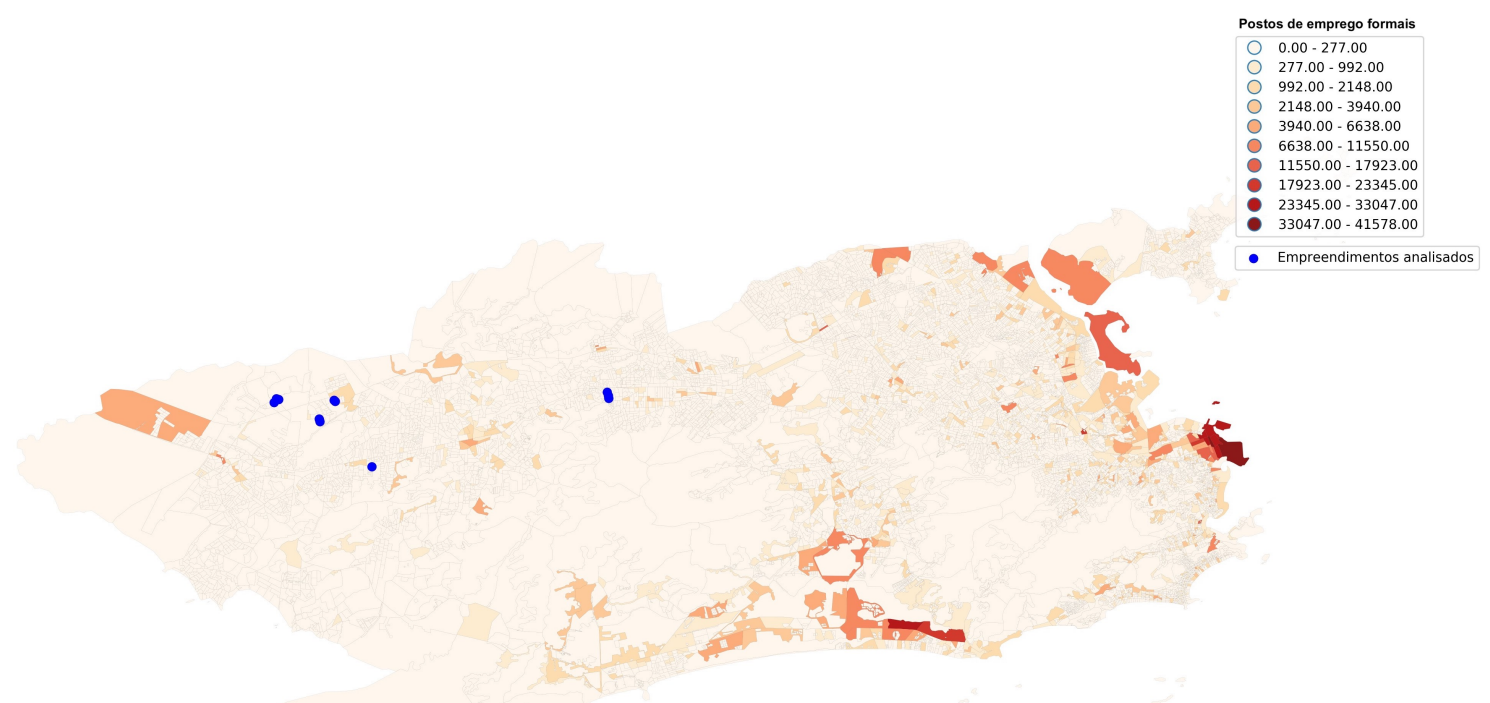

Figura 4 - Distribuição dos postos de emprego formais no Rio de Janeiro por setor censitário

Dados da RAIS de 2011 e Censo 2010. Elaboração própria.

2006 e 2014 para obter as informações de cerca de $75 \%$ da amostra. O balanceamento entre os grupos de tratamento e controle em cada sorteio pode ser visto nas Tabelas 2,3 e $4 .{ }^{11}$

As variáveis de gênero, idade, escolaridade, etnia e portador de deficiência correspondem ao grupo de indivíduos que foi encontrado na RAIS, conforme descrito acima. As variáveis de emprego, setor do emprego e salário formal foram obtidas a partir da RAIS e correspondem ao grupo total dos indivíduos participantes do sorteio.

As três tabelas mostram que os sorteios foram, de fato, aleatórios. Os grupos dos sorteados e dos não sorteados (controle) são bastante parecidos em quase todas as características obtidas da RAIS. Algumas variáveis apresentam diferenças significativas a $5 \%$ ou $10 \%$, porém a estatística $\mathrm{F}$ de uma regressão onde a variável dependente indica se o indivíduo foi sorteado e as variáveis explicativas são as características apresentadas nas tabelas é bastante baixa para os três sorteios, indicando que não há diferenças significativas entre os sorteados e não sorteados.

Apesar da divisão entre sorteios, a população é bastante homogênea. A maior parte dos indivíduos é de cor negra ou parda e teve um salário médio formal em 2010 próximo ao salário mínimo. Além disso, a amostra está razoavelmente dividida entre homens e mulheres e a maior parte dos indivíduos possuía ensino médio completo. Contudo, como as informações são de uma base de dados que possuí apenas trabalhadores formais, é provável que a população que participou dos três sorteios seja composta por mais mulheres

11 Nas Tabelas 21, 22 e 23 mostra-se que, se utilizarmos apenas os dados da RAIS de 2006 a 2010 (períodos anteriores ao sorteio), o balanceamento se mantém. 
do que homens e que a escolaridade seja menor. ${ }^{12}$

Mais da metade (57\%) dos indivíduos teve algum emprego formal em 2010 e a maioria desses trabalhadores estava no setor de serviços da economia.

A tabela ainda mostra que a população que aceitou o benefício habitacional é diferente da população sorteada. Os indivíduos que de fato se tornaram beneficiários do programa possuem renda, taxa de emprego, idade e escolaridade menores nos três sorteios. Além disso, entre os beneficiários há uma proporção maior de negros ou pardos e de mulheres. Esses dados indicam que a população complier, que é sorteada e participa do programa, é mais vulnerável do que os noncompliers, que são sorteados, mas não participam, e do que indivíduos do grupo de controle.

$\overline{12}$ Para se ter uma ideia do perfil da população que está sendo excluída, ver a Seção 3.2.3. 
Tabela 2 - Balanceamento - Sorteio 003

\begin{tabular}{|c|c|c|c|c|c|}
\hline & $\begin{array}{c}(1) \\
\text { Controle }\end{array}$ & $\begin{array}{c}(2) \\
\text { Sorteados }\end{array}$ & $\begin{array}{c}(3) \\
\text { Diferença }(1)-(2)\end{array}$ & $\begin{array}{c}(4) \\
\text { Compliers }\end{array}$ & $\begin{array}{c}(5) \\
\text { Noncompliers }\end{array}$ \\
\hline \% com informação & 0,740 & 0,735 & $\begin{array}{c}0,005 \\
(0,008)\end{array}$ & 0,712 & 0,745 \\
\hline Sexo feminino & 0,539 & 0,536 & $\begin{array}{c}0,004 \\
(0,011)\end{array}$ & 0,638 & 0,493 \\
\hline Indígena & 0,003 & 0,002 & $\begin{array}{c}0,001 \\
(0,001)\end{array}$ & 0,002 & 0,002 \\
\hline Cor branca & 0,379 & 0,372 & $\begin{array}{c}0,007 \\
(0,010)\end{array}$ & 0,354 & 0,380 \\
\hline Cor negra & 0,119 & 0,117 & $\begin{array}{c}0,002 \\
(0,007)\end{array}$ & 0,136 & 0,110 \\
\hline Cor amarela & 0,006 & 0,006 & $\begin{array}{l}-0,000 \\
(0,002)\end{array}$ & 0,006 & 0,006 \\
\hline Cor parda & 0,348 & 0,359 & $\begin{array}{l}-0,011 \\
(0,010)\end{array}$ & 0,408 & 0,338 \\
\hline Cor não identificada & 0,056 & 0,052 & $\begin{array}{c}0,003 \\
(0,005)\end{array}$ & 0,046 & 0,055 \\
\hline Analfabeto & 0,001 & 0,000 & $\begin{array}{c}0,001 \\
(0,001)\end{array}$ & 0,000 & 0,001 \\
\hline Deficiente & 0,010 & 0,006 & $\begin{array}{l}0,004^{*} \\
(0,002)\end{array}$ & 0,006 & 0,006 \\
\hline Completou o ensino fundamental & 0,867 & 0,852 & $\begin{array}{l}0,015^{* *} \\
(0,007)\end{array}$ & 0,837 & 0,859 \\
\hline Completou o ensino médio & 0,641 & 0,635 & $\begin{array}{c}0,006 \\
(0,010)\end{array}$ & 0,586 & 0,655 \\
\hline Completou o ensino superior & 0,098 & 0,098 & $\begin{array}{l}-0,001 \\
(0,006)\end{array}$ & 0,054 & 0,117 \\
\hline Idade & 36,917 & 36,911 & $\begin{array}{c}0,007 \\
(0,229)\end{array}$ & 36,149 & 37,231 \\
\hline $\begin{array}{l}\text { Salário formal em } 2010 \\
(\mathrm{R} \$)\end{array}$ & 581,400 & 571,370 & $\begin{array}{c}10,030 \\
(15,226)\end{array}$ & 388,765 & 651,784 \\
\hline Empregado formalmente em 2010 & 0,567 & 0,561 & $\begin{array}{c}0,007 \\
(0,009)\end{array}$ & 0,524 & 0,577 \\
\hline Trabalha no setor de Serviços & 0,211 & 0,213 & $\begin{array}{l}-0,003 \\
(0,008)\end{array}$ & 0,245 & 0,199 \\
\hline Trabalha no setor Administrativo & 0,178 & 0,177 & $\begin{array}{c}0,002 \\
(0,007)\end{array}$ & 0,167 & 0,181 \\
\hline Trabalha na Indústria & 0,075 & 0,074 & $\begin{array}{c}0,001 \\
(0,005)\end{array}$ & 0,056 & 0,082 \\
\hline Estatística F & & & 0,91 & & \\
\hline $\mathrm{P}$-valor & & & 0,575 & & \\
\hline$N$ & 294884 & 2983 & 297867 & 912 & 2071 \\
\hline
\end{tabular}

Notas: Essa tabela apresenta o balanceamento entre os grupos de tratamento e controle do Sorteio 003, primeiro sorteio realizado em 2011 para seleção dos beneficiários do MCMV no Rio de Janeiro. A unidade de análise é o indivíduo. A amostra inclui todos os indivíduos inscritos no Sorteio 003. Todas as informações apresentadas são da RAIS de 2006 a 2014. As informações de gênero, cor da pele, escolaridade, idade e deficiente são de cerca de $74 \%$ da amostra, cujas informações estavam presentes na RAIS. As informações de salário formal, emprego formal e setor do emprego são de toda a amostra. A primeira coluna apresenta as informações dos indivíduos não sorteados no sorteio do MCMV. A segunda coluna apresenta as informações dos indivíduos sorteados. A terceira coluna indica a diferença entre os grupos e o resultado de um teste $t$ de diferença entre os dois grupos. A quarta coluna apresenta as informações dos indivíduos que foram sorteados e que se tornaram beneficiários do MCMV. A quinta coluna apresenta as informações daqueles que foram sorteados, mas não se tornaram beneficiários. A estatística $\mathrm{F}$ e o p-valor são de uma regressão onde a variável dependente é igual a um se o indivíduo foi sorteado no Sorteio 003 e 0 caso contrário e as variáveis explicativas são as características socioeconômicas da tabela. O erro padrão é clusterizado ao nível do indivíduo.

${ }^{*} p<0,10,{ }^{* *} p<0,05,{ }^{* * *} p<0,01$ 
Tabela 3 - Balanceamento - Sorteio 006

\begin{tabular}{|c|c|c|c|c|c|}
\hline & $\begin{array}{c}(1) \\
\text { Controle }\end{array}$ & $\begin{array}{c}(2) \\
\text { Sorteados }\end{array}$ & $\begin{array}{c}(3) \\
\text { Diferença }(1)-(2)\end{array}$ & $\begin{array}{c}\text { (4) } \\
\text { Compliers }\end{array}$ & $\begin{array}{c}(5) \\
\text { Noncompliers }\end{array}$ \\
\hline \% com informação & 0,747 & 0,750 & $\begin{array}{l}-0,004 \\
(0,005)\end{array}$ & 0,733 & 0,755 \\
\hline Sexo feminino & 0,525 & 0,528 & $\begin{array}{l}-0,003 \\
(0,007)\end{array}$ & 0,633 & 0,501 \\
\hline Indígena & 0,003 & 0,002 & $\begin{array}{c}0,001 \\
(0,001)\end{array}$ & 0,001 & 0,002 \\
\hline Cor branca & 0,383 & 0,382 & $\begin{array}{c}0,000 \\
(0,007)\end{array}$ & 0,385 & 0,382 \\
\hline Cor negra & 0,114 & 0,112 & $\begin{array}{c}0,002 \\
(0,005)\end{array}$ & 0,141 & 0,105 \\
\hline Cor amarela & 0,006 & 0,006 & $\begin{array}{c}0,000 \\
(0,001)\end{array}$ & 0,006 & 0,006 \\
\hline Cor parda & 0,342 & 0,345 & $\begin{array}{l}-0,003 \\
(0,007)\end{array}$ & 0,366 & 0,340 \\
\hline Cor não identificada & 0,055 & 0,061 & $\begin{array}{l}-0,006^{*} \\
(0,003)\end{array}$ & 0,059 & 0,062 \\
\hline Analfabeto & 0,001 & 0,002 & $\begin{array}{c}-0,001^{* *} \\
(0,000)\end{array}$ & 0,004 & 0,001 \\
\hline Deficiente & 0,010 & 0,012 & $\begin{array}{l}-0,002 \\
(0,001)\end{array}$ & 0,012 & 0,012 \\
\hline Completou ensino fundamental & 0,877 & 0,876 & $\begin{array}{c}0,001 \\
(0,005)\end{array}$ & 0,866 & 0,878 \\
\hline Completou ensino médio & 0,660 & 0,662 & $\begin{array}{l}-0,002 \\
(0,007)\end{array}$ & 0,605 & 0,676 \\
\hline Completou ensino superior & 0,110 & 0,105 & $\begin{array}{c}0,005 \\
(0,005)\end{array}$ & 0,069 & 0,114 \\
\hline Idade & 36,994 & 37,009 & $\begin{array}{l}-0,015 \\
(0,153)\end{array}$ & 35,976 & 37,272 \\
\hline $\begin{array}{l}\text { Salário formal em } 2010 \\
(\mathrm{R} \$)\end{array}$ & 623,110 & 624,114 & $\begin{array}{c}-1,004 \\
(11,016)\end{array}$ & 400,710 & 682,729 \\
\hline $\begin{array}{l}\text { Empregado formalmente } \\
\text { em } 2010\end{array}$ & 0,579 & 0,575 & $\begin{array}{c}0,004 \\
(0,006)\end{array}$ & 0,533 & 0,586 \\
\hline Trabalha no setor de Serviços & 0,205 & 0,201 & $\begin{array}{c}0,003 \\
(0,005)\end{array}$ & 0,237 & 0,192 \\
\hline Trabalha no setor Administrativo & 0,185 & 0,186 & $\begin{array}{l}-0,001 \\
(0,005)\end{array}$ & 0,153 & 0,195 \\
\hline Trabalha na Indústria & 0,077 & 0,074 & $\begin{array}{c}0,002 \\
(0,003)\end{array}$ & 0,073 & 0,074 \\
\hline Estatística F & & & 0,87 & & \\
\hline $\mathrm{P}$-valor & & & 0,616 & & \\
\hline$N$ & 318575 & 6505 & 325080 & 1352 & 5153 \\
\hline
\end{tabular}

Notas: Essa tabela apresenta o balanceamento entre os grupos de tratamento e controle do Sorteio 006, segundo sorteio realizado em 2011 para seleção dos beneficiários do MCMV no Rio de Janeiro. A unidade de análise é o indivíduo. A amostra inclui todos os indivíduos inscritos no Sorteio 006. Todas as informações apresentadas são da RAIS de 2006 a 2014. As informações de gênero, cor da pele, escolaridade, idade e deficiente são de cerca de $75 \%$ da amostra, cujas informações estavam presentes na RAIS. As informações de salário formal, emprego formal e setor do emprego são de toda a amostra. A primeira coluna apresenta as informações dos indivíduos não sorteados no sorteio do MCMV. A segunda coluna apresenta as informações dos indivíduos sorteados. A terceira coluna indica a diferença entre os grupos e o resultado de um teste $t$ de diferença entre os dois grupos. A quarta coluna apresenta as informações dos indivíduos que foram sorteados e que se tornaram beneficiários do MCMV. A quinta coluna apresenta as informações daqueles que foram sorteados, mas não se tornaram beneficiários. A estatística $\mathrm{F}$ e o p-valor são de uma regressão onde a variável dependente é igual a um se o indivíduo foi sorteado no Sorteio 006 e 0 caso contrário e as variáveis explicativas são as características socioeconômicas da tabela. O erro padrão é clusterizado ao nível do indivíduo.

${ }^{*} p<0,10,{ }^{* *} p<0,05,{ }^{* * *} p<0,01$ 
Tabela 4 - Balanceamento - Sorteio 009

\begin{tabular}{|c|c|c|c|c|c|}
\hline & $\begin{array}{c}(1) \\
\text { Controle }\end{array}$ & $\begin{array}{c}(2) \\
\text { Sorteados }\end{array}$ & $\begin{array}{c}(3) \\
\text { Diferença }(1)-(2)\end{array}$ & $\begin{array}{c}(4) \\
\text { Compliers }\end{array}$ & $\begin{array}{c}(5) \\
\text { Noncompliers }\end{array}$ \\
\hline \% com informação & 0,747 & 0,747 & $\begin{array}{l}-0,000 \\
(0,004)\end{array}$ & 0,733 & $\begin{array}{l}1 \\
0,749\end{array}$ \\
\hline Sexo feminino & 0,532 & 0,532 & $\begin{array}{l}-0,000 \\
(0,005)\end{array}$ & 0,616 & 0,521 \\
\hline Indígena & 0,003 & 0,003 & $\begin{array}{l}-0,000 \\
(0,001)\end{array}$ & 0,001 & 0,003 \\
\hline Cor branca & 0,380 & 0,387 & $\begin{array}{l}-0,006 \\
(0,005)\end{array}$ & 0,382 & 0,387 \\
\hline Cor negra & 0,115 & 0,113 & $\begin{array}{c}0,002 \\
(0,003)\end{array}$ & 0,136 & 0,110 \\
\hline Cor amarela & 0,006 & 0,004 & $\begin{array}{l}0,002^{* *} \\
(0,001)\end{array}$ & 0,005 & 0,004 \\
\hline Cor parda & 0,342 & 0,334 & $\begin{array}{l}0,008^{*} \\
(0,005)\end{array}$ & 0,378 & 0,329 \\
\hline Cor não identificada & 0,055 & 0,060 & $\begin{array}{l}-0,005^{* *} \\
(0,002)\end{array}$ & 0,047 & 0,062 \\
\hline Analfabeto & 0,001 & 0,001 & $\begin{array}{c}0,000 \\
(0,000)\end{array}$ & 0,001 & 0,001 \\
\hline Deficiente & 0,010 & 0,010 & $\begin{array}{l}-0,000 \\
(0,001)\end{array}$ & 0,014 & 0,010 \\
\hline Completou o ensino fundamental & 0,874 & 0,873 & $\begin{array}{c}0,001 \\
(0,003)\end{array}$ & 0,868 & 0,874 \\
\hline Completou o ensino médio & 0,655 & 0,646 & $\begin{array}{l}0,008^{*} \\
(0,005)\end{array}$ & 0,610 & 0,651 \\
\hline Completou ensino superior & 0,107 & 0,103 & $\begin{array}{c}0,004 \\
(0,003)\end{array}$ & 0,064 & 0,108 \\
\hline Idade & 36,913 & 36,950 & $\begin{array}{l}-0,036 \\
(0,106)\end{array}$ & 35,865 & 37,095 \\
\hline Salário formal em 2010 & 614,399 & 612,536 & $\begin{array}{c}1,862 \\
(7,492)\end{array}$ & 406,398 & 640,803 \\
\hline Empregado formalmente em 2010 & 0,575 & 0,574 & $\begin{array}{c}0,001 \\
(0,004)\end{array}$ & 0,526 & 0,580 \\
\hline Trabalha setor Serviços & 0,206 & 0,205 & $\begin{array}{c}0,001 \\
(0,003)\end{array}$ & 0,244 & 0,200 \\
\hline Trabalha setor Administrativo & 0,182 & 0,179 & $\begin{array}{c}0,003 \\
(0,003)\end{array}$ & 0,164 & 0,181 \\
\hline Trabalha na Indústria & 0,076 & 0,077 & $\begin{array}{l}-0,001 \\
(0,002)\end{array}$ & 0,051 & 0,081 \\
\hline $\begin{array}{l}\text { Estatística F } \\
\text { P-valor }\end{array}$ & & & $\begin{array}{c}1,27 \\
0.192\end{array}$ & & \\
\hline$N$ & 337038 & 14056 & 351094 & 1695 & 12361 \\
\hline
\end{tabular}

Notas: Essa tabela apresenta o balanceamento entre os grupos de tratamento e controle do Sorteio 009, terceiro sorteio realizado em 2011 para seleção dos beneficiários do MCMV no Rio de Janeiro. A unidade de análise é o indivíduo. A amostra inclui todos os indivíduos inscritos no Sorteio 009. Todas as informações apresentadas são da RAIS de 2006 a 2014. As informações de gênero, cor da pele, escolaridade, idade e deficiente são de cerca de $75 \%$ da amostra, cujas informações estavam presentes na RAIS. As informações de salário formal, emprego formal e setor do emprego são de toda a amostra. A primeira coluna apresenta as informações dos indivíduos não sorteados no sorteio do MCMV. A segunda coluna apresenta as informações dos indivíduos sorteados. A terceira coluna indica a diferença entre os grupos e o resultado de um teste t de diferença entre os dois grupos. A quarta coluna apresenta as informações dos indivíduos que foram sorteados e que se tornaram beneficiários do MCMV. A quinta coluna apresenta as informações daqueles que foram sorteados, mas não se tornaram beneficiários. A estatística $\mathrm{F}$ e o p-valor são de uma regressão onde a variável dependente é igual a um se o indivíduo foi sorteado no Sorteio 009 e 0 caso contrário e as variáveis explicativas são as características socioeconômicas da tabela. O erro padrão é clusterizado ao nível do indivíduo.

${ }^{*} p<0,10,{ }^{* *} p<0,05,{ }^{* * *} p<0,01$ 


\subsubsection{Características do domicílio dos beneficiários}

Nessa seção apresenta-se características do domicílio dos beneficiários do Minha Casa Minha Vida. Conforme dito anteriormente, todos os beneficiários do Minha Casa

Minha Vida precisam se cadastrar no Cadastro Único do governo federal. Por isso, o Cadastro Único contém informações completas sobre os indivíduos e o domicílio dos que se tornaram beneficiários do programa.

Infelizmente, nos sorteios realizados em 2011, apenas um quarto do total dos indivíduos que participaram dos sorteios estavam no Cadastro Único em 2012. Por isso, opta-se por apresentar apenas as informações dos domicílios dos beneficiários do programa, para os quais há informações completas em 2012.

Os indivíduos que aceitaram as vagas no programa habitavam em diferentes bairros do Rio de Janeiro antes da mudança para os empreendimentos do MCMV. Isso é mostrado na Figura 5.

O Rio de Janeiro é uma das cidades com a maior quantidade de favelas do país. Muitas dessas favelas estão próximas ao centro da cidade e de regiões nobres da Zona Sul. A pesquisa feita por Cardoso e Lago (2015) indica que muitos dos beneficiários do programa vieram de regiões de urbanização consolidada e áreas de favelas próximas ao centro da cidade.

Efetivamente, o mapa mostra que muitos outros vieram de localizações mais próximas ao centro da cidade. No entanto, muitos dos beneficiários habitavam próximo aos locais dos empreendimentos do MCMV.

As informações para os beneficiários antes da mudança são completas. Após a mudança, muitos dos beneficiários não atualizaram o Cadastro Único. Por isso, utiliza-se apenas as informações daqueles que atualizaram as informações do domicílio. A atualização do Cadastro Único é obrigatória apenas para os beneficiários do Programa Bolsa (PBF) Família. Ou seja, as informações do domicílio após a mudança são, em sua maioria, de famílias beneficiárias do PBF e não são diretamente comparáveis às informações de antes da participação no programa. Por isso, mostra-se apenas as informações que refletem o imóvel concedido pelo programa, que são parecidas entre todos as famílias que se mudaram no programa.

Na Tabela 5 pode-se ver que as moradias do Minha Casa Minha Vida têm condições melhores do que aquelas em que os beneficiários habitavam antes. Os domicílios no MCMV tem mais acesso a serviços públicos como coleta de lixo e iluminação da rede elétrica. Além disso, as moradias também têm condições melhores.

Os dados dessa tabela indicam uma possível melhora nas condições habitacionais daqueles indivíduos que participam do programa. Contudo, a ausência de dados comparáveis para os grupos de controle impede a afirmação de que o programa melhora as 
condições habitacionais dos indivíduos beneficiados. ${ }^{13}$

Tabela 5 - Características do domicílio dos beneficiários

\begin{tabular}{|c|c|c|}
\hline & $\begin{array}{c}(1) \\
\text { Antes }\end{array}$ & $\begin{array}{c}(2) \\
\text { Depois }\end{array}$ \\
\hline $\begin{array}{l}\text { Domicílio particular } \\
\text { permanente }(\%)\end{array}$ & $\begin{array}{c}0,97 \\
(0,156)\end{array}$ & $\begin{array}{c}0,99 \\
(0,0806)\end{array}$ \\
\hline $\begin{array}{l}\text { Qtde de cômodos no } \\
\text { domicílio }\end{array}$ & $\begin{array}{c}4,06 \\
(1,368)\end{array}$ & $\begin{array}{c}4,73 \\
(1,208)\end{array}$ \\
\hline Possui água canalizada (\%) & $\begin{array}{c}0,98 \\
(0,144)\end{array}$ & $\begin{array}{c}0,98 \\
(0,134)\end{array}$ \\
\hline $\begin{array}{l}\text { Abastecimento de água da } \\
\text { rede geral de distribuição }(\%)\end{array}$ & $\begin{array}{c}0,97 \\
(0,167)\end{array}$ & $\begin{array}{c}0,98 \\
(0,125)\end{array}$ \\
\hline $\begin{array}{l}\text { Qtde de famílias no } \\
\text { domicílio }(\%)\end{array}$ & $\begin{array}{c}1,03 \\
(0,335)\end{array}$ & $\begin{array}{c}1,01 \\
(0,0893)\end{array}$ \\
\hline Domicílio com piso de terra (\%) & $\begin{array}{c}0,13 \\
(0,339)\end{array}$ & $\begin{array}{c}0,01 \\
(0,0893)\end{array}$ \\
\hline $\begin{array}{l}\text { Domicílio com paredes } \\
\text { de alvenaria }(\%)\end{array}$ & $\begin{array}{c}0,92 \\
(0,278)\end{array}$ & $\begin{array}{c}0,99 \\
(0,104)\end{array}$ \\
\hline $\begin{array}{l}\text { Acesso a } \\
\text { rede de esgoto }(\%)\end{array}$ & $\begin{array}{c}0,97 \\
(0,169)\end{array}$ & $\begin{array}{c}0,98 \\
(0,149)\end{array}$ \\
\hline $\begin{array}{l}\text { Lixo coletado por empresa } \\
\text { de limpeza urbana }(\%)\end{array}$ & $\begin{array}{c}0,90 \\
(0,298)\end{array}$ & $\begin{array}{c}0,98 \\
(0,146)\end{array}$ \\
\hline $\begin{array}{l}\text { Iluminação elétrica com } \\
\text { medidor próprio }(\%)\end{array}$ & $\begin{array}{c}0,86 \\
(0,343)\end{array}$ & $\begin{array}{c}0,90 \\
(0,305)\end{array}$ \\
\hline $\begin{array}{l}\text { Calçamento no entorno } \\
\text { do domicílio }(\%)\end{array}$ & $\begin{array}{c}0,89 \\
(0,313)\end{array}$ & $\begin{array}{c}0,95 \\
(0,223)\end{array}$ \\
\hline$N$ & 3666 & 1378 \\
\hline
\end{tabular}

Notas: A unidade de análise é o domicílio. Desviopadrão entre parênteses. As informações na coluna (1) são dos domicílios dos beneficiários antes da mudança para o MCMV. Na coluna (2), as informações são de depois da mudança e incluem apenas aqueles domicílios que atualizaram o Cadastro Único após a mudança. As informações foram coletadas a partir do Cadastro Único. Mais informações podem ser encontradas no texto

13 Esse é o clássico problema da teoria econômica de avaliação de impacto. Na ausência de dados do grupo de controle é impossível estabelecer uma relação causal entre o programa e uma melhora habitacional. É possível, por exemplo, que os indivíduos do grupo de controle também tenham melhorado sua condição habitacional no mesmo período em que os indivíduos que participaram do programa. Para mais detalhes, ver (ANGRIST; PISCHKE, 2009). 


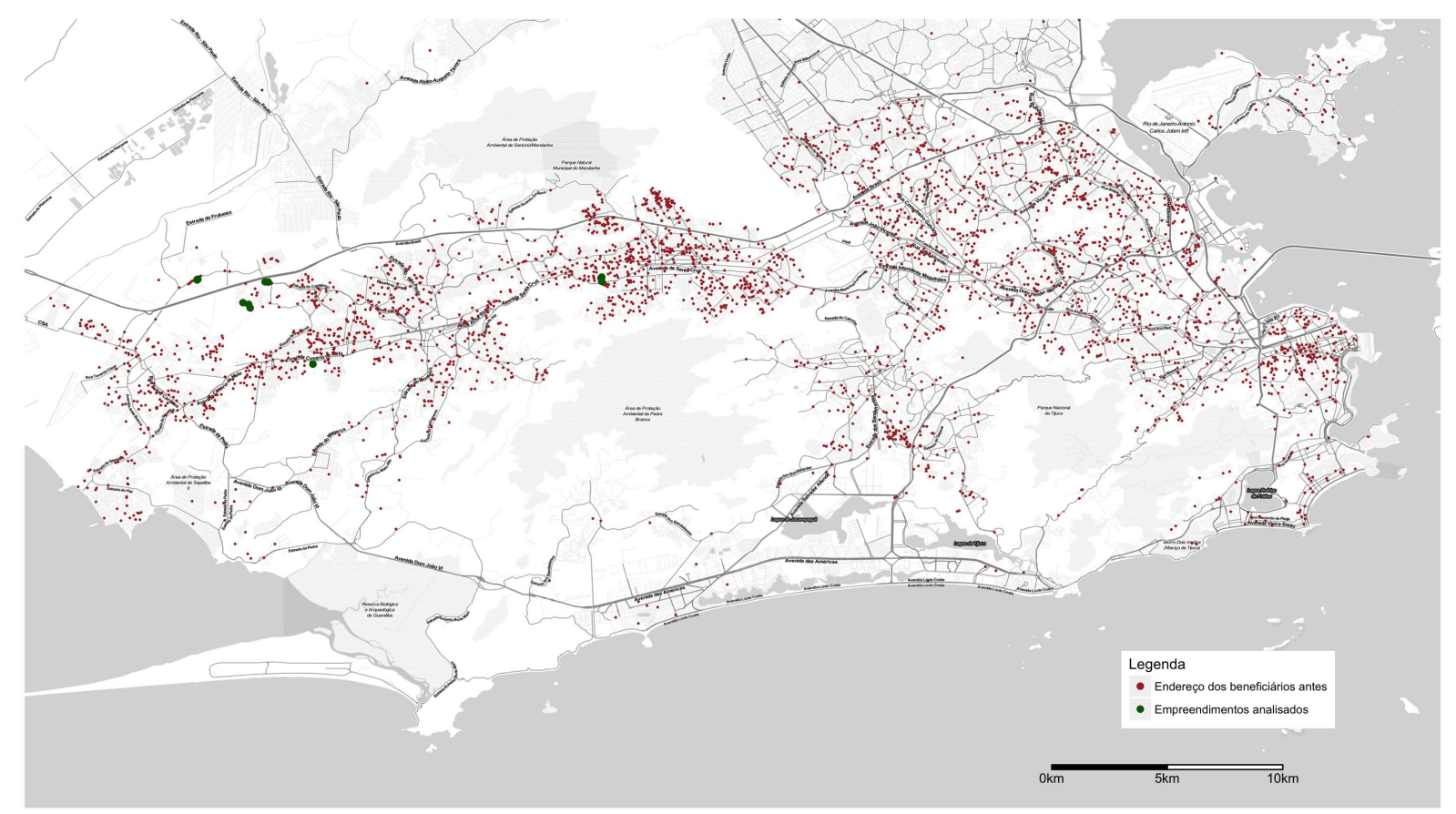

Figura 5 - Localização dos beneficiários antes e depois Dados do Cadastro Único. Elaboração própria.

\subsection{O Minha Casa Minha Vida em São José do Rio Preto}

São José do Rio Preto é uma cidade do interior de São Paulo e a $52^{\text {a }}$ cidade mais populosa do país com uma população de 450 mil pessoas. A cidade foi uma das que mais recebeu empreendimentos do Minha Casa Minha Vida em seu início. Atualmente, é a $17^{\mathrm{a}}$ cidade que mais possui beneficiários na Faixa I no país com cerca de 6556 moradias construídas na cidade.

Em 2013, a prefeitura de São José do Rio Preto selecionou aleatoriamente 2508 famílias para receberem as casas dos conjuntos residenciais chamados de Lealdade e Amizade. A forma principal para a seleção dos beneficiários foi a partir de um sorteio aberto ao público e amplamente divulgado, realizado em 16 de Outubro de $2013^{14}$.

O custo total dos dois conjuntos aos cofres públicos chegou a quase $\mathrm{R} \$ 170 \mathrm{mi}$ lhões ${ }^{15}$. Apesar de terem nomes diferentes, os dois conjuntos habitacionais são contíguos e têm as mesmas características. Cada uma das 2508 casas de $41 \mathrm{~m}^{2}$ foi avaliada em cerca de $\mathrm{R} \$ 68$ mil. Todas as casas têm acesso a saneamento básico, água potável e energia

\footnotetext{
$\overline{14}$ O restante das famílias não foi selecionada de forma aleatória, tendo sido escolhidas por suas características socioeconômicas.

15 Desse total, cerca de $\mathrm{R} \$ 120$ milhões foram desembolsados pelo governo federal e $\mathrm{R} \$ 50$ milhões pela prefeitura de Rio Preto (CUNHA, 2014).
} 
elétrica.

As casas foram entregues em Abril de 2014, data em que os beneficiários começaram a se mudar. Além disso, em 2015, cerca de um ano depois da mudança dos beneficiários, foram inauguradas uma unidade de saúde e uma escola no bairro (CUNHA, 2014).

A análise a seguir concentra-se nas 2356 famílias que foram sorteadas para participar do Minha Casa Minha Vida em São José do Rio Preto. Excluem-se as 152 famílias que foram sorteadas no cadastro de deficientes e idosos. Além disso, excluem-se também as famílias que se tornaram beneficiárias do programa, mas que não foram sorteadas no sorteio de 2013. Do total de 2356 famílias sorteadas, 1665 se tornaram beneficiárias do programa. Ou seja, uma taxa de compliance de cerca de $70 \%$.

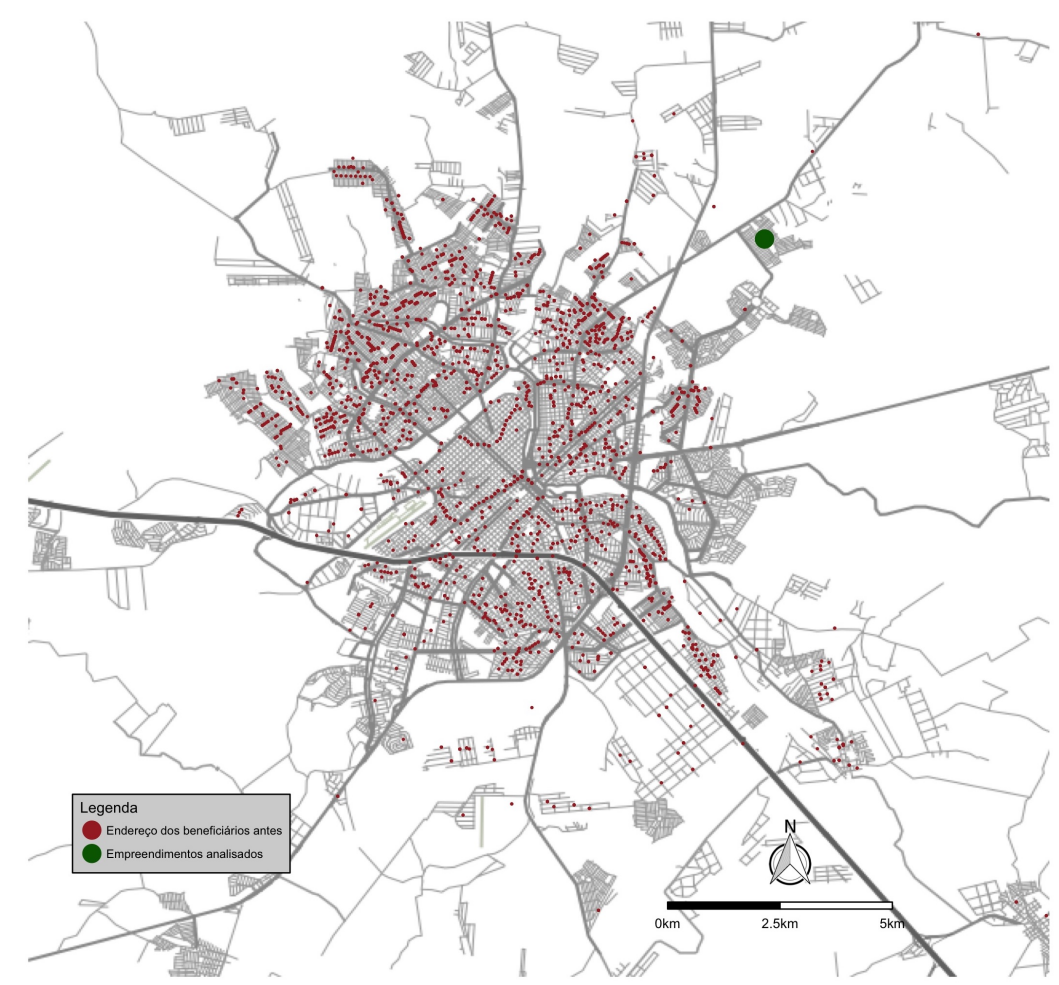

Figura 6 - Endereço dos beneficiários em São José do Rio Preto Dados do Cadastro Único. Elaboração própria. ${ }^{16}$

Da mesma forma que no Rio de Janeiro, os empreendimentos estão situados fora do centro da cidade, região que concentra os empregos formais, como mostram as Figuras 6 e 7.

\subsubsection{Características dos grupos de tratamento e controle}

As informações sobre os participantes do sorteio foram obtidas no site da Empresa Municipal de Construções Populares (Emcop) de São José do Rio Preto. A partir do CPF 


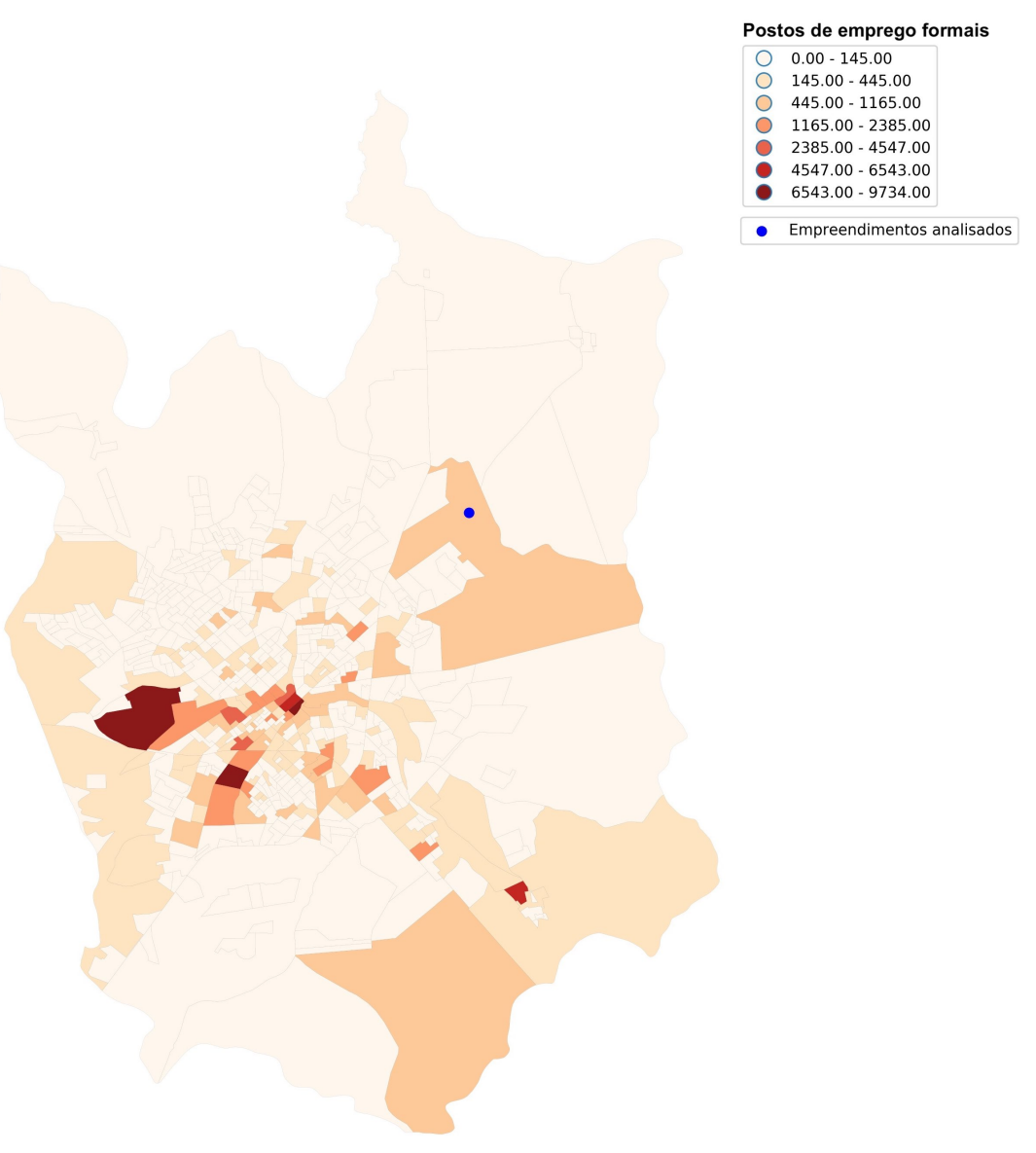

Figura 7 - Distribuição dos postos de emprego formais em São José do Rio Preto Dados da RAIS de 2013. Elaboração própria.

e nome dos indivíduos, buscou-se as informações nas bases sigilosas e identificadas do Cadastro Único e da RAIS.

Em São José do Rio Preto, a prefeitura cadastrou 99\% dos indivíduos que participaram do sorteio no Cadastro Único. Por isso, consegue-se obter informações sobre quase todas as famílias dos grupos de tratamento e controle, diferentemente do caso do Rio de Janeiro. Isso permite uma caracterização muito melhor das famílias e dá mais validade aos resultados. Também foi feita uma análise com o mesmo grupo de variáveis, provenientes da RAIS, construídas para o caso do Rio de Janeiro. Os resultados não se alteraram.

A Tabela 6 mostra que, também para o caso de Rio Preto, os grupos de tratamento e controle são balanceados. Apenas 3 variáveis apresentam diferenças significativas a $5 \%$. Além disso, a estatística $\mathrm{F}$ de uma regressão onde a variável dependente indica se o indivíduo foi sorteado e as variáveis explicativas são as características apresentadas nas tabelas é bastante baixa, indicando que não há diferenças significativas entre os sorteados e não sorteados. Os dados são do Cadastro Único de 2013, ano em que ocorreu o sorteio.

A maior parte da amostra é composta por mulheres de cor branca e quase $60 \%$ 
completaram o ensino médio. A idade média é de cerca de 36 anos, o que indica que a maior parte dos indivíduos está em idade apta ao trabalho. Além disso, cerca de $95 \%$ da amostra declarou ser o chefe da família.

Cerca de $49 \%$ dos indivíduos trabalhava com carteira assinada em 2012, segundo dados do Cadastro Único. Além disso, segundo os dados da RAIS, 59\% tiveram algum emprego no mercado formal nesse mesmo ano. Os indivíduos ganhavam cerca de 1 salário mínimo e a maioria dos que trabalhava formalmente, estava empregada no setor de serviços. Apenas uma minoria (16\%) era beneficiária do programa Bolsa Família na linha de base.

A população dos que efetivamente se tornaram beneficiários do programa (compliers) é composta por mais mulheres e mais indivíduos de cor negra ou parda e que tinham uma renda formal menor. Além disso, as famílias moravam mais próximas aos empreendimentos do programa.

Na Tabela 7, pode-se ver que as características dos domicílios das famílias também são balanceadas entre tratamento e controle. $\mathrm{O}$ valor gasto com aluguel é de cerca de $\mathrm{R} \$$ 198,00 para os dois grupos, o que corresponde a quase 40\% da renda total do domicílio. Além disso, a maior parte das famílias possuía acesso a saneamento básico e energia elétrica na linha de base.

Ambas as tabelas mostram que os grupos de tratamento e controles são balanceados, o que é uma consequência da aleatorização. Portanto, as estimações que serão apresentadas a seguir não devem ter grandes problemas com endogeneidade. 
Tabela 6 - Características dos indivíduos dos grupos de tratamento e controle

\begin{tabular}{|c|c|c|c|c|c|}
\hline & $\begin{array}{c}(1) \\
\text { Controle }\end{array}$ & $\begin{array}{c}(2) \\
\text { Sorteados }\end{array}$ & $\begin{array}{c}(3) \\
\text { Diferença }(1)-(2)\end{array}$ & $\begin{array}{c}(4) \\
\text { Compliers }\end{array}$ & $\begin{array}{c}(5) \\
\text { Noncompliers }\end{array}$ \\
\hline \% com informação no Cadastro Único & 0,983 & 0,991 & $\begin{array}{c}-0,008^{* * *} \\
(0,003)\end{array}$ & 0,991 & 0,991 \\
\hline Beneficiário Bolsa Família & 0,169 & 0,156 & $\begin{array}{c}0,013 \\
(0,009)\end{array}$ & 0,166 & 0,131 \\
\hline Sexo feminino & 0,729 & 0,707 & $\begin{array}{l}0,022^{* *} \\
(0,010)\end{array}$ & 0,738 & 0,633 \\
\hline Idade & 35,644 & 36,212 & $\begin{array}{r}-0,569^{* *} \\
(0,287)\end{array}$ & 36,047 & 36,603 \\
\hline Cor branca & 0,642 & 0,653 & $\begin{array}{l}-0,010 \\
(0,011)\end{array}$ & 0,645 & 0,671 \\
\hline Cor negra & 0,088 & 0,083 & $\begin{array}{c}0,005 \\
(0,007)\end{array}$ & 0,087 & 0,075 \\
\hline Cor amarela & 0,002 & 0,001 & $\begin{array}{c}0,001 \\
(0,001)\end{array}$ & 0,001 & 0,001 \\
\hline Cor parda & 0,264 & 0,258 & $\begin{array}{c}0,006 \\
(0,010)\end{array}$ & 0,264 & 0,243 \\
\hline Indígena & 0,001 & 0,001 & $\begin{array}{l}-0,001 \\
(0,001)\end{array}$ & 0,001 & 0,003 \\
\hline Frequenta escola & 0,028 & 0,028 & $\begin{array}{c}0,000 \\
(0,004)\end{array}$ & 0,029 & 0,026 \\
\hline Analfabeto & 0,027 & 0,025 & $\begin{array}{c}0,001 \\
(0,004)\end{array}$ & 0,024 & 0,029 \\
\hline Completou o ensino fundamental & 0,844 & 0,841 & $\begin{array}{c}0,004 \\
(0,008)\end{array}$ & 0,830 & 0,866 \\
\hline Completou o ensino médio & 0,588 & 0,585 & $\begin{array}{c}0,003 \\
(0,011)\end{array}$ & 0,578 & 0,601 \\
\hline Deficiente & 0,023 & 0,022 & $\begin{array}{c}0,001 \\
(0,003)\end{array}$ & 0,024 & 0,017 \\
\hline Possui emprego com carteira assinada & 0,497 & 0,487 & $\begin{array}{c}0,010 \\
(0,012)\end{array}$ & 0,480 & 0,502 \\
\hline Chefe da família & 0,947 & 0,947 & $\begin{array}{l}-0,000 \\
(0,005)\end{array}$ & 0,966 & 0,902 \\
\hline Salário no emprego (Cadúnico) & 686,301 & 689,604 & $\begin{array}{c}-3,302 \\
(11,679)\end{array}$ & 677,203 & 718,980 \\
\hline Trabalhou nos últimos 12 meses & 0,787 & 0,781 & $\begin{array}{c}0,006 \\
(0,009)\end{array}$ & 0,791 & 0,757 \\
\hline Qtde. meses trabalhada nos últimos 12 meses & 7,904 & 7,879 & $\begin{array}{c}0,026 \\
(0,120)\end{array}$ & 7,959 & 7,691 \\
\hline Renda bruta nos últimos 12 meses & 7110,527 & 7184,505 & $\begin{array}{c}-73,978 \\
(139,368)\end{array}$ & 7077,347 & 7437,367 \\
\hline Teve algum emprego formal em 2012 & 0,594 & 0,590 & $\begin{array}{c}0,004 \\
(0,011)\end{array}$ & 0,574 & 0,629 \\
\hline Trabalha na Indústria & 0,134 & 0,139 & $\begin{array}{l}-0,005 \\
(0,008)\end{array}$ & 0,127 & 0,168 \\
\hline Trabalha no setor Administrativo & 0,137 & 0,137 & $\begin{array}{l}-0,000 \\
(0,008)\end{array}$ & 0,146 & 0,114 \\
\hline Trabalha no setor de serviços & 0,252 & 0,246 & $\begin{array}{c}0,006 \\
(0,010)\end{array}$ & 0,242 & 0,255 \\
\hline Estatística F & & & 0,82 & & \\
\hline P-valor & & & 0,7123 & & \\
\hline$N$ & 9728 & 2356 & 12084 & 1655 & 701 \\
\hline
\end{tabular}

Notas: Dados do Cadastro Único e da RAIS. As informações socioeconômicas são referentes a $99 \%$ da amostra com informações no Cadastro Único. As informações de emprego formal são da RAIS. A primeira coluna apresenta as informações dos indivíduos não sorteados no sorteio do MCMV. A segunda coluna apresenta as informações dos indivíduos sorteados. A terceira coluna indica a diferença entre os grupos e o resultado de um teste t de diferença entre os dois grupos. A quarta coluna apresenta as informações dos indivíduos que foram sorteados e que se tornaram beneficiários do MCMV. A quinta coluna apresenta as informações daqueles que foram sorteados, mas não se tornaram beneficiários. A estatística $\mathrm{F}$ e o p-valor são de uma regressão onde a variável dependente indica se o indivíduo foi sorteado e as variáveis independentes são as informações apresentadas na tabela.

${ }^{*} p<0,10,{ }^{* *} p<0,05,{ }^{* * *} p<0,01$ 
Tabela 7 - Características dos domicílios dos grupos de tratamento e controle

\begin{tabular}{|c|c|c|c|c|c|}
\hline & $\begin{array}{c}(1) \\
\text { Controle }\end{array}$ & $\begin{array}{c}(2) \\
\text { Sorteados }\end{array}$ & $\begin{array}{c}(3) \\
\text { Diferença }(1)-(2)\end{array}$ & $\begin{array}{c}(4) \\
\text { Compliers }\end{array}$ & $\begin{array}{c}(5) \\
\text { Noncompliers }\end{array}$ \\
\hline Beneficiário do Bolsa Família & 0,169 & 0,155 & $\begin{array}{c}0,013 \\
(0,009)\end{array}$ & 0,166 & 0,129 \\
\hline $\begin{array}{l}\text { Distância entre o domicílio } \\
\text { e o empreendimento (em metros) }\end{array}$ & 9566,611 & 9232,167 & $\begin{array}{c}334,444 \\
(741,001)\end{array}$ & 8685,975 & 10524,57 \\
\hline $\begin{array}{l}\text { Distância entre o domicílio e o centro } \\
\text { (em metros) }\end{array}$ & 5304,870 & 5042,953 & $\begin{array}{c}261,917 \\
(746,805)\end{array}$ & 4513,620 & 6290,014 \\
\hline Qtde. pessoas no domicílio & 2,801 & 2,819 & $\begin{array}{l}-0,018 \\
(0,036)\end{array}$ & 2,767 & 2,941 \\
\hline Qtde. famílias no domicílio & 1,214 & 1,236 & $\begin{array}{l}-0,022 \\
(0,014)\end{array}$ & 1,256 & 1,188 \\
\hline Qtde. cômodos no domicílio & 4,488 & 4,494 & $\begin{array}{l}-0,006 \\
(0,029)\end{array}$ & 4,468 & 4,554 \\
\hline Possui água canalizada & 0,989 & 0,989 & $\begin{array}{l}-0,000 \\
(0,002)\end{array}$ & 0,987 & 0,993 \\
\hline Tem acesso a esgoto & 0,949 & 0,948 & $\begin{array}{c}0,002 \\
(0,005)\end{array}$ & 0,948 & 0,946 \\
\hline Tem acesso a coleta de lixo & 0,997 & 0,998 & $\begin{array}{l}-0,001 \\
(0,001)\end{array}$ & 0,999 & 0,997 \\
\hline Paredes de alvenaria & 0,998 & 0,997 & $\begin{array}{c}0,001 \\
(0,001)\end{array}$ & 0,998 & 0,996 \\
\hline Tem energia elétrica & 0,998 & 0,997 & $\begin{array}{c}0,001 \\
(0,001)\end{array}$ & 0,996 & 0,999 \\
\hline Calçamento no entorno do domicílio & 0,950 & 0,945 & $\begin{array}{c}0,004 \\
(0,005)\end{array}$ & 0,948 & 0,939 \\
\hline Piso de cimento & 0,158 & 0,162 & $\begin{array}{l}-0,005 \\
(0,008)\end{array}$ & 0,171 & 0,142 \\
\hline Piso de cerâmica & 0,816 & 0,811 & $\begin{array}{c}0,005 \\
(0,009)\end{array}$ & 0,806 & 0,822 \\
\hline Valor gasto com energia $(\mathrm{R} \$)$ & 65,615 & 64,653 & $\begin{array}{c}0,963 \\
(3,921)\end{array}$ & 62,849 & 68,908 \\
\hline Valor gasto com água $(\mathrm{R} \$)$ & 30,788 & 31,231 & $\begin{array}{l}-0,443 \\
(0,591)\end{array}$ & 30,820 & 32,202 \\
\hline Valor gasto com gás $(\mathrm{R} \$)$ & 21,280 & 20,996 & $\begin{array}{c}0,284 \\
(0,853)\end{array}$ & 20,257 & 22,739 \\
\hline Valor gasto com aluguel $(\mathrm{R} \$)$ & 198,953 & 198,686 & $\begin{array}{c}0,267 \\
(4,502)\end{array}$ & 188,628 & 222,478 \\
\hline Valor gasto com transporte $(\mathrm{R} \$)$ & 22,075 & 21,678 & $\begin{array}{c}0,397 \\
(1,147)\end{array}$ & 20,102 & 25,410 \\
\hline Renda do domicílio $(\mathrm{R} \$)$ & 512,183 & 526,205 & $\begin{array}{r}-14,022 \\
(8,546)\end{array}$ & 520,427 & 539,839 \\
\hline Valor gasto com alimentação $(\mathrm{R} \$)$ & 238,094 & 244,483 & $\begin{array}{c}-6,389^{* *} \\
(2,949)\end{array}$ & 234,585 & 267,844 \\
\hline$N$ & 9566 & 2335 & 11901 & 1640 & 695 \\
\hline
\end{tabular}

Notas: A unidade de análise é o domicílio do indivíduo que participou do sorteio do MCMV. Os dados são do Cadastro Único e representam cerca de $99 \%$ da amostra. A primeira coluna apresenta as informações do domicílio dos indivíduos não sorteados no sorteio do MCMV. A segunda coluna apresenta as informações dos indivíduos sorteados. A terceira coluna indica a diferença entre os grupos e o resultado de um teste $t$ de diferença entre os dois grupos. A quarta coluna apresenta as informações dos indivíduos que foram sorteados e que se tornaram beneficiários do MCMV. A quinta coluna apresenta as informações daqueles que foram sorteados, mas não se tornaram beneficiários. A distância entre o domicílio e o empreendimento é a distância em linha reta entre o endereço dos indivíduos antes do sorteio e os conjuntos residenciais do MCMV. A distância entre o domicílio e o centro é a distância entre o endereço dos indivíduos antes do sorteio e a prefeitura, que fica no centro de São José do Rio Preto. Todos os valores são em $\mathrm{R} \$$ de 2013.

${ }^{*} p<0,10,{ }^{* *} p<0,05,{ }^{* * *} p<0,01$ 


\subsection{Metodologia}

O problema de viés de seleção é o principal problema ao estimar relações causais de um tratamento (por exemplo, um programa governamental). Se não houver uma fonte de exogeneidade, qualquer estudo que compare beneficiários de algum programa com não beneficiários estará sujeito ao viés de seleção. No caso de programas assistenciais para os indivíduos mais pobres, esse viés é quase sempre negativo. Indivíduos que participam de programas sociais tendem a ter uma vulnerabilidade maior em termos de mercado de trabalho, renda e outros. Por isso, uma comparação simples entre as variáveis de indivíduos que participam e que não participam de um programa governamental é enviesada (ANGRIST; PISCHKE, 2009).

Aleatorizar a seleção para o programa resolve o problema de seleção. Nesse caso, os grupos de tratamento (sorteados) e controle (não sorteados) são comparáveis e qualquer variação, após o tratamento, nas variáveis de interesse pode ser atribuída ao programa em questão.

A análise do presente trabalho se beneficiará do fato de que a seleção para o Minha Casa Minha Vida Faixa I no Rio de Janeiro e em São José do Rio Preto foi feita por sorteio. Como a seleção para o programa foi aleatória, a simples comparação entre os indivíduos sorteados e não sorteados garante uma estimativa não enviesada do efeito de ter sido sorteado no $M C M V$, conhecido na literatura como efeito intent-to-treat.

A estimativa desse efeito consiste, basicamente, em calcular as diferenças entre as médias dos grupos de tratamento e controle. Dessa forma, estima-se equações do tipo:

$$
y_{i t}=\alpha_{t}+\beta^{I T T} z_{i t}+\mathbf{x}_{\mathbf{i t}}{ }^{\prime} \delta+\mu_{i t}
$$

Onde $y_{i t}$ indica as variáveis dependentes, que serão renda, emprego e participação no Bolsa Família, $z_{i t}$ é uma variável dummy que indica se o indivíduo foi sorteado e $\mathbf{x}_{\mathbf{i t}}$ são variáveis de controle.

Se a aleatorização foi bem feita, o parâmetro $\beta^{I T T}$ identifica o efeito de ter sido sorteado no Minha Casa Minha Vida e recebido uma oferta para participar do programa.

O fato de a oferta de uma vaga no programa ter sido aleatória garante que a estimação do parâmetro $\beta^{I T T}$ é não enviesada. Contudo, como nem todos os sorteados aceitaram a vaga no programa, a estimação do efeito ITT subestima o efeito de participar do MCMV.

Para contornar o problema de compliance, utiliza-se uma metodologia em dois estágios, onde o sorteio é usado como variável instrumental para a participação no programa. Se o sorteio foi realmente aleatório e se o sorteio não tem qualquer impacto sobre os que decidiram não participar do programa, podemos identificar o efeito do programa sobre os indivíduos beneficiados (ANGRIST; PISCHKE, 2009). 
Dessa forma, utiliza-se um modelo simples em dois estágios para medir o impacto do programa:

$$
y_{i t}=\lambda_{t}+\beta^{T O T} w_{i t}+\mathbf{x}_{\mathbf{i t}}{ }^{\prime} \gamma+\epsilon_{i t}
$$

Onde $y_{i t}$ e $\mathbf{x}_{\mathbf{i t}}$ são definidas como na equação (2.1) e $w_{i t}$ indica se o i-ésimo indivíduo participa do programa no período $t$.

A equação (2.2) é a equação de interesse. Como o compliance não é perfeito nos sorteios do MCMV, a participação no programa se torna endógena. Por isso, $w_{i t}$ é instrumentalizado pelo resultado do sorteio, $z_{i t}$.

Para o caso do emprego, utiliza-se uma variável dummy para indicar se o indivíduo teve algum vínculo de emprego formal no ano $t$. Além disso, estima-se, como robustez, o impacto sobre duas outras variáveis de emprego formal. Na primeira, a partir dos dados da RAIS, construiu-se um painel trimestral, de forma que a variável dependente indica se o indivíduo estava empregado em um dado trimestre. Na segunda, utiliza-se uma variável presente na RAIS, que indica se o indivíduo estava empregado no dia 31/12 de cada ano.

A participação no Bolsa Família é feita de forma análoga, a partir de dados do Cadastro Único que indicam se o indivíduo recebe Bolsa Família em um dado ano. Para o caso da renda, utiliza-se o salário médio do indivíduo no ano.

Inclui-se ainda efeitos fixos temporais para capturar os efeitos macroeconômicos. As variáveis de controle $\mathbf{x}_{\mathbf{i t}}$ são utilizadas para maior precisão das estimativas e incluem variáveis encontradas na RAIS e no Cadastro Único como gênero, escolaridade e idade. O conjunto de variáveis de controle é diferente para as duas cidades apresentadas a seguir. No Rio de Janeiro, utiliza-se variáveis de controle da RAIS. Em Rio Preto, são usadas variáveis de controle a partir do Cadastro Único.

Se o sorteio foi realmente aleatório e não teve qualquer impacto sobre os que decidiram não participar do programa, $\beta^{T O T}$ captura o efeito médio local do tratamento (LATE) sobre os compliers. Isto é, o efeito médio de participar do MCMV sobre aqueles indivíduos que efetivamente se mudam após terem sido sorteados e sobre aqueles que não se mudam porque não foram sorteados (i.e. respeitam o resultado do sorteio).

No entanto, em ambas as cidades analisadas, os indivíduos do grupo de controle que não foram sorteados não têm acesso ao programa. ${ }^{17}$ Isso significa que $\beta^{T O T}$ representa o efeito médio do programa MCMV sobre os tratados, conhecido na literatura como efeito treatment-on-the-treated (ANGRIST; PISCHKE, 2009). Estima-se esse parâmetro por two-stage least squares (2SLS).

17 Os indivíduos que aparecem como participantes do MCMV nos empreendimentos analisados e que não foram sorteados são excluídos da amostra em ambas as cidades. 
No próximo capítulo apresentam-se as estimações das equações (2.1) e (2.2) de forma separada para as cidades do Rio de Janeiro e São José do Rio Preto. 


\section{Resultados}

\subsection{Resultados para o Rio de Janeiro}

\subsubsection{Efeito do sorteio sobre a participação no Minha Casa Minha Vida}

Nesta seção, mostra-se que ter sido sorteado no MCMV no Rio de Janeiro aumenta a probabilidade de participar do programa e que a escolha de participar varia de acordo com características do indivíduo.

Para utilizar o sorteio como variável instrumental para a participação no Minha Casa Minha Vida, é necessário que a oferta de uma vaga no programa, que foi aleatória, aumente a probabilidade de participação. Isso é mostrado nas três primeiras linhas da Tabela 8, que indicam a proporção do compliance de cada sorteio. Em cada uma dessas colunas, a variável dependente é uma variável binária que indica se o indivíduo participa do MCMV após ter sido sorteado em cada um dos sorteios.

Como esperado, o fato de ter sido sorteado explica a participação no programa, o que é indicado pelo grau de significância dos parâmetros e o $\mathrm{R}^{2}$ em cada um dos sorteios. A amostra, nesse caso, é composta por todos os indivíduos que participaram do sorteio correspondente.

Existem algumas razões que podem explicar porque o sorteado não participa do programa. Analisando o compliance do primeiro e do segundo sorteio, parece haver uma preferência pelos empreendimentos localizados mais próximos ao centro e à linha de trem ${ }^{1}$. Além disso, o não enquadramento nas regras do programa também pode explicar a baixa taxa de compliance.

Para se ter uma ideia da diferença entre o grupo dos compliers e dos noncompliers, as informações das linhas seguintes da Tabela 8 exploram a heterogeneidade da participação no programa entre os indivíduos sorteados. A variável dependente em cada uma das colunas é uma variável binária que indica se o indivíduo aceitou a vaga no Minha Casa Minha Vida após ter sido sorteado. As variáveis explicativas são as variáveis apresentadas em cada uma das linhas. As amostras incluem apenas os indivíduos sorteados.

As estimações diferem pouco entre os três sorteios. Mulheres, indivíduos de cor negra ou parda, com menor renda e menor idade e que trabalhavam no setor de serviços têm maior probabilidade de aceitar a participação no programa, uma vez que tenham

1 Especificamente, os empreendimentos Destri e Rio Bonito, localizados mais próximos à linha de trem, tiveram mais de $85 \%$ das vagas preenchidas no primeiro sorteio. Os empreendimentos Park Imperial e Park Royal, mais afastados, tiveram apenas $16 \%$. 
sido sorteados. Adicionalmente, indivíduos que completaram o ensino médio têm menor probabilidade se aceitar a vaga no programa, uma vez que tenham sido sorteados.

\subsubsection{Impactos do programa sobre os indivíduos}

Nesta seção, apresenta-se as estimativas do efeito do programa Minha Casa Minha Vida sobre a taxa de emprego formal, o salário formal e a participação no Bolsa Família para as amostras dos três sorteios ocorridos em 2011 no Rio de Janeiro.

A Tabela 9 apresenta o impacto do programa sobre uma série de variáveis para as amostras principais nos anos de 2012 a 2016 (pós sorteio). A tabela mostra os resultados intent-to-treat (ITT) e de Variável Instrumental, onde a participação no programa é instrumentalizada pelo sorteio. A unidade de observação é o indivíduo em cada ano. Cada um dos painéis A, B e C apresenta as estimações para o grupo dos indivíduos que participaram dos Sorteios 003, 006 e 009, respectivamente. Além disso, a primeira coluna indica a média de cada uma das variáveis dependentes para os grupos de controle.

São apresentados resultados com e sem as variáveis de controle, obtidas da RAIS. Os resultados com variáveis de controle são de cerca de $75 \%$ da amostra total e correspondem aos indivíduos que tiveram algum vínculo de trabalho no mercado formal entre 2006 e 2014 e que, portanto, tinham informações na RAIS.

São incluídas como variáveis de controle o gênero, escolaridade, idade e cor do indivíduo. Além disso, são incluídas informações dos indivíduos no mercado de trabalho formal em 2010 (no ano anterior aos sorteios), como: participação no mercado de trabalho formal, salário formal e setor do último emprego formal que o indivíduo teve em 2010 (Serviços, Administrativo e Indústria). Além disso, são incluídos efeitos fixos temporais. Todos os resultados têm cluster ao nível do indivíduo (JACOB; LUDWIG, 2012).

A variável dependente na primeira linha de cada painel é uma dummy que indica se o indivíduo teve algum emprego formal naquele ano.

Os resultados mostram que a participação no MCMV reduz a probabilidade de estar empregado formalmente nos anos subsequentes ao sorteio. Contudo, apenas no Sorteio 006 o impacto é significante a $5 \%$. As pessoas que foram sorteadas e se mudaram para os empreendimentos do Minha Casa Minha Vida nesse sorteio tiveram uma probabilidade 4,9\% menor de estarem empregadas nos anos subsequentes.

Uma das explicações possíveis para o resultado significante em apenas um sorteio é que os conjuntos residenciais do Sorteio 006 estão mais distantes do transporte público e em áreas de urbanização menos consolidada do que os conjuntos do Sorteio 003. Outra explicação é o fato de que a quantidade de sorteados no Sorteio 006 é duas vezes maior do que a quantidade no Sorteio 003. Além disso, o número de inscritos também é maior. 
Tabela 8 - Efeitos do sorteio e de outras características sobre a participação no programa

\begin{tabular}{|c|c|c|c|}
\hline & \multicolumn{3}{|c|}{ Participa do MCMV } \\
\hline & Sorteio 003 & Sorteio 006 & Sorteio 009 \\
\hline \multicolumn{4}{|l|}{ Grupos de tratamento e controle } \\
\hline Foi sorteado no Sorteio 003 & $\begin{array}{c}0,306^{* * *} \\
(0,000848)\end{array}$ & & \\
\hline Foi sorteado no Sorteio 006 & & $\begin{array}{c}0,208^{* * *} \\
(0,000719)\end{array}$ & \\
\hline Foi sorteado no Sorteio 009 & & & $\begin{array}{c}0,121^{* * *} \\
(0,000561)\end{array}$ \\
\hline$N$ & 297867 & 325080 & 351094 \\
\hline$R^{2}$ & 0,304 & 0,205 & 0,116 \\
\hline $\mathrm{F}$ & 129856,3 & 83584,5 & 46216,0 \\
\hline \multicolumn{4}{|l|}{ Apenas grupos de tratamento } \\
\hline Sexo feminino & $\begin{array}{l}0,103^{* * *} \\
(0,0201)\end{array}$ & $\begin{array}{c}0,0817^{* * *} \\
(0,0119)\end{array}$ & $\begin{array}{l}0,0313^{* * *} \\
(0,00656)\end{array}$ \\
\hline Idade & $\begin{array}{c}-0,00167^{*} \\
(0,000930)\end{array}$ & $\begin{array}{c}-0,00239^{* * *} \\
(0,000560)\end{array}$ & $\begin{array}{c}-0,00110^{\text {*** }} \\
(0,000312)\end{array}$ \\
\hline Cor negra & $\begin{array}{l}0,0683^{* *} \\
(0,0309)\end{array}$ & $\begin{array}{c}0,0578^{* * *} \\
(0,0186)\end{array}$ & $\begin{array}{c}0,0293^{* * *} \\
(0,0103)\end{array}$ \\
\hline Cor parda & $\begin{array}{c}0,0596^{* * *} \\
(0,0208)\end{array}$ & $\begin{array}{c}0,0134 \\
(0,0124)\end{array}$ & $\begin{array}{l}0,0198^{* * *} \\
(0,00693)\end{array}$ \\
\hline Completou o ensino fundamental & $\begin{array}{c}0,0197 \\
(0,0322)\end{array}$ & $\begin{array}{c}0,0345^{*} \\
(0,0203)\end{array}$ & $\begin{array}{c}0,0106 \\
(0,0111)\end{array}$ \\
\hline Completou o ensino médio & $\begin{array}{l}-0,0417^{*} \\
(0,0251)\end{array}$ & $\begin{array}{c}-0,0479^{* * *} \\
(0,0149)\end{array}$ & $\begin{array}{l}-0,0134^{*} \\
(0,00812)\end{array}$ \\
\hline Completou o ensino superior & $\begin{array}{l}-0,0541 \\
(0,0350)\end{array}$ & $\begin{array}{l}-0,0296 \\
(0,0198)\end{array}$ & $\begin{array}{l}-0,0209^{*} \\
(0,0112)\end{array}$ \\
\hline Salário formal em 2010 & $\begin{array}{c}-0,0000837^{* * *} \\
(0,0000143)\end{array}$ & $\begin{array}{c}-0,0000424^{* * *} \\
(0,00000657)\end{array}$ & $\begin{array}{c}-0,0000294^{\text {***}} \\
(0,00000422)\end{array}$ \\
\hline Empregado formalmente em 2010 & $\begin{array}{c}0,0117 \\
(0,0391)\end{array}$ & $\begin{array}{l}-0,0268 \\
(0,0212)\end{array}$ & $\begin{array}{l}-0,0176 \\
(0,0121)\end{array}$ \\
\hline Trabalha no setor de serviços & $\begin{array}{c}0,0908^{* * *} \\
(0,0343)\end{array}$ & $\begin{array}{c}0,0752^{* * *} \\
(0,0193)\end{array}$ & $\begin{array}{c}0,0472^{* * *} \\
(0,0107)\end{array}$ \\
\hline Trabalha no setor administrativo & $\begin{array}{c}0,0407 \\
(0,0337)\end{array}$ & $\begin{array}{l}0,00677 \\
(0,0188)\end{array}$ & $\begin{array}{c}0,0167 \\
(0,0105)\end{array}$ \\
\hline Trabalha na Indústria & $\begin{array}{c}0,0231 \\
(0,0422)\end{array}$ & $\begin{array}{c}0,0763^{* * *} \\
(0,0242)\end{array}$ & $\begin{array}{c}0,0000535 \\
(0,0133)\end{array}$ \\
\hline$N$ & 2192 & 4882 & 10501 \\
\hline$R^{2}$ & 0,061 & 0,042 & 0,020 \\
\hline $\mathrm{F}$ & 11,89 & 17,79 & 18,00 \\
\hline
\end{tabular}

Notas: Cada uma das colunas indica um sorteio diferente. As primeiras três linhas incluem todos os participantes em cada sorteio e a variável dependente indica a participação no programa MCMV. Cada linha apresenta os resultados de uma regressão onde a váriavel independente indica se o indivíduo foi sorteado naquele sorteio. As linhas seguintes incluem apenas os indivíduos que foram sorteados. A variável dependente também indica a participação no MCMV. As informações são da RAIS de 2006 a 2014, conforme descrito no texto.

Erros padrão clusterizados por indivíduo entre parênteses

${ }^{*} p<0,10,{ }^{* *} p<0,05,{ }^{* * *} p<0,01$ 
Isso reduz o erro padrão nas estimações e ajuda a dar significância às estimativas. ${ }^{2}$

Na Figura 8 pode-se observar o impacto do MCMV ao longo do tempo em cada sorteio. Para o Sorteio 006, o gráfico mostra que o efeito se torna mais negativo ao longo do tempo, passando a ter significância estatística a $5 \%$ a partir do terceiro ano após o sorteio. Quatro anos após o sorteio, a estimativa do efeito treatment-on-the-treated é de $10 \%$ de redução na taxa de emprego. Para o Sorteio 003, esse efeito é significante a 5\% apenas no último ano em nossa amostra, cinco anos após o sorteio.

Essa tendência do efeito parece indicar um impacto de médio longo prazo e não apenas de curto prazo. Um efeito de curto prazo poderia significar uma fase de transição para a nova moradia. Uma vez que se adaptassem ao novo ambiente, o efeito tenderia a se dissipar, como ocorreu em alguns estudos nos EUA (WOOD; TURNHAM; MILLS, 2008). Isso não parece ser o caso aqui, onde o efeito, para todos os sorteios, parece aumentar ao longo do tempo.

Adicionalmente, na Tabela 9, estima-se o efeito sobre o emprego formal de duas outras formas. Na primeira forma, transformou-se a RAIS em um painel trimestral. Nesse caso, a variável dependente é uma dummy que indica se o indivíduo estava empregado em cada um dos trimestres entre os anos de 2012 a 2016. As estimativas se mantém parecidas, com a única estimativa significante a $5 \%$ sendo a do Sorteio 006,

$\mathrm{Na}$ segunda forma, utilizou-se outra variável presente na RAIS, que indica se o indivíduo estava empregado formalmente no último dia de cada ano (31/12). Nesse caso, a variável dependente é igual a um se o indivíduo termina o ano empregado e zero caso contrário. Nas estimações o impacto negativo se mantém, contudo ele é mais significante nos Sorteios 003 e 006. Nesse último, a estimativa é significante a $1 \%$.

A menor taxa de emprego entre os beneficiários pode ser o resultado de dois processos diferentes. Por um lado, os beneficiários podem ter encontrado uma dificuldade maior de encontrar emprego ou de permanecer no mercado de trabalho. Por outro, pode ter havido uma migração do mercado de trabalho formal para o informal. Contudo, ambos os processos representam uma deterioração das condições de trabalho.

Esses resultados são robustos a modelos não lineares, conforme demonstra-se na Tabela 25 do apêndice. Além disso, também são feitas estimações com variáveis de controle obtidas a partir dos anos de 2006 a 2010 da RAIS, isto é, apenas com os anos antes dos sorteios. Na Tabela 24 pode-se ver que o sinal e a magnitude dos coeficientes estimados são similares.

Por fim, são feitas estimações excluindo os indivíduos sorteados em outros sorteios

2 O Sorteio 009, por outro lado, teve uma taxa de compliance de apenas $12 \%$. Isso significa que o impacto sobre a taxa de emprego deveria ser muito grande para que pudesse afetar a taxa de emprego do grupo inteiro dos sorteados e, assim, causar uma diferença significativa entre as taxas de emprego do grupo de sorteados e não sorteados. 
de cada uma das amostras dos sorteios 003, 006 e 009. Isto é, na amostra do Sorteio 003, exclui-se os indivíduos sorteados nos Sorteios 006 e 009 e assim sucessivamente. Essas estimativas são apresentadas na Tabela 20. Não há qualquer alteração nos resultados. 
Tabela 9 - Impactos do programa - Rio de Janeiro

\begin{tabular}{|c|c|c|c|c|c|}
\hline & $\begin{array}{l}\text { Média do grupo } \\
\text { de controle }\end{array}$ & $\begin{array}{c}(1) \\
\text { ITT sem controles }\end{array}$ & $\begin{array}{c}(2) \\
\text { ITT com controles }\end{array}$ & $\begin{array}{c}(3) \\
\text { VI sem controles } \\
\end{array}$ & $\begin{array}{c}(4) \\
\text { VI com controles } \\
\end{array}$ \\
\hline $\begin{array}{l}\text { Painel A: Sorteio } \mathbf{0 0 3} \\
\text { Empregado formalmente } \\
\text { (anual) }\end{array}$ & 0,539 & $\begin{array}{l}-0,013 \\
(0,008)\end{array}$ & $\begin{array}{l}-0,012^{*} \\
(0,007)\end{array}$ & $\begin{array}{l}-0,042 \\
(0,027)\end{array}$ & $\begin{array}{l}-0,040^{*} \\
(0,023)\end{array}$ \\
\hline $\begin{array}{l}\text { Empregado formalmente } \\
\text { (trimestral) }\end{array}$ & 0,479 & $\begin{array}{l}-0,013 \\
(0,008)\end{array}$ & $\begin{array}{l}-0,012^{*} \\
(0,007)\end{array}$ & $\begin{array}{l}-0,041 \\
(0,025)\end{array}$ & $\begin{array}{l}-0,040^{*} \\
(0,023)\end{array}$ \\
\hline Empregado em 31/12 & 0,441 & $\begin{array}{l}-0,014^{*} \\
(0,008)\end{array}$ & $\begin{array}{l}-0,014^{*} \\
(0,007)\end{array}$ & $\begin{array}{l}-0,046^{*} \\
(0,025)\end{array}$ & $\begin{array}{l}-0,048^{*} \\
(0,025)\end{array}$ \\
\hline $\begin{array}{l}\text { Salário formal } \\
\text { (anual) }\end{array}$ & 923,3 & $\begin{array}{l}-33,620 \\
(21,873)\end{array}$ & $\begin{array}{l}-33,260^{*} \\
(19,027)\end{array}$ & $\begin{array}{l}-109,965 \\
(71,103)\end{array}$ & $\begin{array}{c}-112,340^{*} \\
(64,060)\end{array}$ \\
\hline Participação no Bolsa Família & 0,114 & $\begin{array}{c}0,020^{* * *} \\
(0,005)\end{array}$ & $\begin{array}{c}0,021^{* * *} \\
(0,005)\end{array}$ & $\begin{array}{c}0,065^{* * *} \\
(0,017)\end{array}$ & $\begin{array}{c}0,070^{* * *} \\
(0,018)\end{array}$ \\
\hline Número de indivíduos & 297867 & 297867 & 220411 & 297867 & 220411 \\
\hline $\begin{array}{l}\text { Painel B: Sorteio } 006 \\
\text { Empregado formalmente } \\
\text { (anual) }\end{array}$ & 0,549 & $\begin{array}{l}-0,008 \\
(0,006)\end{array}$ & $\begin{array}{c}-0,010^{* *} \\
(0,005)\end{array}$ & $\begin{array}{l}-0,037 \\
(0,026)\end{array}$ & $\begin{array}{c}-0,049^{* *} \\
(0,023)\end{array}$ \\
\hline $\begin{array}{l}\text { Empregado formalmente } \\
\text { (trimestral) }\end{array}$ & 0,490 & $\begin{array}{l}-0,010^{*} \\
(0,005)\end{array}$ & $\begin{array}{r}-0,012^{* *} \\
(0,005)\end{array}$ & $\begin{array}{l}-0,048^{*} \\
(0,025)\end{array}$ & $\begin{array}{c}-0,059^{* *} \\
(0,023)\end{array}$ \\
\hline Empregado em 31/12 & 0,452 & $\begin{array}{c}-0,011^{* *} \\
(0,005)\end{array}$ & $\begin{array}{c}-0,014^{* *} \\
(0,005)\end{array}$ & $\begin{array}{c}-0,054^{* *} \\
(0,025)\end{array}$ & $\begin{array}{r}-0,067^{* *} \\
(0,024)\end{array}$ \\
\hline $\begin{array}{l}\text { Salário formal } \\
\text { (anual) }\end{array}$ & 987,2 & $\begin{array}{c}-8,758 \\
(16,715)\end{array}$ & $\begin{array}{c}-9,697 \\
(14,992)\end{array}$ & $\begin{array}{l}-42,140 \\
(80,293)\end{array}$ & $\begin{array}{l}-47,771 \\
(73,785)\end{array}$ \\
\hline Participação no Bolsa Família & 0,0996 & $\begin{array}{l}0,007^{* *} \\
(0,003)\end{array}$ & $\begin{array}{l}0,007^{* *} \\
(0,003)\end{array}$ & $\begin{array}{l}0,033^{* *} \\
(0,015)\end{array}$ & $\begin{array}{l}0,037^{* *} \\
(0,016)\end{array}$ \\
\hline Número de indivíduos & 325080 & 325080 & 242791 & 325080 & 242791 \\
\hline $\begin{array}{l}\text { Painel C: Sorteio } 009 \\
\text { Empregado formalmente } \\
\text { (anual) }\end{array}$ & 0,548 & $\begin{array}{l}-0,005 \\
(0,004)\end{array}$ & $\begin{array}{l}-0,005 \\
(0,003)\end{array}$ & $\begin{array}{l}-0,040 \\
(0,032)\end{array}$ & $\begin{array}{l}-0,040 \\
(0,027)\end{array}$ \\
\hline $\begin{array}{l}\text { Empregado formalmente } \\
\text { (trimestral) }\end{array}$ & 0,489 & $\begin{array}{l}-0,004 \\
(0,004)\end{array}$ & $\begin{array}{c}-0,004 \\
(0,003)\end{array}$ & $\begin{array}{l}-0,034 \\
(0,030)\end{array}$ & $\begin{array}{l}-0,033 \\
(0,027)\end{array}$ \\
\hline Empregado em 31/12 & 0,451 & $\begin{array}{l}-0,002 \\
(0,004)\end{array}$ & $\begin{array}{l}-0,002 \\
(0,003)\end{array}$ & $\begin{array}{l}-0,020 \\
(0,030)\end{array}$ & $\begin{array}{l}-0,014 \\
(0,029)\end{array}$ \\
\hline $\begin{array}{l}\text { Salário formal } \\
\text { (anual) }\end{array}$ & 977,5 & $\begin{array}{c}-8,663 \\
(10,721)\end{array}$ & $\begin{array}{l}-6,148 \\
(9,771)\end{array}$ & $\begin{array}{l}-71,838 \\
(88,767)\end{array}$ & $\begin{array}{l}-51,980 \\
(82,553)\end{array}$ \\
\hline Participação no Bolsa Família & 0,109 & $\begin{array}{l}-0,003 \\
(0,002)\end{array}$ & $\begin{array}{l}-0,002 \\
(0,002)\end{array}$ & $\begin{array}{l}-0,022 \\
(0,019)\end{array}$ & $\begin{array}{l}-0,015 \\
(0,019)\end{array}$ \\
\hline Número de indivíduos & 351094 & 351094 & 262218 & 351094 & 262218 \\
\hline Efeito fixo temporal & & Sim & Sim & Sim & Sim \\
\hline
\end{tabular}

Notas: Cada um dos painéis representa uma amostra separada, composta apenas por aqueles indivíduos que participaram do respectivo sorteio. As colunas (1) e (2) indicam os efeitos intent-to-treat do Minha Casa Minha Vida sobre as variáveis dependentes em cada uma das linhas. Os resultados são de regressões de MQO onde cada variável dependente é regredida contra uma variável binária que indica se o indivíduo foi sorteado naquele sorteio. As colunas (3) e (4) são os resultados de uma regressão em dois estágios, onde a participação no programa é instrumentalizada pelo sorteio. As estimativas representam os efeitos treatment-on-thetreated, conforme descrito no texto. As colunas (1) e (3) apresentam os resultados para toda a amostra sem quaisquer variáveis de controle. As colunas (2) e (4) apresentam os resultados com variáveis de controle para cerca de $75 \%$ da amostra, que corresponde àqueles indivíduos que tiveram algum vínculo formal entre os anos de 2006 e 2014. Para esses indivíduos foi possível criar variáveis de controle, que são apresentadas nas tabelas de balanceamento. A variável empregado formalmente (anual) é uma dummy que indica se o indivíduo teve algum emprego formal em um dado ano. A variável empregado formalmente (trimestral) também é uma dummy que indica se o indivíduo estava empregado em cada trimestre. A variável empregado em 31/12 é uma variável da RAIS que indica se o indivíduo estava empregado em 31/12 de cada ano. A variável salário formal indica o salário médio do indivíduo em cada ano. Todas essas regressões são para os anos de 2012 a 2016, posteriores ao sorteio. A variável de participação no Bolsa Família é uma dummy que indica se o indivíduo recebe Bolsa Família em cada um dos anos entre 2012 e 2017. A primeira coluna apresenta as médias de cada variável dependente para o grupo de controle.

Todos os erros padrão apresentados têm cluster ao nível do indivíduo.

${ }^{*} p<0,10,{ }^{* *} p<0,05,{ }^{* * *} p<0,01$ 

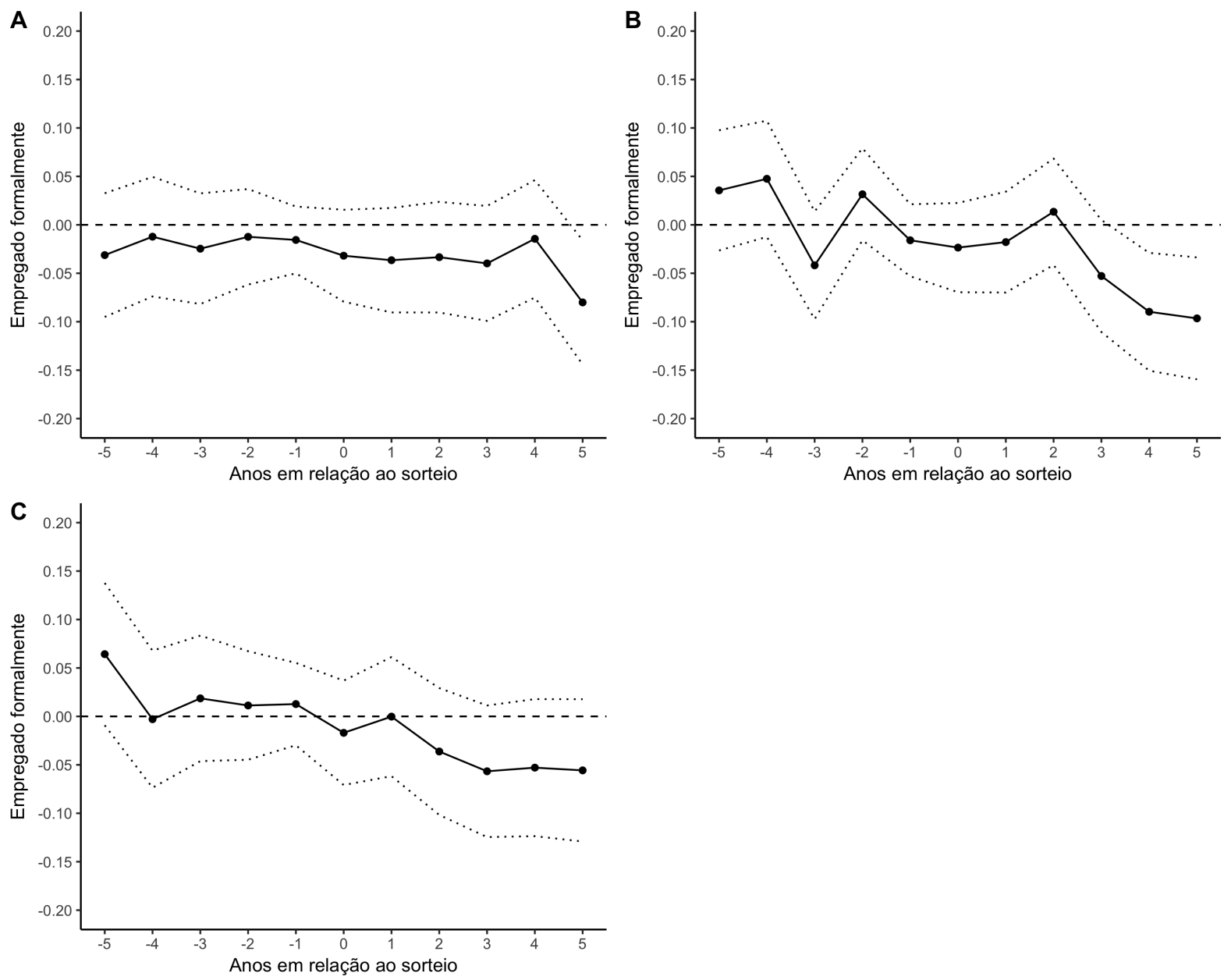

Figura 8 - Efeito do programa sobre a probabilidade de emprego ao longo do tempo para cada sorteio.

Notas: Os gráficos A, B e C correspondem aos sorteios 003, 006 e 009, respectivamente. As linhas representam as estimativas de variável instrumental com variáveis de controle em cada ano, conforme descrito no texto. As linhas tracejadas representam o intervalo de confiança de $95 \%$. O ano zero é o ano dos sorteios (2011). Os dados são da RAIS de 2006 a 2016.

A estimação do efeito do programa sobre a renda enfrenta dificuldades maiores, dada a natureza da base de dados utilizada. A partir da RAIS, podem ser obtidos apenas os valores das rendas dos indivíduos que trabalhavam no mercado formal no período analisado, excluindo-se assim as informações de renda daqueles que trabalham no mercado informal e que são parte significante da amostra. ${ }^{3}$

Por isso, calcula-se apenas o efeito do programa sobre o salário no mercado formal, mostrado na segunda linha de cada painel da Tabela 9. Isto é, para aqueles indivíduos que não tiveram vínculo formal em um dado ano, imputa-se o valor zero para o salário.

3 Conforme mencionado anteriormente, $75 \%$ dos indivíduos da amostra passaram pelo mercado de trabalho formal em algum momento entre 2006 e 2014. Isso significa que pelo menos um quarto dos indivíduos possuem outras fontes de renda fora do mercado formal. Esse número deve ser ainda maior se considerarmos que alguns indivíduos podem alternar entre mercado formal e informal durante o período analisado. 
Ainda que imperfeita, a estimativa parece indicar que não houve efeito sobre a renda para aqueles beneficiados pelo programa. Apenas a estimativa para o Sorteio 003 é significante a $10 \%$ e negativa com as variáveis de controle incluídas.

O Bolsa Família é o principal programa de transferência direta de renda no Brasil. Atualmente, o programa beneficia cerca de 14 milhões de pessoas em situação de pobreza e extrema pobreza em todo o país.

São elegíveis as famílias que têm renda mensal de até $\mathrm{R} \$ 85$ por pessoa ou famílias que têm renda entre $R \$ 85$ e $R \$ 170$ por pessoa e que têm gestantes ou crianças de até 17 anos em sua composição. A participação no Bolsa Família é, portanto, um indicador importante para verificar a situação econômica das famílias.

A terceira linha de cada painel da Tabela 9 apresenta os resultados de impacto do Minha Casa Minha Vida sobre a participação no Bolsa Família. Os dados são para os anos de 2012 a 2017. A variável dependente é uma variável binária que indica a participação no programa Bolsa Família em um dado ano.

Os resultados indicam que a participação no Bolsa Família aumentou de forma significativa tanto no Sorteio 003, quanto no Sorteio 006. No primeiro, esse aumento foi de $7 \%$. No segundo, o aumento foi de $3,7 \%$.

No entanto, um resultado positivo ou negativo não significa necessariamente uma mudança na situação econômica das famílias da amostra. Para participar do Minha Casa Minha Vida ou do Bolsa Família as famílias devem se cadastrar no Cadastro Único. Portanto, é possível que o fato de ter sido sorteado no MCMV e ter feito o Cadastro Único tenha facilitado a participação no Bolsa Família. Isso significaria que o aumento da participação no Bolsa Família não pode ser explicado pelo fato de o indivíduo ter se mudado para um empreendimento do MCMV, mas sim por ter diminuído o custo de cadastro no Cadastro Único.

Infelizmente, os dados obtidos do Cadastro Único cobrem apenas o período entre 2012 e 2017. Ou seja, não é possível verificar se os grupos de tratamento e controle tinham taxas de participação semelhantes no Bolsa Família antes do ano em que aconteceram os sorteios. $^{4}$

Na Tabela 10 explora-se o efeito do programa sobre a taxa de emprego formal e a participação no Bolsa Família para alguns subgrupos em cada um dos sorteios. Para simplificar a apresentação, mostra-se apenas o efeito intent-to-treat para as variáveis de emprego formal (anual) e participação no Bolsa Família. A Tabela mostra aqueles grupos em que o efeito do programa foi maior ou menor.

4 No entanto, na próxima seção, mostra-se que no caso de São José do Rio Preto, onde os dados do Cadastro Único são completos e anteriores a realização do sorteio, a participação no Bolsa Família também aumenta de forma significativa e a taxa de emprego formal cai. 
Para o emprego formal, a tabela mostra alguns padrões interessantes. Apesar de o resultado para a amostra principal não ser significante a 5\% para os Sorteios 003 e 009, a análise por subgrupos revela que alguns grupos tiveram um efeito negativo maior e mais significante. Por exemplo, no Sorteio 003, indivíduos de cor parda tiveram um efeito negativo maior e mais significante do que o efeito para a amostra principal. No Sorteio 009, aqueles que trabalhavam no setor de serviços ou haviam completado o ensino médio também tiveram um efeito negativo maior e mais significante do que o da amostra principal.

No Sorteio 006, onde o efeito foi mais significante para a amostra principal, o efeito negativo é mais significante para aqueles indivíduos com escolaridade maior (ensino fundamental ou médio completos) e sobre aqueles que trabalharam formalmente no ano anterior ao sorteio.

Para a participação no Bolsa Família, a tabela mostra que o efeito da amostra principal é similar para quase todos os subgrupos analisados. 
Tabela 10 - Impactos do programa por subgrupo - Rio de Janeiro

\begin{tabular}{|c|c|c|c|c|c|c|}
\hline & \multicolumn{3}{|c|}{$\begin{array}{c}\text { Empregado formalmente } \\
\text { ITT }\end{array}$} & \multicolumn{3}{|c|}{$\begin{array}{c}\text { Participação no Bolsa Família } \\
\text { ITT }\end{array}$} \\
\hline & Sorteio 003 & Sorteio 006 & Sorteio 009 & Sorteio 003 & Sorteio 006 & Sorteio 009 \\
\hline \multirow[t]{2}{*}{ Amostra principal (Tabela 9) } & $-0,012^{*}$ & $-0,010^{* *}$ & $-0,005$ & $0,021^{* * *}$ & $0,007 * *$ & $-0,002$ \\
\hline & $(0,007)$ & $(0,005)$ & $(0,003)$ & $(0,017)$ & $(0,015)$ & $(0,019)$ \\
\hline \multirow[t]{2}{*}{ Sexo feminino } & $-0,00917$ & $-0,0120^{*}$ & $-0,00784^{*}$ & $0,0214^{* *}$ & 0,00349 & $-0,00532$ \\
\hline & $(0,0100)$ & $(0,00672)$ & $(0,00461)$ & $(0,00874)$ & $(0,00556)$ & $(0,00381)$ \\
\hline \multirow[t]{2}{*}{ Sexo masculino } & $-0,0138$ & $-0,00596$ & $-0,00157$ & $0,0192^{* * *}$ & $0,0135^{* * *}$ & 0,00298 \\
\hline & $(0,00953)$ & $(0,00644)$ & $(0,00445)$ & $(0,00580)$ & $(0,00358)$ & $(0,00221)$ \\
\hline \multirow[t]{2}{*}{ Idoso } & $-0,0453$ & 0,0449 & 0,00832 & $-0,00445^{* * *}$ & $-0,00373^{* * *}$ & 0,00641 \\
\hline & $(0,0545)$ & $(0,0371)$ & $(0,0345)$ & $(0,00156)$ & $(0,00104)$ & $(0,00827)$ \\
\hline \multirow[t]{2}{*}{ Não idoso } & $-0,0106$ & $-0,0101^{* *}$ & $-0,00544^{*}$ & $0,0205^{* * *}$ & $0,00816^{* *}$ & $-0,00143$ \\
\hline & $(0,00705)$ & $(0,00474)$ & $(0,00326)$ & $(0,00562)$ & $(0,00349)$ & $(0,00236)$ \\
\hline \multirow[t]{2}{*}{ Cor branca } & 0,00378 & $-0,00983$ & $-0,00805$ & $0,0156^{*}$ & 0,00459 & 0,00255 \\
\hline & $(0,0115)$ & $(0,00797)$ & $(0,00537)$ & $(0,00870)$ & $(0,00539)$ & $(0,00376)$ \\
\hline \multirow[t]{2}{*}{ Cor negra ou parda } & $-0,0222^{* *}$ & $-0,0105$ & $-0,000608$ & $0,0296 * * *$ & $0,0113^{* *}$ & $-0,00587$ \\
\hline & $(0,0103)$ & $(0,00693)$ & $(0,00487)$ & $(0,00892)$ & $(0,00565)$ & $(0,00383)$ \\
\hline \multirow[t]{2}{*}{ Cor negra } & 0,0150 & $-0,0105$ & 0,000530 & 0,000493 & $-0,00275$ & $-0,0130^{*}$ \\
\hline & $(0,0189)$ & $(0,0140)$ & $(0,00943)$ & $(0,0175)$ & $(0,0111)$ & $(0,00771)$ \\
\hline \multirow[t]{2}{*}{ Cor parda } & $-0,0341^{* * *}$ & $-0,0105$ & $-0,000858$ & $0,0392^{* * *}$ & $0,0160^{* *}$ & $-0,00347$ \\
\hline & $(0,0122)$ & $(0,00796)$ & $(0,00568)$ & $(0,0103)$ & $(0,00655)$ & $(0,00442)$ \\
\hline \multirow[t]{2}{*}{ Analfabeto } & $-0,237 * * *$ & $0,110^{*}$ & $-0,135$ & $-0,258^{* * *}$ & 0,0227 & 0,0757 \\
\hline & $(0,0483)$ & $(0,0604)$ & $(0,142)$ & $(0,0457)$ & $(0,0792)$ & $(0,135)$ \\
\hline \multirow[t]{2}{*}{ Ensino fundamental completo } & $-0,00610$ & $-0,0111^{* *}$ & $-0,00656^{*}$ & $0,0218^{* * *}$ & $0,00906^{* *}$ & $-0,000352$ \\
\hline & $(0,00746)$ & $(0,00497)$ & $(0,00342)$ & $(0,00589)$ & $(0,00362)$ & $(0,00244)$ \\
\hline \multirow[t]{2}{*}{ Ensino médio completo } & $-0,00597$ & $-0,0117^{* *}$ & $-0,00959^{* *}$ & $0,0157^{* *}$ & $0,0114^{* * *}$ & 0,00138 \\
\hline & $(0,00847)$ & $(0,00558)$ & $(0,00383)$ & $(0,00622)$ & $(0,00388)$ & $(0,00264)$ \\
\hline \multirow[t]{2}{*}{ Ensino superior completo } & $-0,0174$ & $-0,0117$ & $-0,000519$ & $0,0290^{* *}$ & $-0,000323$ & 0,00268 \\
\hline & $(0,0184)$ & $(0,0124)$ & $(0,00796)$ & $(0,0120)$ & $(0,00445)$ & $(0,00356)$ \\
\hline \multirow[t]{2}{*}{ Deficiente } & $-0,00506$ & $-0,0503$ & 0,0222 & $-0,0235$ & $-0,0105$ & 0,0173 \\
\hline & $(0,0703)$ & $(0,0469)$ & $(0,0282)$ & $(0,0308)$ & $(0,0258)$ & $(0,0223)$ \\
\hline \multirow[t]{2}{*}{ Não deficiente } & $-0,0112$ & $-0,00910^{*}$ & $-0,00550^{*}$ & $0,0204^{* * *}$ & $0,00827 * *$ & $-0,00154$ \\
\hline & $(0,00704)$ & $(0,00473)$ & $(0,00327)$ & $(0,00561)$ & $(0,00348)$ & $(0,00236)$ \\
\hline \multirow[t]{2}{*}{ Empregado formalmente em 2010} & $-0,0126^{*}$ & $-0,0120^{* *}$ & $-0,00647^{*}$ & $0,0198 * * *$ & $0,00819^{* *}$ & $-0,00122$ \\
\hline & $(0,00758)$ & $(0,00511)$ & $(0,00351)$ & $(0,00574)$ & $(0,00346)$ & $(0,00229)$ \\
\hline \multirow[t]{2}{*}{ Não empregado (formalmente) em 2010} & $-0,00290$ & $-0,00230$ & $-0,00184$ & 0,0201 & 0,00824 & $-0,00266$ \\
\hline & $(0,0166)$ & $(0,0111)$ & $(0,00780)$ & $(0,0145)$ & $(0,00936)$ & $(0,00667)$ \\
\hline \multirow[t]{2}{*}{ Trabalha na Indústria } & $-0,000244$ & $-0,000431$ & $-0,00393$ & 0,0114 & 0,00135 & 0,00708 \\
\hline & $(0,0207)$ & $(0,0141)$ & $(0,00978)$ & $(0,0156)$ & $(0,00859)$ & $(0,00632)$ \\
\hline \multirow[t]{2}{*}{ Trabalha no setor Administrativo } & $-0,0268^{* *}$ & $-0,0207^{* *}$ & $-0,00765$ & $0,0215^{* *}$ & $0,0157^{* *}$ & $-0,00579$ \\
\hline & $(0,0136)$ & $(0,00913)$ & $(0,00622)$ & $(0,00939)$ & $(0,00612)$ & $(0,00374)$ \\
\hline \multirow[t]{2}{*}{ Trabalha no setor de serviços } & $-0,00341$ & $-0,00620$ & $-0,0134^{* *}$ & $0,0257^{* *}$ & 0,00631 & 0,00185 \\
\hline & $(0,0126)$ & $(0,00878)$ & $(0,00614)$ & $(0,0108)$ & $(0,00678)$ & $(0,00462)$ \\
\hline
\end{tabular}

Notas: As colunas apresentam resultados intent-to-treat do efeito do programa MCMV sobre as variáveis de emprego formal (anual) e participação no Bolsa Família em cada sorteio. Cada uma das linhas é de uma regressão diferente, onde a amostra é restrita àquele subgrupo. O resultado de cada linha é o coeficiente de uma variável dummy que indica se o indivíduo foi sorteado no respectivo sorteio. Todos os resultados são para as amostras com variáveis de controle, o que corresponde a cerca de $75 \%$ do total da amostra em cada sorteio.

Todos os erros-padrão são clusterizados ao nível do indivíduo.

${ }^{*} p<0,10,{ }^{* *} p<0,05,{ }^{* * *} p<0,01$ 


\subsection{Resultados para São José do Rio Preto}

\subsubsection{Efeito do sorteio sobre a participação no Minha Casa Minha Vida}

Mostra-se nessa seção que, da mesma forma que no Rio de Janeiro, o sorteio aumenta a probabilidade de participação no programa em S. José do Rio Preto.

Na Tabela 11 pode-se observar que $70 \%$ dos indivíduos sorteados se tornaram beneficiários do programa. Isso significa que utilizar o sorteio como variável instrumental nas estimações é possível.

Essa taxa de compliance é muito mais alta do que as taxas encontradas no Rio de Janeiro. É muito provável que essa diferença seja explicada pela forma que foram conduzidas as inscrições no programa. Em São José do Rio Preto, a inscrição teve várias etapas. Ao longo de 2012 os interessados se inscreveram para participar do programa. Em seguida, a prefeitura verificou o enquadramento dessas famílias nas regras do programa. ${ }^{5}$ Apenas os que se enquadraram nas regras puderam participar do sorteio, realizado em 2013. Portanto, o processo de seleção foi bastante diferente do Rio de Janeiro, onde a lista de inscritos provinha de um cadastro habitacional antigo.

Na coluna (2), explora-se a heterogeneidade para a participação no programa entre os indivíduos sorteados. A variável dependente é uma dummy que indica se o indivíduo se mudou para a casa do MCMV. As estimações mostram que mulheres e chefes de família tinham uma chance maior de participarem do programa. Indivíduos com ensino fundamental completo e com maiores salários tinham uma probabilidade menor de aceitarem a vaga, uma vez que tenham sido sorteados. Além disso, indivíduos que moravam mais perto do local dos conjuntos residenciais também tinham uma chance maior de se mudarem para as casas do programa.

$\overline{5}$ Ver < http://www.riopreto.sp.gov.br/PortalGOV/do/noticias?op=viewForm\&coConteudo=110928 $>$. 
Tabela 11 - Efeitos do sorteio e de outras características do indivíduo sobre a participação no programa - Rio Preto

\begin{tabular}{lcc}
\hline \hline & $(1)$ & $(2)$ \\
& Todos os indivíduos & Grupo Tratamento \\
\hline Foi sorteado & $0,703^{* * *}$ & \\
Beneficiário do Bolsa Família & $(0,00270)$ & 0,000238 \\
& & $(0,0265)$ \\
Empregado formalmente em 2012 & $-0,0132$ \\
Sexo feminino & $(0,0443)$ \\
Idade & $0,0780^{* * *}$ \\
Cor negra & $(0,0224)$ \\
Cor parda & $-0,00179^{*}$ \\
Completou o ensino fundamental & $(0,000918)$ \\
Completou o ensino médio & 0,0311 \\
& $(0,0331)$ \\
Deficiente & 0,0230 \\
Distância do domicílio ao empreendimento $(\mathrm{km})$ & $(0,0218)$ \\
& $-0,0714^{* *}$ \\
Valor gasto com aluguel & $(0,0320)$ \\
Salário formal em 2012 & 0,000919 \\
Trabalha na indústria & $(0,0237)$ \\
Trabalha no setor administrativo & 0,0538 \\
Trabalha no setor de serviços & $(0,0584)$ \\
\hline F & $-0,00000165^{* *}$ \\
\hline \hline
\end{tabular}

Notas: A primeira coluna apresenta o resultado de uma regressão onde a variável dependente indica a participação no programa e a variável independente indica se o indivíduo foi sorteado. Ela representa a taxa de compliance dos indivíduos sorteados. A segunda coluna apresenta os resultados de uma regressão apenas com os indivíduos sorteados. A variável dependente indica a participação no programa MCMV e as variáveis independentes indicam características socioeconômicas dos indivíduos sorteados.

Erro-padrão com cluster de indivíduo entre parênteses ${ }^{*} p<0,10,{ }^{* *} p<0,05,{ }^{* * *} p<0,01$

\subsubsection{Impactos do programa sobre os indivíduos}

A Tabela 12 mostra os resultados principais para a amostra de São José do Rio Preto. A tabela mostra as estimações para o efeito ITT e o de Variável Instrumental, conforme definidos na seção de Metodologia. Apresenta-se o impacto do programa sobre três variáveis principais: emprego formal, salário formal e participação no programa Bolsa Família.

A primeira linha indica o efeito do programa sobre a taxa de emprego formal. Nesse caso, classifica-se o indivíduo como empregado (formalmente) se ele teve algum vínculo formal naquele ano.

Observa-se um impacto negativo na taxa de emprego formal. Os indivíduos sorteados no programa tiveram sua taxa de emprego formal reduzida entre $2,3 \%$ e $2,5 \%$. 
Considerando a taxa de compliance de $70 \%$, isso significa que aqueles que aceitaram a vaga no programa e se mudaram para os conjuntos residenciais do Minha Casa Minha Vida tiveram a sua taxa de emprego formal reduzida entre 3,3\% e 3,6\% nos três anos subsequentes a mudança.

É interessante notar que ambas as amostras do Rio de Janeiro e de São José do Rio Preto mostraram um impacto negativo do programa e de magnitude similar. No entanto, o efeito é mais significativo no caso da cidade do interior de São Paulo. Isso possivelmente é um reflexo da taxa de compliance, que é significantemente maior no caso de Rio Preto.

Além disso, estima-se, como robustez, o impacto sobre duas outras variáveis de emprego formal. Na primeira, transformou-se a RAIS em um painel trimestral, de forma que a variável dependente indica se o indivíduo estava empregado em um dado trimestre entre os anos de 2014 a 2016. Na segunda, utiliza-se uma variável presente na RAIS, que indica se o indivíduo estava empregado no dia 31/12 de cada ano. As estimações para essas variáveis têm magnitude e significância similares.

Na segunda linha, observa-se o efeito sobre o salário formal. Nesse caso, calculou-se o salário médio dos indivíduos que tiveram vínculo formal em um dado ano. Da mesma forma que no caso do Rio de Janeiro, não há efeito sobre o salário formal.

Na terceira linha, apresenta-se o impacto do programa sobre a participação no Bolsa Família. O efeito estimado é positivo, indicando que participar do Minha Casa Minha Vida aumenta também a participação no Bolsa Família em até $4 \%$.

Os dados do Cadastro Único para a amostra de São José do Rio Preto antecedem a realização do sorteio, diferentemente da amostra do Rio de Janeiro ${ }^{6}$. Além disso, cerca de $99 \%$ da amostra de Rio Preto estava no Cadastro Único em 2013. Isso sugere que o aumento de beneficiários do Bolsa Família é, de fato, um impacto do Minha Casa Minha Vida e não um efeito da inserção no Cadastro Único, conforme foi sugerido para o caso do Rio de Janeiro.

Na Tabela 13 é explorada a heterogeneidade do efeito sobre diferentes grupos. Apresenta-se apenas os efeitos intent-to-treat para facilitar a exposição. Pode-se ver que o efeito sobre o emprego formal é negativo e significante para grande parte dos subgrupos. Indivíduos que tiveram e que não tiveram emprego formal no ano anterior ao sorteio tiveram um impacto negativo e de magnitude similar. Da mesma forma, indivíduos de cor branca e não branca (negros e pardos) também tiveram impacto negativo e significante.

É interessante notar que o efeito sobre a taxa de emprego formal é muito maior entre aqueles que eram beneficiários do programa Bolsa Família na linha de base. Além disso, o efeito é maior também entre aqueles indivíduos que ganhavam menos do que um

6 Os dados sigilosos do Cadastro Único obtidos são de 2012 a 2017. O sorteio em Rio Preto foi realizado em Outubro de 2013. No Rio de Janeiro, os sorteios foram realizados no segundo semestre de 2011. 
salário mínimo.

As mulheres tiveram um efeito maior e mais significante para a taxa de emprego formal e participação no Bolsa Família do que os homens. Entre as mulheres, houve uma redução na taxa de emprego formal de $2,8 \%$ nos anos subsequentes ao sorteio. Para os homens, essa redução foi de cerca de 1\%, mas a estimativa não foi estatisticamente significante.

Além disso, nas últimas duas linhas, incluiu-se a distância do domicílio na linha de base aos empreendimentos Lealdade e Amizade. As estimações mostram que o efeito é mais significativo para os indivíduos que moravam a mais de $10 \mathrm{~km}$ dos empreendimentos do Minha Casa Minha Vida.

O impacto sobre a participação no Bolsa Família é positivo e de magnitude similar entre os subgrupos analisados.

Por fim, na Figura 9 pode-se ver a tendência do impacto ao longo dos anos. No caso do emprego formal, o impacto é negativo e significante logo no primeiro ano após o sorteio, ano em que os indivíduos efetivamente se mudaram para os conjuntos residenciais. Três anos após o sorteio, o impacto deixa de ser significante a 5\%. Como as bases da RAIS para 2017 e 2018 ainda não estão disponíveis, é difícil dizer se o efeito negativo é de médio-longo prazo, como parece ser o caso no Rio de Janeiro. Ou se o efeito é de curto prazo, tendo um impacto sobre a taxa de emprego apenas nos dois primeiros anos após a mudança.

Para a participação no Bolsa Família, o impacto positivo aparece a partir do segundo ano após o sorteio e permanece até o último ano em que os dados estavam disponíveis. ${ }^{7}$

7 Essa data coincide com a data de atualização obrigatória do Cadastro Único. A cada dois anos, os indivíduos cadastrados no Cadastro Único devem atualizar os seus dados para permanecerem no cadastro. Isso é obrigatório, sobretudo, para os beneficiários do programa Bolsa Família. Os agentes do governo, que cuidam do programa, procuram as famílias para a atualização. No caso da amostra de Rio Preto, cerca de 69\% das famílias permaneceram no Cadastro Único até 2016. 
Tabela 12 - Impactos do programa sobre os indivíduos - Rio Preto

\begin{tabular}{|c|c|c|c|c|c|}
\hline & $\begin{array}{l}\text { Média do } \\
\text { grupo de controle }\end{array}$ & $\begin{array}{c}(1) \\
\text { ITT } \\
\text { sem controles }\end{array}$ & $\begin{array}{c}(2) \\
\text { ITT } \\
\text { com controles }\end{array}$ & $\begin{array}{c}(3) \\
\text { VI } \\
\text { sem controles }\end{array}$ & $\begin{array}{c}(4) \\
\text { VI } \\
\text { com controles }\end{array}$ \\
\hline $\begin{array}{l}\text { Empregado formalmente } \\
\text { (anual) }\end{array}$ & 0,556 & $\begin{array}{c}-0,025^{* *} \\
(0,010)\end{array}$ & $\begin{array}{c}-0,023^{* * *} \\
(0,008)\end{array}$ & $\begin{array}{c}-0,036^{* *} \\
(0,015)\end{array}$ & $\begin{array}{c}-0,033^{* * *} \\
(0,011)\end{array}$ \\
\hline $\begin{array}{l}\text { Empregado formalmente } \\
\text { (trimestral) }\end{array}$ & 0,473 & $\begin{array}{c}-0,025^{* *} \\
(0,010)\end{array}$ & $\begin{array}{c}-0,024^{* * *} \\
(0,007)\end{array}$ & $\begin{array}{c}-0,035^{* * *} \\
(0,014)\end{array}$ & $\begin{array}{c}-0,034^{* * *} \\
(0,010)\end{array}$ \\
\hline $\begin{array}{l}\text { Empregado formalmente } \\
\text { em } 31 / 12\end{array}$ & 0,419 & $\begin{array}{c}-0,021^{* *} \\
(0,010)\end{array}$ & $\begin{array}{c}-0,021^{* * *} \\
(0,008)\end{array}$ & $\begin{array}{c}-0,030^{* *} \\
(0,014)\end{array}$ & $\begin{array}{c}-0,030^{* * *} \\
(0,011)\end{array}$ \\
\hline $\begin{array}{l}\text { Salário no mercado } \\
\text { formal }\end{array}$ & 783,9 & $\begin{array}{l}-19,069 \\
(18,216)\end{array}$ & $\begin{array}{l}-21,199 \\
(14,046)\end{array}$ & $\begin{array}{l}-27,146 \\
(25,882)\end{array}$ & $\begin{array}{l}-30,105 \\
(19,901)\end{array}$ \\
\hline $\begin{array}{l}\text { Recebe } \\
\text { Bolsa Família }\end{array}$ & 0,131 & $\begin{array}{c}0,020^{* * *} \\
(0,007)\end{array}$ & $\begin{array}{c}0,028^{* * *} \\
(0,005)\end{array}$ & $\begin{array}{c}0,029^{* * *} \\
(0,010)\end{array}$ & $\begin{array}{c}0,040^{* * *} \\
(0,007)\end{array}$ \\
\hline Efeito fixo temporal & & Sim & Sim & Sim & Sim \\
\hline Número de indivíduos & 12084 & 12084 & 11843 & 12084 & 11843 \\
\hline
\end{tabular}

Notas: As colunas (1) e (2) indicam os efeitos intent-to-treat do Minha Casa Minha Vida sobre as variáveis dependentes em cada uma das linhas. Os resultados são de regressões de MQO onde cada variável dependente é regredida contra uma variável binária que indica se o indivíduo foi sorteado naquele sorteio. As colunas (3) e (4) são os resultados de uma regressão em dois estágios, onde a participação no programa é instrumentalizada pelo sorteio. As estimativas representam os efeitos treatment-on-the-treated, conforme descrito no texto. As colunas (1) e (3) apresentam os resultados para toda a amostra sem quaisquer variáveis de controle. As colunas (2) e (4) apresentam os resultados com variáveis de controle para cerca de $99 \%$, que corresponde àqueles indivíduos com informação no Cadastro Único. As variáveis de controle são aquelas apresentadas na tabela de balanceamento. A variável empregado formalmente (anual) é uma dummy que indica se o indivíduo teve algum emprego formal em um dado ano. A variável empregado formalmente (trimestral) também é uma dummy que indica se o indivíduo estava empregado em cada trimestre. A variável empregado em 31/12 é uma variável da RAIS que indica se o indivíduo estava empregado em 31/12 de cada ano. A variável salário formal indica o salário médio do indivíduo em cada ano. Todas essas regressões são para os anos de 2014 a 2016, posteriores ao sorteio. A variável de participação no Bolsa Família é uma dummy que indica se o indivíduo recebe Bolsa Família em cada um dos anos entre 2014 e 2016. A primeira coluna apresenta as médias de cada variável dependente para o grupo de controle.

Todos os erros padrão apresentados têm cluster ao nível do indivíduo.

${ }^{*} p<0,10,{ }^{* *} p<0,05,{ }^{* * *} p<0,01$ 
Tabela 13 - Impactos do programa por subgrupo - Rio Preto

\begin{tabular}{|c|c|c|}
\hline & $\begin{array}{l}\text { Empregado formalmente } \\
\text { ITT }\end{array}$ & $\begin{array}{c}\text { Participação no Bolsa Família } \\
\text { ITT }\end{array}$ \\
\hline Amostra principal (Tabela 12) & $\begin{array}{c}-0,023^{* * *} \\
(0,008)\end{array}$ & $\begin{array}{c}0,028^{* * *} \\
(0,005)\end{array}$ \\
\hline Beneficiário Bolsa Família em 2013 & $\begin{array}{c}-0,0808^{* * *} \\
(0,0206)\end{array}$ & $\begin{array}{l}0,0387^{* *} \\
(0,0199)\end{array}$ \\
\hline Não beneficiário Bolsa Família em 2013 & $\begin{array}{c}-0,0127 \\
(0,00818)\end{array}$ & $\begin{array}{l}0,0259^{* * *} \\
(0,00479)\end{array}$ \\
\hline Sexo masculino & $\begin{array}{l}-0,0108 \\
(0,0135)\end{array}$ & $\begin{array}{c}0,00837 \\
(0,00685)\end{array}$ \\
\hline Sexo feminino & $\begin{array}{r}-0,0281^{* * *} \\
(0,00920)\end{array}$ & $\begin{array}{l}0,0344^{* * *} \\
(0,00674)\end{array}$ \\
\hline Idosos & $\begin{array}{c}0,0209 \\
(0,0129)\end{array}$ & $\begin{array}{l}-0,00354 \\
(0,00252)\end{array}$ \\
\hline Não idosos & $\begin{array}{r}-0,0245^{* * *} \\
(0,00789)\end{array}$ & $\begin{array}{l}0,0286^{* * *} \\
(0,00544)\end{array}$ \\
\hline Cor branca & $\begin{array}{l}-0,0189^{* *} \\
(0,00939)\end{array}$ & $\begin{array}{l}0,0215^{* * *} \\
(0,00608)\end{array}$ \\
\hline Cor negra ou parda & $\begin{array}{c}-0,0294^{* *} \\
(0,0131)\end{array}$ & $\begin{array}{l}0,0409^{* * *} \\
(0,00989)\end{array}$ \\
\hline Cor negra & $\begin{array}{l}-0,0392 \\
(0,0272)\end{array}$ & $\begin{array}{l}0,0424^{* *} \\
(0,0184)\end{array}$ \\
\hline Cor parda & $\begin{array}{l}-0,0258^{*} \\
(0,0150)\end{array}$ & $\begin{array}{r}0,0406^{* * *} \\
(0,0117)\end{array}$ \\
\hline Alfabetizado & $\begin{array}{r}-0,0242^{* * *} \\
(0,00775)\end{array}$ & $\begin{array}{l}0,0285^{* * *} \\
(0,00533)\end{array}$ \\
\hline Analfabeto & $\begin{array}{c}0,0200 \\
(0,0385)\end{array}$ & $\begin{array}{l}-0,00245 \\
(0,0285)\end{array}$ \\
\hline Não frequentava escola & $\begin{array}{r}-0,0201^{* * * *} \\
(0,00768)\end{array}$ & $\begin{array}{l}0,0282^{* * *} \\
(0,00535)\end{array}$ \\
\hline Frequentava escola & $\begin{array}{l}-0,109^{* *} \\
(0,0521)\end{array}$ & $\begin{array}{l}0,00359 \\
(0,0204)\end{array}$ \\
\hline Não possui ensino médio completo & $\begin{array}{l}-0,0120 \\
(0,0114)\end{array}$ & $\begin{array}{l}0,0346^{* * *} \\
(0,00818)\end{array}$ \\
\hline Possui ensino médio completo & $\begin{array}{c}-0,0317^{* * *} \\
(0,0102)\end{array}$ & $\begin{array}{l}0,0242^{* * *} \\
(0,00670)\end{array}$ \\
\hline Chefe da família & $\begin{array}{r}-0,0270^{* * *} \\
(0,00782)\end{array}$ & $\begin{array}{l}0,0280^{* * *} \\
(0,00537)\end{array}$ \\
\hline Não deficiente & $\begin{array}{r}-0,0244^{* * *} \\
(0,00774)\end{array}$ & $\begin{array}{l}0,0289^{* * *} \\
(0,00531)\end{array}$ \\
\hline Deficiente & $\begin{array}{c}0,0453 \\
(0,0385)\end{array}$ & $\begin{array}{l}-0,0326 \\
(0,0309)\end{array}$ \\
\hline Não teve emprego formal em 2012 & $\begin{array}{c}-0,0258^{* *} \\
(0,0117)\end{array}$ & $\begin{array}{c}0,0338^{* * *} \\
(0,0085)\end{array}$ \\
\hline Teve emprego formal em 2012 & $\begin{array}{l}-0,0194^{* *} \\
(0,00988)\end{array}$ & $\begin{array}{l}0,0235^{* * *} \\
(0,00651)\end{array}$ \\
\hline Ganhava menos que um salário mínimo & $\begin{array}{c}-0,0362^{* * *} \\
(0,0129)\end{array}$ & $\begin{array}{l}0,0414^{* * *} \\
(0,00965)\end{array}$ \\
\hline Ganhava mais que um salário mínimo & $\begin{array}{c}-0,0142 \\
(0,00933)\end{array}$ & $\begin{array}{l}0,0207^{* * *} \\
(0,00582)\end{array}$ \\
\hline Trabalhava na indústria & $\begin{array}{l}-0,0187 \\
(0,0208)\end{array}$ & $\begin{array}{l}0,0270^{* *} \\
(0,0131)\end{array}$ \\
\hline Trabalhava no setor administrativo & $\begin{array}{l}-0,0270 \\
(0,0186)\end{array}$ & $\begin{array}{l}0,0296^{* *} \\
(0,0125)\end{array}$ \\
\hline Trabalhava no setor de serviços & $\begin{array}{c}-0,0408^{* *} \\
(0,0164)\end{array}$ & $\begin{array}{l}0,0225^{* *} \\
(0,0109)\end{array}$ \\
\hline Morava a mais de $10 \mathrm{~km}$ do empreendimento & $\begin{array}{c}-0,0409^{* *} \\
(0,0170)\end{array}$ & $\begin{array}{l}0,0308^{* *} \\
(0,0121)\end{array}$ \\
\hline Morava a menos de $10 \mathrm{~km}$ do empreendimento & $\begin{array}{l}-0,0135 \\
(0,0086)\end{array}$ & $\begin{array}{c}0,0265^{* * *} \\
(0,0058)\end{array}$ \\
\hline
\end{tabular}

Notas: As colunas apresentam resultados intent-to-treat do efeito do programa MCMV sobre as variáveis de emprego formal (anual) e participação no Bolsa Família. Cada uma das linhas é de uma regressão diferente, onde a amostra é restrita àquele subgrupo. O resultado de cada linha é o coeficiente de uma variável dummy que indica se o indivíduo foi sorteado. Todos os resultados são para as amostras com variáveis de controle, o que corresponde a cerca de $99 \%$ do total da amostra.

Todos os erros-padrão têm cluster ao nível do indivíduo.

${ }^{*} p<0,10,{ }^{* *} p<0,05,{ }^{* * *} p<0,01$ 

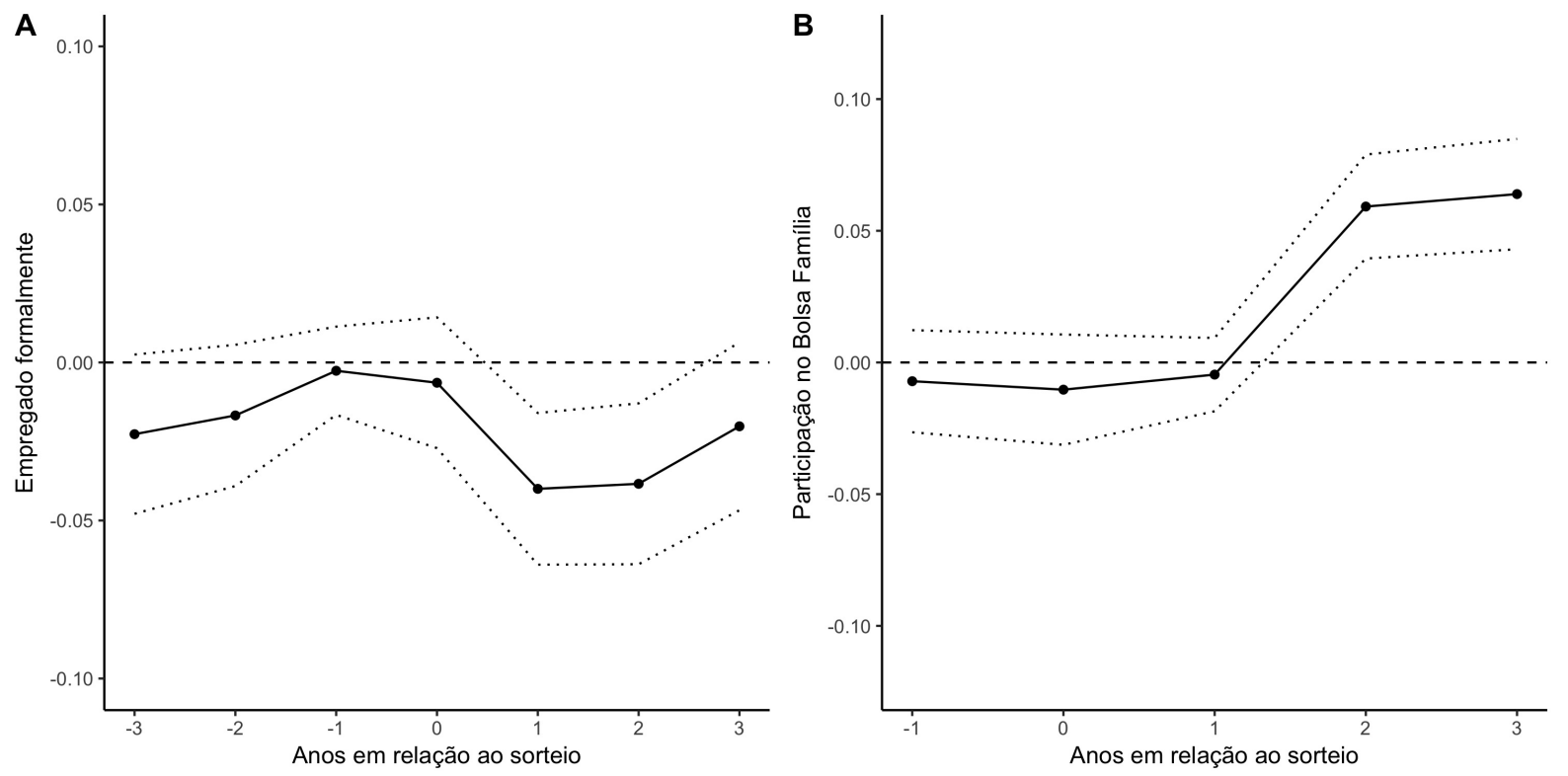

Figura 9 - Efeito do programa sobre a probabilidade de emprego e participação no Bolsa Família ao longo do tempo.

Notas: Os gráficos A e B representam regressões de variável instrumental com variáveis de controle em cada ano, conforme descrito no texto. A amostra inclui aqueles indivíduos com informações no Cadastro Único (99\% da amostra total). As linhas tracejadas representam o intervalo de confiança de $95 \%$. O ano zero é o ano do sorteio (2013). Dados da RAIS de 2009 a 2016 e do Cadastro Único de 2012 a 2016. Elaboração própria.

\subsubsection{Resultados com variáveis da RAIS}

Na seção 2.2, constrói-se as amostras para o Rio de Janeiro a partir de informações da RAIS, base que contém todos os trabalhadores formais do país em um dado ano. Nessa seção, faz-se o mesmo para o caso de São José do Rio Preto.

Nessa seção, busca-se comparar as características dos indivíduos em São José do Rio Preto e os resultados da seção anterior, com as características e resultados de uma amostra formada apenas por informações da RAIS, à semelhança do que foi feito para o Rio de Janeiro. O objetivo é comparar esses resultados com aqueles da amostra completa e verificar se há grandes diferenças entre ambos.

Constrói-se uma amostra de indivíduos com informação na RAIS entre os anos de 2009 e 2014. O balanceamento entre os grupos de tratamento e controle a partir dessas informações é apresentado na Tabela 14. As informações são de cerca de $76 \%$ de todos os indivíduos.

Nota-se, em primeiro lugar, que o balanceamento entre os grupos de tratamento e controle se mantém. Não há diferenças significativas entre os dois grupos naquelas variáveis que conseguimos construir a partir da RAIS.

Ao comparar as informações dessa tabela com as informações da Tabela 6, onde 
as informações são de todos os indivíduos, nota-se que a amostra de indivíduos da RAIS possui menos mulheres e mais indivíduos de cor branca. E ainda, os indivíduos apresentam maior escolaridade e menor idade.

Essas diferenças são explicadas pelo fato de que a amostra de indivíduos da RAIS é composta por aqueles que tiveram algum vínculo de emprego formal no período analisado. Isto é, pessoas que não trabalham formalmente, como idosos, mulheres e indivíduos de menor escolaridade, e que compõe os $25 \%$ restantes para os quais não há informações e que, portanto, são excluídos da análise.

É provável que, na seção sobre o Rio de Janeiro, esse perfil demográfico também esteja excluído dos resultados principais. Isto é, ao usar as variáveis de controle da RAIS, exclui-se uma parcela significante de mulheres, negros e indivíduos de escolaridade menor. Isso pode prejudicar a validade externa daquelas estimações.

Na Tabela 15 apresentam-se os resultados para essa amostra composta apenas por indivíduos com informações na RAIS. Nota-se que, apesar de estarmos excluindo $25 \%$ da amostra, os resultados são bastante semelhantes ao caso em que todos os indivíduos são incluídos. Ao comparar esses resultados com os resultados da Tabela 12, onde as colunas (2) e (4) apresentam os resultados com as variáveis de controle do Cadastro Único, percebe-se que os coeficientes estimados têm magnitude e significância similares para todas as variáveis dependentes apresentadas.

Ou seja, mesmo excluindo um quarto da amostra, os resultados ainda se mantém. Os resultados da Tabela 15 indicam que a exclusão de parte da amostra pode não ser um problema tão grande assim.

Isso faz sentido para o caso de empregos formais, pois os indivíduos que não tiveram nenhum vínculo formal no período analisado, provavelmente não terão vínculos nos anos posteriores ao sorteio. 
Tabela 14 - Balanceamento com variáveis RAIS - São José do Rio Preto

\begin{tabular}{|c|c|c|c|c|c|}
\hline & $\begin{array}{c}(1) \\
\text { Controle }\end{array}$ & $\begin{array}{c}(2) \\
\text { Sorteados }\end{array}$ & $\begin{array}{c}(3) \\
\text { Diferença (1) - (2) }\end{array}$ & $\begin{array}{c}(4) \\
\text { Compliers }\end{array}$ & $\begin{array}{c}(5) \\
\text { Noncompliers }\end{array}$ \\
\hline \% com informação na RAIS & 0,765 & 0,757 & $\begin{array}{c}0,009 \\
(0,010)\end{array}$ & 0,739 & 0,799 \\
\hline Sexo feminino & 0,686 & 0,672 & $\begin{array}{c}0,014 \\
(0,012)\end{array}$ & 0,706 & 0,596 \\
\hline Indígena & 0,001 & 0,002 & $\begin{array}{c}-0,001 \\
(0,001)\end{array}$ & 0,002 & 0,000 \\
\hline Cor branca & 0,767 & 0,767 & $\begin{array}{c}0,000 \\
(0,011)\end{array}$ & 0,774 & 0,752 \\
\hline Cor negra & 0,062 & 0,055 & $\begin{array}{c}0,007 \\
(0,006)\end{array}$ & 0,058 & 0,048 \\
\hline Cor amarela & 0,003 & 0,002 & $\begin{array}{c}0,000 \\
(0,001)\end{array}$ & 0,002 & 0,002 \\
\hline Cor parda & 0,129 & 0,131 & $\begin{array}{c}-0,001 \\
(0,009)\end{array}$ & 0,130 & 0,132 \\
\hline Cor não identificada & 0,029 & 0,033 & $\begin{array}{c}-0,004 \\
(0,004)\end{array}$ & 0,026 & 0,046 \\
\hline Analfabeto & 0,001 & 0,002 & $\begin{array}{l}-0,001 \\
(0,001)\end{array}$ & 0,002 & 0,002 \\
\hline Deficiente & 0,007 & 0,006 & $\begin{array}{c}0,001 \\
(0,002)\end{array}$ & 0,005 & 0,007 \\
\hline Completou ensino fundamental & 0,906 & 0,904 & $\begin{array}{c}0,003 \\
(0,008)\end{array}$ & 0,908 & 0,895 \\
\hline Completou ensino médio & 0,679 & 0,679 & $\begin{array}{c}0,000 \\
(0,012)\end{array}$ & 0,669 & 0,702 \\
\hline Completou ensino superior & 0,043 & 0,045 & $\begin{array}{c}-0,002 \\
(0,005)\end{array}$ & 0,047 & 0,041 \\
\hline Idade & 30,972 & 30,980 & $\begin{array}{l}-0,007 \\
(0,267)\end{array}$ & 30,566 & 31,884 \\
\hline Salário formal em 2012 & 1014,425 & 1035,694 & $\begin{array}{l}-21,269 \\
(12,978)\end{array}$ & 988,891 & 1136,516 \\
\hline Salário em dez/12 & 518,916 & 517,613 & $\begin{array}{c}1,303 \\
(15,725)\end{array}$ & 459,614 & 654,543 \\
\hline Empregado formalmente em 31/12/12 & 0,454 & 0,446 & $\begin{array}{c}0,008 \\
(0,012)\end{array}$ & 0,425 & 0,494 \\
\hline Empregado formalmente em 2012 & 0,594 & 0,590 & $\begin{array}{c}0,004 \\
(0,011)\end{array}$ & 0,574 & 0,629 \\
\hline Trabalha no setor de Serviços & 0,251 & 0,241 & $\begin{array}{c}0,009 \\
(0,010)\end{array}$ & 0,238 & 0,248 \\
\hline Trabalha no setor Administrativo & 0,137 & 0,140 & $\begin{array}{l}-0,002 \\
(0,008)\end{array}$ & 0,149 & 0,118 \\
\hline Trabalha na Indústria & 0,134 & 0,140 & $\begin{array}{c}-0,007 \\
(0,008)\end{array}$ & 0,126 & 0,174 \\
\hline$N$ & 9728 & 2356 & 12084 & 1655 & 701 \\
\hline
\end{tabular}

Notas: A unidade de análise é o indivíduo. Todas as informações apresentadas são da RAIS de 2009 a 2014. As Informações de gênero, cor da pele, escolaridade, idade e deficiente são de cerca de $76 \%$ da amostra, cujas informações estavam presentes na RAIS. As informações de salário formal, emprego formal e setor do emprego são de toda a amostra. A primeira coluna apresenta as informações dos indivíduos não sorteados no sorteio do MCMV. A segunda coluna apresenta as informações dos indivíduos sorteados. A terceira coluna indica a diferença entre os grupos e o resultado de um teste $t$ de diferença entre os dois grupos. A quarta coluna apresenta as informações dos indivíduos que foram sorteados e que se tornaram beneficiários do MCMV. A quinta coluna apresenta as informações daqueles que foram sorteados, mas não se tornaram beneficiários. A estatística F e o p-valor são de uma regressão onde a variável dependente é igual a um se o indivíduo foi sorteado no MCMV e 0 caso contrário. O erro padrão é clusterizado ao nível do indivíduo.

${ }^{*} p<0,10,{ }^{* *} p<0,05,{ }^{* * *} p<0,01$ 
Tabela 15 - Impactos do programa sobre a probabilidade de emprego formal - Amostra RAIS

\begin{tabular}{|c|c|c|c|c|c|}
\hline & $\begin{array}{c}\text { Média do } \\
\text { grupo de controle }\end{array}$ & $\begin{array}{c}(1) \\
\text { ITT sem controles }\end{array}$ & $\begin{array}{c} \\
\text { ITT com controles RAIS }\end{array}$ & $\begin{array}{c}(3) \\
\text { VI sem controles }\end{array}$ & $\begin{array}{c}(4) \\
\text { VI com controles RAIS }\end{array}$ \\
\hline $\begin{array}{l}\text { Empregado formalmente } \\
\text { (anual) }\end{array}$ & 0,556 & $\begin{array}{c}-0,025^{* *} \\
(0,010)\end{array}$ & $\begin{array}{c}-0,029^{* * *} \\
(0,009)\end{array}$ & $\begin{array}{c}-0,036^{* *} \\
(0,015)\end{array}$ & $\begin{array}{c}-0,042^{* * *} \\
(0,014)\end{array}$ \\
\hline $\begin{array}{l}\text { Empregado formalmente } \\
\text { (trimestral) }\end{array}$ & 0,473 & $\begin{array}{c}-0,025^{* *} \\
(0,010)\end{array}$ & $\begin{array}{c}-0,029^{* * *} \\
(0,009)\end{array}$ & $\begin{array}{c}-0,035^{* * *} \\
(0,014)\end{array}$ & $\begin{array}{c}-0,043^{* * *} \\
(0,013)\end{array}$ \\
\hline Empregado em 31/12 & 0,419 & $\begin{array}{c}-0,021^{* *} \\
(0,010)\end{array}$ & $\begin{array}{c}-0,026^{* *} \\
(0,010)\end{array}$ & $\begin{array}{c}-0,030^{* *} \\
(0,014)\end{array}$ & $\begin{array}{c}-0,038^{* * *} \\
(0,015)\end{array}$ \\
\hline $\begin{array}{l}\text { Salário formal } \\
\text { (anual) }\end{array}$ & 783,9 & $\begin{array}{l}-19,069 \\
(18,216)\end{array}$ & $\begin{array}{l}-17,729 \\
(20,681)\end{array}$ & $\begin{array}{l}-27,146 \\
(25,882)\end{array}$ & $\begin{array}{l}-25,920 \\
(30,170)\end{array}$ \\
\hline Recebe Bolsa Família & 0,131 & $\begin{array}{c}0,020^{* * *} \\
(0,007)\end{array}$ & $\begin{array}{c}0,024^{* * *} \\
(0,007)\end{array}$ & $\begin{array}{c}0,029^{* * *} \\
(0,010)\end{array}$ & $\begin{array}{c}0,035^{* * *} \\
(0,011)\end{array}$ \\
\hline Efeito fixo temporal & & Sim & Sim & Sim & Sim \\
\hline Número de indivíduos & & 12084 & 9228 & 12084 & 9228 \\
\hline
\end{tabular}

Notas: As colunas (1) e (2) indicam os efeitos intent-to-treat do Minha Casa Minha Vida sobre as variáveis dependentes em cada uma das linhas. Os resultados são de regressões de MQO onde cada variável dependente é regredida contra uma variável binária que indica se o indivíduo foi sorteado naquele sorteio. As colunas (3) e (4) são os resultados de uma regressão em dois estágios, onde a participação no programa é instrumentalizada pelo sorteio. As estimativas representam os efeitos treatment-on-the-treated, conforme descrito no texto. As colunas (1) e (3) apresentam os resultados para toda a amostra sem quaisquer variáveis de controle. As colunas (2) e (4) apresentam os resultados com variáveis de controle para cerca de $76 \%$, que corresponde àqueles indivíduos com informação na RAIS entre os anos de 2009 e 2014, à semelhança do que foi feito para o caso do Rio de Janeiro. As variáveis de controle são aquelas apresentadas na tabela de balanceamento. A variável empregado formalmente (anual) é uma dummy que indica se o indivíduo teve algum emprego formal em um dado ano. A variável empregado formalmente (trimestral) também é uma dummy que indica se o indivíduo estava empregado em cada trimestre. A variável empregado em 31/12 é uma variável da RAIS que indica se o indivíduo estava empregado em 31/12 de cada ano. A variável salário formal indica o salário médio do indivíduo em cada ano. Todas essas regressões são para os anos de 2014 a 2016 , posteriores ao sorteio. A variável de participação no Bolsa Família é uma dummy que indica se o indivíduo recebe Bolsa Família em cada um dos anos entre 2014 e 2016.

Todos os erros padrão apresentados têm cluster ao nível do indivíduo

${ }^{*} p<0,10,{ }^{* *} p<0,05,{ }^{* * *} p<0,01$ 


\section{Discussão e Conclusão}

Programas habitacionais podem afetar os indivíduos beneficiados de diversas maneiras. A literatura econômica tem buscado explorar como a provisão de vouchers ou de moradias afeta o desempenho dos indivíduos no mercado de trabalho.

Isso é feito não apenas para explorar efeitos indiretos de programas habitacionais, mas também para trazer mais informações ao debate sobre como o governo deve ajudar as famílias mais necessitadas. Além disso, a ideia de que a assistência habitacional traz externalidades positivas para as famílias beneficiadas é uma das principais razões para o alto investimento nesse tipo de programa, que é bastante popular no mundo todo.

No Brasil, o Minha Casa Minha Vida atingiu um tamanho bastante relevante em apenas 8 anos de existência, entregando mais de 1,2 milhão de casas apenas na Faixa I do programa, destinada aos mais pobres. O programa é um dos mais custosos para os cofres públicos e tem sido alvo de críticas, pois as moradias construídas pelo programa têm se localizado em regiões periféricas, com pouca infraestrutura, o que impõe um custo adicional aos indivíduos beneficiados: o custo da distância.

O Rio de Janeiro é a cidade com mais unidades habitacionais do MCMV Faixa I no Brasil. Na primeira fase do programa no município, a grande maioria dos empreendimentos inaugurados estava na periferia, afastados de centros de emprego, lazer e demais serviços. Isso levou diversos autores a criticar o MCMV, ressaltando que o programa, ao construir grandes conjuntos habitacionais na periferia, revive experiências fracassadas do passado.

Além da distância dos centros, ainda existem razões econômicas apontadas pela literatura pelas quais programas desse tipo podem afetar negativamente a oferta de trabalho, desincentivando o indivíduo a participar do mercado de trabalho.

O presente trabalho é um dos primeiros a analisar microdados do Minha Casa Minha Vida. Além disso, explora uma fonte de exogeneidade rara na literatura: a aleatorização da seleção dos beneficiários do programa.

Os resultados apresentados mostram que o Minha Casa Minha Vida não tem qualquer efeito positivo sobre a taxa de emprego formal. Não só isso, as estimativas nos permitem afirmar que o MCMV teve um efeito negativo sobre a taxa de emprego formal tanto na cidade de São José do Rio Preto, quanto na cidade do Rio de Janeiro, onde o efeito é mais forte no sorteio em que as casas estavam localizadas em regiões mais distantes.

Esse efeito negativo é de cerca de 3,3\% na cidade de São José do Rio Preto e varia entre $4 \%$ e 4,9\% na cidade do Rio de Janeiro, de acordo com o sorteio. Contudo, a renda formal dos indivíduos parece não ter sido afetada. 
Novos estudos, que consigam dados para o mercado informal, serão muito importantes para determinar se houve uma migração do mercado de trabalho formal para o informal ou se, de fato, houve uma redução da taxa de emprego entre os beneficiários do programa.

A maior parte dos indivíduos beneficiados pelo MCMV, nos casos analisados por este trabalho, tem menos de 65 anos e participa do mercado de trabalho. Entre 2006 e 2014, cerca de $75 \%$ da amostra teve um emprego formal, o que indica que a população beneficiada pelo programa participa ativamente do mercado de trabalho formal.

Nesse sentido, é interessante que, no Rio de Janeiro, o efeito negativo do MCMV sobre a taxa de emprego formal seja maior e mais significante para aqueles indivíduos que tinham um emprego formal no ano anterior aos sorteios. A possibilidade da existência de um efeito negativo sobre a taxa de emprego formal deve ser levada em conta pelos formuladores do programa, sobretudo se o mecanismo que causa essa redução esteja ligado a localização dos conjuntos habitacionais.

Dada a natureza dos dados, o mecanismo de transmissão exato desse efeito negativo não pode ser isolado. No entanto, no Rio de Janeiro, o efeito negativo foi maior no sorteio em que as casas do MCMV estavam em regiões mais distantes. Além disso, em S. José do Rio Preto, o efeito foi mais negativo para aqueles que, na linha de base, moravam a mais de $10 \mathrm{~km}$ dos conjuntos habitacionais, sugerindo que a distância importa.

Outro ponto importante é o prazo do efeito sobre a taxa de emprego formal. No Rio de Janeiro, o efeito negativo aumenta com o tempo. No primeiro e no segundo sorteio analisados, o impacto negativo chega a quase $10 \%$ cinco anos após o sorteio, indicando um efeito negativo de médio-longo prazo.

Em S. José do Rio Preto, o impacto sobre a taxa de emprego formal continua negativo, mas perde significância estatística no terceiro ano após o sorteio. No entanto, como não há dados para os anos seguintes, não é possível afirmar que o efeito é de curto prazo, o que contrastaria com o caso do Rio de Janeiro.

Além disso, mostra-se também que o programa tem um efeito positivo sobre a participação no Bolsa Família, programa que é destinado a famílias economicamente vulneráveis. Isso pode indicar uma piora na situação econômica entre os beneficiados.

Os resultados são bastante relevantes para as políticas habitacionais no Brasil. Além disso, muitos países em desenvolvimento lançaram programas habitacionais com características similares ao MCMV nos últimos anos. No entanto, ainda são poucos os estudos sobre esses programas. Esse trabalho contribuirá também para essa literatura.

Essas estimativas sugerem que o programa precisa se atentar a efeitos adversos que podem estar ocorrendo. Dado o seu alto custo, o Minha Casa Minha Vida não pode prejudicar ou desincentivar o emprego de seus beneficiários. Pelo contrário, a casa própria 
deveria ser um meio de estabilidade para que os indivíduos pudessem escapar da pobreza. 



\section{Referências}

ANGRIST, J.; PISCHKE, J.-S. Mostly Harmless Econometrics: An Empiricist's Companion. 1. ed. Princeton University Press, 2009. Disponível em: <https: //EconPapers.repec.org/RePEc:pup:pbooks:8769>. Citado 3 vezes nas páginas 39, 46 e 47.

BARNHARDT, S.; FIELD, E.; PANDE, R. Moving to opportunity or isolation? network effects of a randomized housing lottery in urban india. American Economic Journal: Applied Economics, v. 9, n. 1, p. 1-32, January 2017. Citado na página 23.

BONDUKI, N. Política habitacional e inclusão social no brasil: revisão histórica e novas perspectivas no governo lula. Revista eletrônica de Arquitetura e Urbanismo, v. 1, n. 1, p. 70-104, 2008. Citado 2 vezes nas páginas 24 e 26.

BRASIL, M. d. C. Pesquisa de Satisfação dos beneficiários do Programa Minha Casa Minha Vida. 2014. Citado 2 vezes nas páginas 18 e 26.

BUCKLEY, R. M.; KALLERGIS, A.; WAINER, L. The emergence of large-scale housing programs: Beyond a public finance perspective. Habitat International, v. 54, n. Part 3, p. 199 - 209, 2016. ISSN 0197-3975. Housing the Planet: Evolution of Global Housing Policies. Disponível em: <http://www.sciencedirect.com/science/article/pii/ S0197397515302083>. Citado 2 vezes nas páginas 21 e 23.

CARDOSO, A. L.; LAGO, L. C. Avaliação do programa minha casa minha vida na região metropolitana do rio de janeiro: Impactos urbanos e sociais. Observatório das Metropóles, 2015. Citado 4 vezes nas páginas 18, 29, 31 e 38.

CENSO, D. Características da população e dos domicílios: resultados do universo. 2010. Citado na página 23.

CHETTY, R.; HENDREN, N.; KATZ, L. F. The effects of exposure to better neighborhoods on children: New evidence from the moving to opportunity experiment. American Economic Review, v. 106, n. 4, p. 855-902, April 2016. Disponível em: $<$ http://www.aeaweb.org/articles?id=10.1257/aer.20150572>. Citado na página 22.

COLlinsOn, R.; Ellen, I. G.; LUDWIG, J. Low-Income Housing Policy. [S.1.], 2015. (Working Paper Series, 21071). Disponível em: <http://www.nber.org/papers/w21071>. Citado na página 21.

CUNHA, G. R. da. O Programa Minha Casa Minha Vida em São José do Rio Preto/SP: Estado, Mercado, Planejamento Urbano e Habitação. Tese (Doutorado) - Instituto de Arquitetura e Urbanismo de São Carlos, Universidade de São Paulo, São Carlos, SP, 8 2014. Citado 2 vezes nas páginas 40 e 41.

CURRIE, J.; GAHVARI, F. Transfers in cash and in-kind: Theory meets the data. Journal of Economic Literature, American Economic Association, v. 46, n. 2, p. 333-383, 2008. ISSN 00220515. Disponível em: < http://www.jstor.org/stable/27646992>. Citado na página 21. 
CURRIE, J.; YELOWITZ, A. Are public housing projects good for kids? Journal of Public Economics, v. 75, n. 1, p. 99 - 124, 2000. ISSN 0047-2727. Disponível em: <http://www.sciencedirect.com/science/article/pii/S0047272799000651>. Citado 2 vezes nas páginas 21 e 22 .

GOBILLON, L.; SELOD, H.; ZENOU, Y. The mechanisms of spatial mismatch. Urban Studies, v. 44, n. 12, p. 2401-2427, 2007. Disponível em: <https://doi.org/10.1080/ 00420980701540937>. Citado na página 26.

JACOB, B. A.; LUDWIG, J. The effects of housing assistance on labor supply: Evidence from a voucher lottery. American Economic Review, v. 102, n. 1, p. 272-304, February 2012. Disponível em: < http://www.aeaweb.org/articles?id=10.1257/aer.102.1.272>. Citado 4 vezes nas páginas 17, 21, 22 e 50.

KAIN, J. F. Housing segregation, negro employment, and metropolitan decentralization*. The Quarterly Journal of Economics, v. 82, n. 2, p. 175-197, 1968. Disponível em: $<$ http://dx.doi.org/10.2307/1885893>. Citado 2 vezes nas páginas 18 e 26 .

KLING, J. R.; LIEBMAN, J. B.; KATZ, L. F. Experimental analysis of neighborhood effects. Econometrica, v. 75, n. 1, p. 83-119, 2007. Citado na página 22.

LUDWIG, J. et al. Long-term neighborhood effects on low-income families: Evidence from moving to opportunity. American Economic Review, v. 103, n. 3, p. 226-31, May 2013. Disponível em: <http://www.aeaweb.org/articles?id=10.1257/aer.103.3.226>. Citado na página 22.

MARQUES, E.; RODRIGUES, L. O programa minha casa minha vida na metrópole paulistana: atendimento habitacional e padrões de segregação. Revista Brasileira de Estudos Urbanos e Regionais, v. 15, p. 159-177, 2013. ISSN 1517-4115. Disponível em: $<$ http://www.redalyc.org/articulo.oa?id $=513951684011>$. Citado 5 vezes nas páginas $17,18,24,25$ e 26.

ONU-HABITAT. Urbanization and development: emerging futures; world cities report 2016. UN Habitat, 2016. Citado na página 17.

PEQUENO, L. R. B.; RENATO, L. Minha Casa Minha Vida em Fortaleza: novas periferias? Anais: Encontros Nacionais da ANPUR, v. 15, p. 1-17, 2013. Citado 3 vezes nas páginas 17,18 e 25.

PINHEIRO, F. J. Déficit Habitacional no Brasil 2013 - 2014. 2016. Citado na página 24.

ROLNIK, R. et al. O Programa Minha Casa Minha Vida nas regiões metropolitanas de São Paulo e Campinas: aspectos socioespaciais e segregação. Cadernos Metrópole, v. 17, n. 33, p. 127-154, 2015. ISSN 2236-9996. Disponível em: <http://dx.doi.org/10.1590/ 2236-9996.2015-3306>. Citado 3 vezes nas páginas 17, 18 e 25.

SHRODER, M. Does housing assistance perversely affect self-sufficiency? a review essay. Journal of Housing Economics, v. 11, n. 4, p. 381-417, 2002. Disponível em: <https://EconPapers.repec.org/RePEc:eee:jhouse:v:11:y:2002:i:4:p:381-417>. Citado na página 17 . 
SILVA, M. L. d.; TOURINHO, H. L. Z. O banco nacional de habitação e o programa minha casa minha vida: duas políticas habitacionais e uma mesma lógica locacional.

Cadernos Metrópole, scielo, v. 17, p. 401 - 417, 11 2015. ISSN 2236-9996. Disponível em: $<$ http://www.scielo.br/scielo.php?script=sci_arttext\&pid=S2236-99962015000200401\& nrm $=$ iso $>$. Citado na página 26.

SUSIN, S. Longitudinal Outcomes of Subsidized Housing Recipients in Matched Survey and Administrative Data. Cityscape, v. 8, n. 2, p. 189-218, 2005. ISSN 1936-007X. Citado na página 22.

WOOD, M.; TURNHAM, J.; MILLS, G. Housing affordability and family wellbeing: Results from the housing voucher evaluation. Housing Policy Debate, Routledge, v. 19, n. 2, p. 367-412, 2008. Citado 4 vezes nas páginas 17, 21, 22 e 52. 

Apêndices 



\section{APÊNDICE A - Tabelas}

Tabela 16 - Empreendimentos por sorteio - Rio de Janeiro

\begin{tabular}{lllll}
\hline Empreendimento & Sorteado 003 & Sorteado 006 & Sorteado 009 & Total \\
\hline Cascais & 4 & 354 & 56 & 413 \\
Destri & 411 & 11 & 2 & 411 \\
Estoril & 73 & 100 & 230 & 400 \\
Évora & 17 & 18 & 411 & 446 \\
Park Imperial & 46 & 72 & 161 & 278 \\
Park Royal & 59 & 85 & 134 & 277 \\
Res. Rio Bonito & 148 & 8 & 3 & 157 \\
Sevilha & 4 & 236 & 15 & 254 \\
Taroni & 10 & 198 & 2 & 209 \\
Toledo & 72 & 228 & 135 & 434 \\
Vidal & 59 & 20 & 142 & 220 \\
Zaragosa & 9 & 22 & 404 & 435 \\
Total & 912 & 1352 & 1695 & 3934 \\
\hline
\end{tabular}

Notas: A tabela apresenta os 12 conjuntos habitacionais cuja seleção dos beneficiários se deu através dos sorteios, realizados em 2011. As colunas indicam em qual dos sorteios os beneficiários dos empreendimentos foram sorteados. 
Tabela 17 - Balanceamento - Sorteio 003

\begin{tabular}{|c|c|c|c|c|c|}
\hline & $\begin{array}{c}(1) \\
\text { Controle }\end{array}$ & $\begin{array}{c}(2) \\
\text { Sorteados }\end{array}$ & $\begin{array}{c}(3) \\
\text { Diferença }(1)-(2)\end{array}$ & $\begin{array}{c}(4) \\
\text { Compliers }\end{array}$ & $\begin{array}{c}(5) \\
\text { Noncompliers }\end{array}$ \\
\hline \% com informação & 0,740 & 0,734 & $\begin{array}{c}0,006 \\
(0,008)\end{array}$ & 0,710 & 0,744 \\
\hline Sexo feminino & 0,539 & 0,535 & $\begin{array}{c}0,004 \\
(0,011)\end{array}$ & 0,644 & 0,490 \\
\hline Indígena & 0,003 & 0,002 & $\begin{array}{c}0,001 \\
(0,001)\end{array}$ & 0,002 & 0,002 \\
\hline Cor branca & 0,379 & 0,372 & $\begin{array}{c}0,007 \\
(0,011)\end{array}$ & 0,345 & 0,384 \\
\hline Cor negra & 0,119 & 0,117 & $\begin{array}{c}0,002 \\
(0,007)\end{array}$ & 0,139 & 0,108 \\
\hline Cor amarela & 0,006 & 0,007 & $\begin{array}{l}-0,000 \\
(0,002)\end{array}$ & 0,006 & 0,007 \\
\hline Cor parda & 0,348 & 0,360 & $\begin{array}{l}-0,012 \\
(0,010)\end{array}$ & 0,413 & 0,337 \\
\hline Cor não identificada & 0,055 & 0,053 & $\begin{array}{c}0,003 \\
(0,005)\end{array}$ & 0,047 & 0,055 \\
\hline Analfabeto & 0,001 & 0,000 & $\begin{array}{c}0,001 \\
(0,001)\end{array}$ & 0,000 & 0,001 \\
\hline Deficiente & 0,010 & 0,006 & $\begin{array}{l}0,004^{* *} \\
(0,002)\end{array}$ & 0,006 & 0,006 \\
\hline Completou o ensino fundamental 1 & 0,975 & 0,978 & $\begin{array}{l}-0,003 \\
(0,003)\end{array}$ & 0,979 & 0,977 \\
\hline Completou o ensino fundamental & 0,867 & 0,853 & $\begin{array}{l}0,014^{* *} \\
(0,007)\end{array}$ & 0,835 & 0,860 \\
\hline Completou o ensino médio & 0,641 & 0,636 & $\begin{array}{c}0,005 \\
(0,010)\end{array}$ & 0,584 & 0,657 \\
\hline Completou o ensino superior & 0,098 & 0,097 & $\begin{array}{c}0,000 \\
(0,006)\end{array}$ & 0,054 & 0,116 \\
\hline Idade & 36,913 & 36,907 & $\begin{array}{c}0,005 \\
(0,232)\end{array}$ & 36,291 & 37,165 \\
\hline Salário formal em 2010 & 581,308 & 570,920 & $\begin{array}{c}10,388 \\
(15,337)\end{array}$ & 385,957 & 651,933 \\
\hline Salário em dez/2010 & 557,233 & 553,395 & $\begin{array}{c}3,838 \\
(17,668)\end{array}$ & 318,342 & 656,346 \\
\hline Empregado formalmente em 31/12/10 & 0,484 & 0,472 & $\begin{array}{c}0,012 \\
(0,010)\end{array}$ & 0,408 & 0,500 \\
\hline Empregado formalmente em 2010 & 0,567 & 0,559 & $\begin{array}{c}0,008 \\
(0,009)\end{array}$ & 0,520 & 0,576 \\
\hline Trabalha no setor de Serviços & 0,211 & 0,213 & $\begin{array}{l}-0,002 \\
(0,008)\end{array}$ & 0,243 & 0,200 \\
\hline Trabalha no setor Administrativo & 0,178 & 0,176 & $\begin{array}{c}0,002 \\
(0,007)\end{array}$ & 0,165 & 0,181 \\
\hline Trabalha na Indústria & 0,075 & 0,074 & $\begin{array}{c}0,001 \\
(0,005)\end{array}$ & 0,057 & 0,082 \\
\hline Estatística F & & & 0,95 & & \\
\hline P-valor & & & 0,5204 & & \\
\hline$N$ & 277991 & 2922 & 280913 & 890 & 2032 \\
\hline
\end{tabular}

Notas: Essa tabela apresenta o balanceamento entre os grupos de tratamento e controle do Sorteio 003 com a exclusão de todos os sorteados nos Sorteios 006 e 009. Todas as informações apresentadas são da RAIS de 2006 a 2014. As informações de gênero, cor da pele, escolaridade, idade e deficiente são de cerca de $75 \%$ da amostra, cujas informações estavam presentes na RAIS. As informações de salário formal, emprego formal e setor do emprego são de toda a amostra. A primeira coluna apresenta as informações dos indivíduos não sorteados no sorteio do MCMV. A segunda coluna apresenta as informações dos indivíduos sorteados. A terceira coluna indica a diferença entre os grupos e o resultado de um teste $t$ de diferença entre os dois grupos. A quarta coluna apresenta as informações dos indivíduos que foram sorteados e que se tornaram beneficiários do MCMV. A quinta coluna apresenta as informações daqueles que foram sorteados, mas não se tornaram beneficiários. A estatística F e o p-valor são de uma regressão onde a variável dependente é igual a um se o indivíduo foi sorteado no Sorteio 003 e 0 caso contrário. O erro padrão é clusterizado ao nível do indivíduo.

${ }^{*} p<0,10,{ }^{* *} p<0,05,{ }^{* * *} p<0,01$ 
Tabela 18 - Balanceamento - Sorteio 006

\begin{tabular}{|c|c|c|c|c|c|}
\hline & $\begin{array}{c}(1) \\
\text { Controle }\end{array}$ & $\begin{array}{c}(2) \\
\text { Sorteados }\end{array}$ & $\begin{array}{c}(3) \\
\text { Diferença }(1)-(2)\end{array}$ & $\begin{array}{c}(4) \\
\text { Compliers }\end{array}$ & $\begin{array}{c}(5) \\
\text { Noncompliers }\end{array}$ \\
\hline \% com informação & 0,747 & 0,751 & $\begin{array}{l}-0,004 \\
(0,005)\end{array}$ & 0,733 & 0,755 \\
\hline Sexo feminino & 0,525 & 0,528 & $\begin{array}{l}-0,004 \\
(0,007)\end{array}$ & 0,636 & 0,501 \\
\hline Indígena & 0,003 & 0,002 & $\begin{array}{c}0,001 \\
(0,001)\end{array}$ & 0,001 & 0,002 \\
\hline Cor branca & 0,383 & 0,382 & $\begin{array}{c}0,000 \\
(0,007)\end{array}$ & 0,382 & 0,382 \\
\hline Cor negra & 0,114 & 0,112 & $\begin{array}{c}0,003 \\
(0,005)\end{array}$ & 0,143 & 0,103 \\
\hline Cor amarela & 0,006 & 0,006 & $\begin{array}{c}0,000 \\
(0,001)\end{array}$ & 0,006 & 0,006 \\
\hline Cor parda & 0,342 & 0,345 & $\begin{array}{l}-0,003 \\
(0,007)\end{array}$ & 0,368 & 0,340 \\
\hline Cor não identificada & 0,055 & 0,061 & $\begin{array}{c}-0,007^{* *} \\
(0,003)\end{array}$ & 0,058 & 0,062 \\
\hline Analfabeto & 0,001 & 0,002 & $\begin{array}{c}-0,001^{* *} \\
(0,000)\end{array}$ & 0,004 & 0,001 \\
\hline Deficiente & 0,010 & 0,012 & $\begin{array}{l}-0,001 \\
(0,001)\end{array}$ & 0,011 & 0,012 \\
\hline Completou o ensino fundamental 1 & 0,977 & 0,978 & $\begin{array}{l}-0,001 \\
(0,002)\end{array}$ & 0,978 & 0,978 \\
\hline Completou o ensino fundamental & 0,877 & 0,876 & $\begin{array}{c}0,001 \\
(0,005)\end{array}$ & 0,866 & 0,878 \\
\hline Completou o ensino médio & 0,660 & 0,662 & $\begin{array}{l}-0,002 \\
(0,007)\end{array}$ & 0,603 & 0,676 \\
\hline Completou o ensino superior & 0,110 & 0,105 & $\begin{array}{c}0,005 \\
(0,005)\end{array}$ & 0,069 & 0,114 \\
\hline Idade & 36,998 & 37,030 & $\begin{array}{l}-0,032 \\
(0,154)\end{array}$ & 36,086 & 37,268 \\
\hline Salário formal em 2010 & 623,357 & 625,249 & $\begin{array}{c}-1,891 \\
(11,079)\end{array}$ & 399,505 & 683,989 \\
\hline Salário formal em dez/2010 & 606,132 & 589,673 & $\begin{array}{c}16,459 \\
(12,749)\end{array}$ & 326,804 & 658,074 \\
\hline Empregado formalmente em 31/12/10 & 0,501 & 0,491 & $\begin{array}{c}0,010 \\
(0,007)\end{array}$ & 0,411 & 0,512 \\
\hline Empregado formalmente em 2010 & 0,579 & 0,575 & $\begin{array}{c}0,004 \\
(0,006)\end{array}$ & 0,532 & 0,586 \\
\hline Trabalha no setor de Serviços & 0,205 & 0,201 & $\begin{array}{c}0,004 \\
(0,005)\end{array}$ & 0,236 & 0,192 \\
\hline Trabalha no setor Administrativo & 0,185 & 0,186 & $\begin{array}{l}-0,002 \\
(0,005)\end{array}$ & 0,152 & 0,196 \\
\hline Trabalha na Indústria & 0,076 & 0,074 & $\begin{array}{c}0,002 \\
(0,003)\end{array}$ & 0,074 & 0,074 \\
\hline Estatística F & & & 0,90 & & \\
\hline $\begin{array}{l}\mathrm{P} \text {-valor } \\
N\end{array}$ & 303358 & 6451 & $\begin{array}{l}0,5864 \\
309809\end{array}$ & 1332 & 5119 \\
\hline
\end{tabular}

Notas: Essa tabela apresenta o balanceamento entre os grupos de tratamento e controle do Sorteio 006 com a exclusão de todos os sorteados nos Sorteios 003 e 009. Todas as informações apresentadas são da RAIS de 2006 a 2014. As informações de gênero, cor da pele, escolaridade, idade e deficiente são de cerca de $75 \%$ da amostra, cujas informações estavam presentes na RAIS. As informações de salário formal, emprego formal e setor do emprego são de toda a amostra. A primeira coluna apresenta as informações dos indivíduos não sorteados no sorteio do MCMV. A segunda coluna apresenta as informações dos indivíduos sorteados. A terceira coluna indica a diferença entre os grupos e o resultado de um teste $t$ de diferença entre os dois grupos. A quarta coluna apresenta as informações dos indivíduos que foram sorteados e que se tornaram beneficiários do MCMV. A quinta coluna apresenta as informações daqueles que foram sorteados, mas não se tornaram beneficiários. A estatística $\mathrm{F}$ e o p-valor são de uma regressão onde a variável dependente é igual a um se o indivíduo foi sorteado no Sorteio 006 e 0 caso contrário. O erro padrão é clusterizado ao nível do indivíduo.

${ }^{*} p<0,10,{ }^{* *} p<0,05,{ }^{* * *} p<0,01$ 
Tabela 19 - Balanceamento - Sorteio 009

\begin{tabular}{|c|c|c|c|c|c|}
\hline & $\begin{array}{c}(1) \\
\text { Controle }\end{array}$ & $\begin{array}{c}(2) \\
\text { Sorteados }\end{array}$ & $\begin{array}{c}\text { (3) } \\
\text { Diferença }(1)-(2)\end{array}$ & $\begin{array}{c}(4) \\
\text { Compliers }\end{array}$ & $\begin{array}{c}\text { (5) } \\
\text { Noncompliers }\end{array}$ \\
\hline \% com informação & 0,747 & 0,747 & $\begin{array}{l}-0,000 \\
(0,004)\end{array}$ & 0,731 & 0,749 \\
\hline Sexo feminino & 0,532 & 0,532 & $\begin{array}{l}-0,000 \\
(0,005)\end{array}$ & 0,618 & 0,520 \\
\hline Indígena & 0,003 & 0,003 & $\begin{array}{l}-0,000 \\
(0,001)\end{array}$ & 0,001 & 0,003 \\
\hline Cor branca & 0,380 & 0,387 & $\begin{array}{l}-0,007 \\
(0,005)\end{array}$ & 0,382 & 0,388 \\
\hline Cor negra & 0,115 & 0,113 & $\begin{array}{c}0,002 \\
(0,003)\end{array}$ & 0,137 & 0,110 \\
\hline Cor amarela & 0,006 & 0,004 & $\begin{array}{l}0,002^{* *} \\
(0,001)\end{array}$ & 0,005 & 0,004 \\
\hline Cor parda & 0,343 & 0,334 & $\begin{array}{l}0,008^{*} \\
(0,005)\end{array}$ & 0,378 & 0,329 \\
\hline Cor não identificada & 0,055 & 0,060 & $\begin{array}{c}-0,004^{*} \\
(0,002)\end{array}$ & 0,046 & 0,061 \\
\hline Analfabeto & 0,001 & 0,001 & $\begin{array}{c}0,000 \\
(0,000)\end{array}$ & 0,001 & 0,001 \\
\hline Deficiente & 0,010 & 0,010 & $\begin{array}{c}0,000 \\
(0,001)\end{array}$ & 0,013 & 0,010 \\
\hline Completou o ensino fundamental 1 & 0,976 & 0,975 & $\begin{array}{c}0,001 \\
(0,002)\end{array}$ & 0,967 & 0,976 \\
\hline Completou o ensino fundamental & 0,874 & 0,873 & $\begin{array}{c}0,001 \\
(0,003)\end{array}$ & 0,867 & 0,874 \\
\hline Completou o ensino médio & 0,655 & 0,646 & $\begin{array}{l}0,008^{*} \\
(0,005)\end{array}$ & 0,609 & 0,651 \\
\hline Completou o ensino superior & 0,107 & 0,103 & $\begin{array}{c}0,005 \\
(0,003)\end{array}$ & 0,064 & 0,108 \\
\hline Idade & 36,913 & 36,953 & $\begin{array}{l}-0,040 \\
(0,106)\end{array}$ & 35,915 & 37,091 \\
\hline Salário formal em 2010 & 614,470 & 612,464 & $\begin{array}{c}2,006 \\
(7,503)\end{array}$ & 406,001 & 640,689 \\
\hline Salário formal em dez/2010 & 595,864 & 604,284 & $\begin{array}{l}-8,420 \\
(8,688)\end{array}$ & 333,565 & 641,294 \\
\hline Empregado formalmente em 31/12/2010 & 0,496 & 0,503 & $\begin{array}{l}-0,007 \\
(0,005)\end{array}$ & 0,421 & 0,514 \\
\hline Empregado formalmente em 2010 & 0,575 & 0,574 & $\begin{array}{c}0,001 \\
(0,004)\end{array}$ & 0,525 & 0,580 \\
\hline Trabalha no setor de Serviços & 0,206 & 0,205 & $\begin{array}{c}0,001 \\
(0,003)\end{array}$ & 0,244 & 0,200 \\
\hline Trabalha no setor Administrativo & 0,182 & 0,179 & $\begin{array}{c}0,003 \\
(0,003)\end{array}$ & 0,162 & 0,181 \\
\hline Trabalha na Indústria & 0,076 & 0,077 & $\begin{array}{l}-0,001 \\
(0,002)\end{array}$ & 0,051 & 0,081 \\
\hline Estatística F & & & 1,24 & & \\
\hline $\mathrm{P}$-valor & & & 0,2108 & & \\
\hline$N$ & 336425 & 14027 & 350452 & 1687 & 12340 \\
\hline
\end{tabular}

Notas: Essa tabela apresenta o balanceamento entre os grupos de tratamento e controle do Sorteio 009 com a exclusão de todos os sorteados nos Sorteios 003 e 006. Todas as informações apresentadas são da RAIS de 2006 a 2014. As informações de gênero, cor da pele, escolaridade, idade e deficiente são de cerca de $75 \%$ da amostra, cujas informações estavam presentes na RAIS. As informações de salário formal, emprego formal e setor do emprego são de toda a amostra. A primeira coluna apresenta as informações dos indivíduos não sorteados no sorteio do MCMV. A segunda coluna apresenta as informações dos indivíduos sorteados. A terceira coluna indica a diferença entre os grupos e o resultado de um teste $t$ de diferença entre os dois grupos. A quarta coluna apresenta as informações dos indivíduos que foram sorteados e que se tornaram beneficiários do MCMV. A quinta coluna apresenta as informações daqueles que foram sorteados, mas não se tornaram beneficiários. A estatística $\mathrm{F}$ e o p-valor são de uma regressão onde a variável dependente é igual a um se o indivíduo foi sorteado no Sorteio 009 e 0 caso contrário. O erro padrão é clusterizado ao nível do indivíduo.

${ }^{*} p<0,10,{ }^{* *} p<0,05,{ }^{* * *} p<0,01$ 
Tabela 20 - Impactos do programa no Rio de Janeiro - Excluindo outros sorteados

\begin{tabular}{|c|c|c|c|c|}
\hline & $\begin{array}{c}(1) \\
\text { ITT sem controles }\end{array}$ & $\begin{array}{c}(2) \\
\text { ITT com controles }\end{array}$ & $\begin{array}{c}(3) \\
\text { VI sem controles }\end{array}$ & $\begin{array}{c}(4) \\
\text { VI com controles }\end{array}$ \\
\hline \multicolumn{5}{|l|}{ Painel A: Sorteio 003} \\
\hline Empregado formalmente & $-0,015^{*}$ & $-0,013^{*}$ & $-0,050^{*}$ & $-0,046^{*}$ \\
\hline (anual) & $(0,008)$ & $(0,007)$ & $(0,027)$ & $(0,024)$ \\
\hline \multirow[t]{2}{*}{ Recebe Bolsa Família } & $0,019^{* * *}$ & $0,021^{* * *}$ & $0,064^{* * *}$ & $0,070^{* * *}$ \\
\hline & $(0,005)$ & $(0,005)$ & $(0,017)$ & $(0,018)$ \\
\hline Número de indivíduos & 280913 & 207822 & 280913 & 207822 \\
\hline \multicolumn{5}{|l|}{ Painel B: Sorteio 006} \\
\hline Empregado formalmente & $-0,008$ & $-0,010^{* *}$ & $-0,038$ & $-0,050^{* *}$ \\
\hline (anual) & $(0,006)$ & $(0,005)$ & $(0,027)$ & $(0,023)$ \\
\hline \multirow[t]{2}{*}{ Recebe Bolsa Família } & $0,007^{* *}$ & $0,007^{* *}$ & $0,032^{* *}$ & $0,037^{* *}$ \\
\hline & $(0,003)$ & $(0,003)$ & $(0,016)$ & $(0,017)$ \\
\hline Número de indivíduos & 309809 & 231347 & 309809 & 231347 \\
\hline \multicolumn{5}{|l|}{ Painel C: Sorteio 009} \\
\hline Empregado formalmente & $-0,005$ & $-0,005$ & $-0,041$ & $-0,040$ \\
\hline (anual) & $(0,004)$ & $(0,003)$ & $(0,032)$ & $(0,027)$ \\
\hline \multirow[t]{2}{*}{ Recebe Bolsa Família } & $-0,003$ & $-0,002$ & $-0,023$ & $-0,015$ \\
\hline & $(0,002)$ & $(0,002)$ & $(0,019)$ & $(0,019)$ \\
\hline Número de indivíduos & 350452 & 261740 & 350452 & 261740 \\
\hline Dummies de ano & Sim & Sim & Sim & Sim \\
\hline
\end{tabular}

Notas: Cada um dos painéis representa uma amostra separada, composta apenas por aqueles indivíduos que participaram do respectivo sorteio. Em cada um dos painéis, exclui-se aqueles indivíduos sorteados nos dois outros sorteios. As colunas (1) e (2) indicam os efeitos intent-to-treat do Minha Casa Minha Vida sobre as variáveis dependentes em cada uma das linhas. Os resultados são de regressões de MQO onde cada variável dependente é regredida contra uma variável binária que indica se o indivíduo foi sorteado naquele sorteio. As colunas (3) e (4) são os resultados de uma regressão em dois estágios, onde a participação no programa é instrumentalizada pelo sorteio. As estimativas representam os efeitos treatment-on-the-treated, conforme descrito no texto. As colunas (1) e (3) apresentam os resultados para toda a amostra sem quaisquer variáveis de controle. As colunas (2) e (4) apresentam os resultados com variáveis de controle para cerca de $75 \%$ da amostra, que corresponde àqueles indivíduos que tiveram algum vínculo formal entre os anos de 2006 e 2014. Para esses indivíduos foi possível criar variáveis de controle, que são apresentadas nas tabelas de balanceamento. A variável empregado formalmente (anual) é uma dummy que indica se o indivíduo teve algum emprego formal em um dado ano. Essas regressões são para os anos de 2012 a 2016, posteriores ao sorteio. A variável de participação no Bolsa Família é uma dummy que indica se o indivíduo recebe Bolsa Família em cada um dos anos entre 2012 e 2017. A primeira coluna apresenta as médias de cada variável dependente para o grupo de controle.

Todos os erros padrão apresentados têm cluster ao nível do indivíduo.

${ }^{*} p<0,10,{ }^{* *} p<0,05,{ }^{* * *} p<0,01$ 
Tabela 21 - Balanceamento - Sorteio 003

\begin{tabular}{|c|c|c|c|c|c|}
\hline & $\begin{array}{c}(1) \\
\text { Controle }\end{array}$ & $\begin{array}{c}(2) \\
\text { Sorteados }\end{array}$ & $\begin{array}{c}(3) \\
\text { Diferença }(1)-(2)\end{array}$ & $\begin{array}{c}(4) \\
\text { Compliers }\end{array}$ & $\begin{array}{c}(5) \\
\text { Noncompliers }\end{array}$ \\
\hline \% com informação & 0,681 & 0,677 & $\begin{array}{c}0,004 \\
(0,009)\end{array}$ & 0,644 & 0,691 \\
\hline Sexo feminino & 0,523 & 0,531 & $\begin{array}{l}-0,008 \\
(0,011)\end{array}$ & 0,646 & 0,484 \\
\hline Indígena & 0,003 & 0,003 & $\begin{array}{c}-0,001 \\
(0,001)\end{array}$ & 0,000 & 0,005 \\
\hline Cor branca & 0,409 & 0,399 & $\begin{array}{c}0,009 \\
(0,011)\end{array}$ & 0,376 & 0,409 \\
\hline Cor negra & 0,126 & 0,121 & $\begin{array}{c}0,005 \\
(0,007)\end{array}$ & 0,155 & 0,108 \\
\hline Cor amarela & 0,006 & 0,008 & $\begin{array}{c}-0,002 \\
(0,002)\end{array}$ & 0,012 & 0,007 \\
\hline Cor parda & 0,336 & 0,343 & $\begin{array}{c}-0,007 \\
(0,011)\end{array}$ & 0,371 & 0,332 \\
\hline Cor não identificada & 0,120 & 0,124 & $\begin{array}{l}-0,004 \\
(0,007)\end{array}$ & 0,085 & 0,140 \\
\hline Analfabeto & 0,002 & 0,001 & $\begin{array}{c}0,001 \\
(0,001)\end{array}$ & 0,002 & 0,001 \\
\hline Completou o ensino fundamental 1 & 0,976 & 0,979 & $\begin{array}{l}-0,002 \\
(0,003)\end{array}$ & 0,981 & 0,978 \\
\hline Completou o ensino fundamental & 0,851 & 0,853 & $\begin{array}{c}-0,002 \\
(0,008)\end{array}$ & 0,821 & 0,867 \\
\hline Completou o ensino médio & 0,586 & 0,585 & $\begin{array}{c}0,000 \\
(0,011)\end{array}$ & 0,542 & 0,603 \\
\hline Completou o ensino superior & 0,058 & 0,057 & $\begin{array}{c}0,001 \\
(0,005)\end{array}$ & 0,026 & 0,070 \\
\hline Idade & 37,005 & 37,149 & $\begin{array}{l}-0,144 \\
(0,238)\end{array}$ & 36,359 & 37,473 \\
\hline Salário formal em 2010 & 581,400 & 571,370 & $\begin{array}{c}10,030 \\
(15,226)\end{array}$ & 388,765 & 651,784 \\
\hline Empregado formalmente em 2010 & 0,567 & 0,561 & $\begin{array}{c}0,007 \\
(0,009)\end{array}$ & 0,524 & 0,577 \\
\hline Trabalha no setor de serviços & 0,211 & 0,213 & $\begin{array}{l}-0,002 \\
(0,008)\end{array}$ & 0,245 & 0,199 \\
\hline Trabalha no setor administrativo & 0,178 & 0,176 & $\begin{array}{c}0,002 \\
(0,007)\end{array}$ & 0,171 & 0,179 \\
\hline Trabalha na indústria & 0,075 & 0,075 & $\begin{array}{c}0,001 \\
(0,005)\end{array}$ & 0,054 & 0,084 \\
\hline$N$ & 294884 & 2983 & 297867 & 912 & 2071 \\
\hline
\end{tabular}

Notas: Essa tabela apresenta o balanceamento entre os grupos de tratamento e controle do Sorteio 003. Todas as informações apresentadas são da RAIS de 2006 a 2010. As informações de gênero, cor da pele, escolaridade, idade e deficiente são de cerca de $68 \%$ da amostra, cujas informações estavam presentes na RAIS. As informações de salário formal, emprego formal e setor do emprego são de toda a amostra. A primeira coluna apresenta as informações dos indivíduos não sorteados no sorteio do MCMV. A segunda coluna apresenta as informações dos indivíduos sorteados. A terceira coluna indica a diferença entre os grupos e o resultado de um teste $\mathrm{t}$ de diferença entre os dois grupos. A quarta coluna apresenta as informações dos indivíduos que foram sorteados e que se tornaram beneficiários do MCMV. A quinta coluna apresenta as informações daqueles que foram sorteados, mas não se tornaram beneficiários.

${ }^{*} p<0,10,{ }^{* *} p<0,05,{ }^{* * *} p<0,01$ 
Tabela 22 - Balanceamento - Sorteio 006

\begin{tabular}{|c|c|c|c|c|c|}
\hline & $\begin{array}{c}(1) \\
\text { Controle }\end{array}$ & $\begin{array}{c}(2) \\
\text { Sorteados }\end{array}$ & $\begin{array}{c}(3) \\
\text { Diferença }(1)-(2)\end{array}$ & $\begin{array}{c}(4) \\
\text { Compliers }\end{array}$ & $\begin{array}{c}(5) \\
\text { Noncompliers }\end{array}$ \\
\hline \% com informação & 0,691 & 0,696 & $\begin{array}{l}-0,005 \\
(0,006)\end{array}$ & 0,666 & 0,704 \\
\hline Sexo feminino & 0,511 & 0,515 & $\begin{array}{l}-0,004 \\
(0,008)\end{array}$ & 0,620 & 0,488 \\
\hline Indígena & 0,003 & 0,002 & $\begin{array}{c}0,000 \\
(0,001)\end{array}$ & 0,001 & 0,002 \\
\hline Cor branca & 0,412 & 0,425 & $\begin{array}{l}-0,013^{*} \\
(0,007)\end{array}$ & 0,414 & 0,427 \\
\hline Cor negra & 0,121 & 0,117 & $\begin{array}{c}0,005 \\
(0,005)\end{array}$ & 0,141 & 0,111 \\
\hline Cor amarela & 0,006 & 0,006 & $\begin{array}{c}0,000 \\
(0,001)\end{array}$ & 0,004 & 0,006 \\
\hline Cor parda & 0,330 & 0,327 & $\begin{array}{c}0,003 \\
(0,007)\end{array}$ & 0,371 & 0,316 \\
\hline Cor não identificada & 0,128 & 0,123 & $\begin{array}{c}0,005 \\
(0,005)\end{array}$ & 0,068 & 0,137 \\
\hline Analfabeto & 0,001 & 0,001 & $\begin{array}{c}0,001 \\
(0,001)\end{array}$ & 0,002 & 0,001 \\
\hline Completou o ensino fundamental 1 & 0,978 & 0,979 & $\begin{array}{l}-0,001 \\
(0,002)\end{array}$ & 0,979 & 0,980 \\
\hline Completou o ensino fundamental & 0,861 & 0,860 & $\begin{array}{c}0,001 \\
(0,005)\end{array}$ & 0,844 & 0,864 \\
\hline Completou o ensino médio & 0,604 & 0,604 & $\begin{array}{c}0,000 \\
(0,007)\end{array}$ & 0,561 & 0,615 \\
\hline Completou o ensino superior & 0,067 & 0,066 & $\begin{array}{c}0,000 \\
(0,004)\end{array}$ & 0,036 & 0,074 \\
\hline Idade & 37,058 & 37,087 & $\begin{array}{l}-0,029 \\
(0,159)\end{array}$ & 36,139 & 37,322 \\
\hline Salário formal em 2010 & 623,110 & 624,114 & $\begin{array}{c}-1,004 \\
(11,016)\end{array}$ & 400,710 & 682,729 \\
\hline Empregado formalmente em 2010 & 0,579 & 0,575 & $\begin{array}{c}0,004 \\
(0,006)\end{array}$ & 0,533 & 0,586 \\
\hline Trabalha no setor de serviços & 0,205 & 0,203 & $\begin{array}{c}0,002 \\
(0,005)\end{array}$ & 0,238 & 0,194 \\
\hline Trabalha no setor administrativo & 0,184 & 0,186 & $\begin{array}{c}-0,002 \\
(0,005)\end{array}$ & 0,154 & 0,195 \\
\hline Trabalha na indústria & 0,077 & 0,072 & $\begin{array}{c}0,004 \\
(0,003)\end{array}$ & 0,073 & 0,072 \\
\hline$N$ & 318575 & 6505 & 325080 & 1352 & 5153 \\
\hline
\end{tabular}

Notas: Essa tabela apresenta o balanceamento entre os grupos de tratamento e controle do Sorteio 006. Todas as informações apresentadas são da RAIS de 2006 a 2010. As informações de gênero, cor da pele, escolaridade, idade e deficiente são de cerca de $69 \%$ da amostra, cujas informações estavam presentes na RAIS. As informações de salário formal, emprego formal e setor do emprego são de toda a amostra. A primeira coluna apresenta as informações dos indivíduos não sorteados no sorteio do MCMV. A segunda coluna apresenta as informações dos indivíduos sorteados. A terceira coluna indica a diferença entre os grupos e o resultado de um teste $t$ de diferença entre os dois grupos. A quarta coluna apresenta as informações dos indivíduos que foram sorteados e que se tornaram beneficiários do MCMV. A quinta coluna apresenta as informações daqueles que foram sorteados, mas não se tornaram beneficiários.

${ }^{*} p<0,10,{ }^{* *} p<0,05,{ }^{* * *} p<0,01$ 
Tabela 23 - Balanceamento - Sorteio 009

\begin{tabular}{|c|c|c|c|c|c|}
\hline & $\begin{array}{c}(1) \\
\text { Controle }\end{array}$ & $\begin{array}{c}(2) \\
\text { Sorteados }\end{array}$ & $\begin{array}{c}\text { (3) } \\
\text { Diferença (1) - (2) }\end{array}$ & $\begin{array}{c}(4) \\
\text { Compliers }\end{array}$ & $\begin{array}{c}(5) \\
\text { Noncompliers }\end{array}$ \\
\hline \% com informação & 0,687 & 0,690 & $\begin{array}{l}-0,003 \\
(0,004)\end{array}$ & 0,661 & 0,694 \\
\hline Sexo feminino & 0,516 & 0,517 & $\begin{array}{l}-0,001 \\
(0,005)\end{array}$ & 0,610 & 0,505 \\
\hline Indígena & 0,003 & 0,002 & $\begin{array}{c}0,001 \\
(0,001)\end{array}$ & 0,002 & 0,002 \\
\hline Cor branca & 0,410 & 0,416 & $\begin{array}{l}-0,007 \\
(0,005)\end{array}$ & 0,432 & 0,414 \\
\hline Cor negra & 0,121 & 0,125 & $\begin{array}{l}-0,003 \\
(0,003)\end{array}$ & 0,161 & 0,120 \\
\hline Cor amarela & 0,006 & 0,006 & $\begin{array}{c}0,001 \\
(0,001)\end{array}$ & 0,005 & 0,006 \\
\hline Cor parda & 0,330 & 0,315 & $\begin{array}{c}0,015^{* * *} \\
(0,005)\end{array}$ & 0,328 & 0,313 \\
\hline Cor não identificada & 0,130 & 0,136 & $\begin{array}{c}-0,007^{*} \\
(0,003)\end{array}$ & 0,072 & 0,145 \\
\hline Analfabeto & 0,001 & 0,001 & $\begin{array}{c}0,000 \\
(0,000)\end{array}$ & 0,002 & 0,001 \\
\hline Completou o ensino fundamental 1 & 0,978 & 0,976 & $\begin{array}{c}0,002 \\
(0,002)\end{array}$ & 0,970 & 0,976 \\
\hline Completou o ensino fundamental & 0,859 & 0,855 & $\begin{array}{c}0,004 \\
(0,004)\end{array}$ & 0,835 & 0,858 \\
\hline Completou o ensino médio & 0,599 & 0,595 & $\begin{array}{c}0,004 \\
(0,005)\end{array}$ & 0,550 & 0,601 \\
\hline Completou o ensino superior & 0,065 & 0,061 & $\begin{array}{c}0,004 \\
(0,003)\end{array}$ & 0,029 & 0,065 \\
\hline Idade & 37,027 & 37,084 & $\begin{array}{l}-0,057 \\
(0,110)\end{array}$ & 36,010 & 37,224 \\
\hline Salário formal em 2010 & 614,399 & 612,536 & $\begin{array}{c}1,862 \\
(7,492)\end{array}$ & 406,398 & 640,803 \\
\hline Empregado formalmente em 2010 & 0,575 & 0,574 & $\begin{array}{c}0,001 \\
(0,004)\end{array}$ & 0,526 & 0,580 \\
\hline Trabalha no setor de serviços & 0,206 & 0,205 & $\begin{array}{c}0,001 \\
(0,003)\end{array}$ & 0,241 & 0,200 \\
\hline Trabalha no setor administrativo & 0,182 & 0,179 & $\begin{array}{c}0,002 \\
(0,003)\end{array}$ & 0,166 & 0,181 \\
\hline Trabalha na indústria & 0,076 & 0,076 & $\begin{array}{l}-0,001 \\
(0,002)\end{array}$ & 0,053 & 0,080 \\
\hline$N$ & 337038 & 14056 & 351094 & 1695 & 12361 \\
\hline
\end{tabular}

Notas: Essa tabela apresenta o balanceamento entre os grupos de tratamento e controle do Sorteio 009. Todas as informações apresentadas são da RAIS de 2006 a 2010. As informações de gênero, cor da pele, escolaridade, idade e deficiente são de cerca de $69 \%$ da amostra, cujas informações estavam presentes na RAIS. As informações de salário formal, emprego formal e setor do emprego são de toda a amostra. A primeira coluna apresenta as informações dos indivíduos não sorteados no sorteio do MCMV. A segunda coluna apresenta as informações dos indivíduos sorteados. A terceira coluna indica a diferença entre os grupos e o resultado de um teste $\mathrm{t}$ de diferença entre os dois grupos. A quarta coluna apresenta as informações dos indivíduos que foram sorteados e que se tornaram beneficiários do MCMV. A quinta coluna apresenta as informações daqueles que foram sorteados, mas não se tornaram beneficiários.

${ }^{*} p<0,10,{ }^{* *} p<0,05,{ }^{* * *} p<0,01$ 
Tabela 24 - Impactos do programa sobre a probabilidade de emprego formal - RAIS 2006 a 2010

\begin{tabular}{|c|c|c|c|c|}
\hline & $\begin{array}{c}(1) \\
\text { ITT sem controles }\end{array}$ & $\begin{array}{c}(2) \\
\text { ITT com controles }\end{array}$ & $\begin{array}{c}(3) \\
\text { VI sem controles }\end{array}$ & $\begin{array}{c}(4) \\
\text { VI com controles }\end{array}$ \\
\hline $\begin{array}{l}\text { Painel A: Sorteio } 003 \\
\text { Empregado formalmente } \\
\text { (anual) }\end{array}$ & $\begin{array}{l}-0,013 \\
(0,008)\end{array}$ & $\begin{array}{l}-0,009 \\
(0,007)\end{array}$ & $\begin{array}{l}-0,042 \\
(0,027)\end{array}$ & $\begin{array}{l}-0,032 \\
(0,025)\end{array}$ \\
\hline Recebe Bolsa Família & $\begin{array}{c}0,020^{* * *} \\
(0,005)\end{array}$ & $\begin{array}{c}0,019^{* * *} \\
(0,005)\end{array}$ & $\begin{array}{c}0,065^{* * *} \\
(0,017)\end{array}$ & $\begin{array}{c}0,064^{* * *} \\
(0,018)\end{array}$ \\
\hline Número de indivíduos & 297867 & 202835 & 297867 & 202835 \\
\hline $\begin{array}{l}\text { Painel B: Sorteio } 006 \\
\text { Empregado formalmente } \\
\text { (anual) }\end{array}$ & $\begin{array}{l}-0,008 \\
(0,006)\end{array}$ & $\begin{array}{c}-0,011^{* *} \\
(0,005)\end{array}$ & $\begin{array}{l}-0,037 \\
(0,026)\end{array}$ & $\begin{array}{c}-0,057^{* *} \\
(0,024)\end{array}$ \\
\hline Recebe Bolsa Família & $\begin{array}{l}0,007^{* *} \\
(0,003)\end{array}$ & $\begin{array}{l}0,007^{* *} \\
(0,003)\end{array}$ & $\begin{array}{l}0,033^{* *} \\
(0,015)\end{array}$ & $\begin{array}{l}0,038^{* *} \\
(0,017)\end{array}$ \\
\hline Número de indivíduos & 325080 & 224636 & 325080 & 224636 \\
\hline $\begin{array}{l}\text { Painel C: Sorteio } 009 \\
\text { Empregado formalmente } \\
\text { (anual) }\end{array}$ & $\begin{array}{l}-0,005 \\
(0,004)\end{array}$ & $\begin{array}{l}-0,004 \\
(0,003)\end{array}$ & $\begin{array}{l}-0,040 \\
(0,032)\end{array}$ & $\begin{array}{l}-0,037 \\
(0,029)\end{array}$ \\
\hline Recebe Bolsa Família & $\begin{array}{l}-0,003 \\
(0,002)\end{array}$ & $\begin{array}{l}-0,000 \\
(0,002)\end{array}$ & $\begin{array}{l}-0,022 \\
(0,019)\end{array}$ & $\begin{array}{l}-0,002 \\
(0,019)\end{array}$ \\
\hline Número de indivíduos & 351094 & 241376 & 351094 & 241376 \\
\hline Efeito fixo temporal & Sim & Sim & Sim & Sim \\
\hline
\end{tabular}

Notas: Cada um dos painéis representa uma amostra separada, composta apenas por aqueles indivíduos que participaram do respectivo sorteio. As colunas (1) e (2) indicam os efeitos intent-to-treat do Minha Casa Minha Vida sobre as variáveis dependentes em cada uma das linhas. Os resultados são de regressões de MQO onde cada variável dependente é regredida contra uma variável binária que indica se o indivíduo foi sorteado naquele sorteio. As colunas (3) e (4) são os resultados de uma regressão em dois estágios, onde a participação no programa é instrumentalizada pelo sorteio. As estimativas representam os efeitos treatment-on-the-treated, conforme descrito no texto. As colunas (1) e (3) apresentam os resultados para toda a amostra sem quaisquer variáveis de controle. As colunas (2) e (4) apresentam os resultados com variáveis de controle para cerca de $69 \%$ da amostra, que corresponde àqueles indivíduos que tiveram algum vínculo formal entre os anos de 2006 e 2010. Para esses indivíduos foi possível criar variáveis de controle, que são apresentadas nas tabelas de balanceamento. A variável empregado formalmente (anual) é uma dummy que indica se o indivíduo teve algum emprego formal em um dado ano. Essas regressões são para os anos de 2012 a 2016, posteriores ao sorteio. A variável de participação no Bolsa Família é uma dummy que indica se o indivíduo recebe Bolsa Família em cada um dos anos entre 2012 e 2017. A primeira coluna apresenta as médias de cada variável dependente para o grupo de controle.

Todos os erros padrão apresentados têm cluster ao nível do indivíduo.

${ }^{*} p<0,10,{ }^{* *} p<0,05,{ }^{* * *} p<0,01$ 
Tabela 25 - Impactos do programa (Probit) - Rio de Janeiro

\begin{tabular}{|c|c|c|c|}
\hline & $\begin{array}{l}\text { Média do grupo } \\
\text { de controle }\end{array}$ & $\begin{array}{c}\text { (1) } \\
\text { ITT sem controles }\end{array}$ & $\begin{array}{c}(2) \\
\text { ITT com controles }\end{array}$ \\
\hline $\begin{array}{l}\text { Painel A: Sorteio } 003 \\
\text { Empregado formalmente } \\
\text { (anual) }\end{array}$ & 0,539 & $\begin{array}{l}-0,013 \\
(0,008)\end{array}$ & $\begin{array}{l}-0,012^{*} \\
(0,007)\end{array}$ \\
\hline Participação no Bolsa Família & 0,114 & $\begin{array}{c}0,020^{* * *} \\
(0,005)\end{array}$ & $\begin{array}{c}0,021^{* * *} \\
(0,005)\end{array}$ \\
\hline Número de indivíduos & 297867 & 297867 & 220411 \\
\hline $\begin{array}{l}\text { Painel B: Sorteio } 006 \\
\text { Empregado formalmente } \\
\text { (anual) }\end{array}$ & 0,549 & $\begin{array}{l}-0,008 \\
(0,005)\end{array}$ & $\begin{array}{c}-0,010^{* *} \\
(0,005)\end{array}$ \\
\hline Participação no Bolsa Família & 0,0996 & $\begin{array}{l}0,007^{* *} \\
(0,003)\end{array}$ & $\begin{array}{l}0,007^{* *} \\
(0,003)\end{array}$ \\
\hline Número de indivíduos & 325080 & 325080 & 242791 \\
\hline $\begin{array}{l}\text { Painel C: Sorteio } \mathbf{0 o g} \\
\text { Empregado formalmente } \\
\text { (anual) }\end{array}$ & 0,548 & $\begin{array}{l}-0,005 \\
(0,004)\end{array}$ & $\begin{array}{l}-0,005 \\
(0,003)\end{array}$ \\
\hline Participação no Bolsa Família & 0,109 & $\begin{array}{l}-0,003 \\
(0,002)\end{array}$ & $\begin{array}{l}-0,002 \\
(0,002)\end{array}$ \\
\hline Número de indivíduos & 351094 & 351094 & 262218 \\
\hline Efeito fixo temporal & & Sim & Sim \\
\hline
\end{tabular}

Notas: Cada um dos painéis representa uma amostra separada, composta apenas por aqueles indivíduos que participaram do respectivo sorteio. As colunas (1) e (2) indicam os efeitos intent-to-treat do Minha Casa Minha Vida sobre as variáveis dependentes em cada uma das linhas. Os resultados são de regressões de probit onde cada variável dependente é regredida contra uma variável binária que indica se o indivíduo foi sorteado naquele sorteio. As estimativas são dos efeitos marginais. A coluna (1) apresenta os resultados para toda a amostra sem quaisquer variáveis de controle. A coluna (2) apresenta os resultados com variáveis de controle para cerca de $75 \%$ da amostra, que corresponde àqueles indivíduos que tiveram algum vínculo formal entre os anos de 2006 e 2014. Para esses indivíduos foi possível criar variáveis de controle, que são apresentadas nas tabelas de balanceamento. A variável empregado formalmente (anual) é uma dummy que indica se o indivíduo teve algum emprego formal em um dado ano. Essas regressões são para os anos de 2012 a 2016, posteriores ao sorteio. A variável de participação no Bolsa Família é uma dummy que indica se o indivíduo recebe Bolsa Família em cada um dos anos entre 2012 e 2017. A primeira coluna apresenta as médias de cada variável dependente para o grupo de controle.

Todos os erros padrão apresentados têm cluster ao nível do indivíduo.

${ }^{*} p<0,10,{ }^{* *} p<0,05,{ }^{* * *} p<0,01$ 